\title{
Single and dual chamber pacing in patients with conduction disorders
}

Citation for published version (APA):

van Mechelen, R. (1986). Single and dual chamber pacing in patients with conduction disorders. [Doctoral Thesis, Maastricht University]. Rijksuniversiteit Limburg. https://doi.org/10.26481/dis.19861121rm

Document status and date:

Published: 01/01/1986

DOI:

10.26481/dis.19861121rm

Document Version:

Publisher's PDF, also known as Version of record

\section{Please check the document version of this publication:}

- A submitted manuscript is the version of the article upon submission and before peer-review. There can be important differences between the submitted version and the official published version of record.

People interested in the research are advised to contact the author for the final version of the publication, or visit the DOI to the publisher's website.

- The final author version and the galley proof are versions of the publication after peer review.

- The final published version features the final layout of the paper including the volume, issue and page numbers.

Link to publication

\footnotetext{
General rights rights.

- You may freely distribute the URL identifying the publication in the public portal. please follow below link for the End User Agreement:

www.umlib.nl/taverne-license

Take down policy

If you believe that this document breaches copyright please contact us at:

repository@maastrichtuniversity.nl

providing details and we will investigate your claim.
}

Copyright and moral rights for the publications made accessible in the public portal are retained by the authors and/or other copyright owners and it is a condition of accessing publications that users recognise and abide by the legal requirements associated with these

- Users may download and print one copy of any publication from the public portal for the purpose of private study or research.

- You may not further distribute the material or use it for any profit-making activity or commercial gain

If the publication is distributed under the terms of Article $25 \mathrm{fa}$ of the Dutch Copyright Act, indicated by the "Taverne" license above, 
SINGLE AND DUAL CHAMBER PACING

IN PATIENTS

WITH CONDUCTION DISORDERS 


\title{
SINGLE AND DUAL CHAMBER PACING IN PATIENTS WITH CONDUCTION DISORDERS
}

\author{
PROEFSCHRIFT \\ TER VERKRIJGING VAN DE GRAAD VAN DOCTOR \\ IN DE GENEESKUNDE \\ AAN DE RIJKSUNIVERSITEIT LIMBURG TE MAASTRICHT, \\ OP GEZAG VAN DE RECTOR MAGNIFICUS \\ PROF. DR. F. I. M. BONKE \\ VOLGENS BESLUIT VAN HET COLLEGE VAN DEKANEN \\ IN HET OPENBAAR TE VERDEDIGEN IN DE AULA \\ VAN DE LNIVERSITEIT OP 21 NOVEMBER 1986, \\ DES NAMIDDAGS TE 2.00 UUR
}

DOOR

ROB VAN MECHELEN

GEBOREN TE UTRECHT, 24 SEPTEMBER 1947 
Promotor : Prof. Dr. H.J.J. Wellens, Maastricht

Co-promotor : Dr. K. den Dulk, Maastricht

Referenten : Prof. Dr. M.A. Allessie, Maastricht

Dr. P.A. Levine, Boston, Verenigde Staten

Prof. Dr. E.O. Robles de Medina, Utrecht

Het verschijnen van dit proefschrift werd mogelijk gemaakt door de steun van de maatschap cardiologie St. Franciscus Gasthuis, Kleiweg 500, 3045 PM Rotterdam. 
All work and no play makes Jack a dull boy. 


\section{CONTENTS}

$\begin{array}{ll}\text { Acknowledgments } & 7\end{array}$

1. Introduction 9

2. Atrio-ventricular and ventriculo-atrial conduction in patients with symptomatic sinus node dysfunction

3. Serial electrophysiologic studies after single chamber atrial pacemaker implantation in patients with symptomatic sinus node dysfunction

4. Responses of an AV universal (DDD) pulse generator to programmed single ventricular extrastimuli

5. The prevalence of retrograde conduction in heart block after DDD pacemaker implantation

6. Pacemaker electrocardiography of rate smoothing during DDD pacing.

7. Atrial capture and dual chamber pacing

8. Fallure to sense $P$ waves during DDD pacing

Summary

Samenvatting

Curriculum vitae 


\section{ACKNOWLEDGMENTS}

In 1980, my associate and friend dr. Frans Hagemeijer, arranged the acquisition of an electrical stimulator and all the equipment necessary to perform electrophysiologic studies in our hospital. This work would not have been possible without his initiative and his encouragement.

I am very grateful to Eva Kiwiet, Hans de Boer and Sari de Koning for their invaluable support. I am indebted to dr. Adri Schelling who introduced the use of personal computers in our electrophysiology laboratory and pacemaker clinic, by which data handling was facilitated. In addition, the use of a wordprocessor made secretarial assistance superfluous.

1 would like to express my thanks to Mr. Wim de Wilde, Mrs. Leny van den Burg, Mrs. Marjo Vesters, Mr. Tjerk de Boer and all the fellows in cardiology for their assistance. For their critical review special thanks are due to dr. Hein Wellens, dr. Etienne Robles de Medina, dr. Karel den Dulk, dr. Paul Levine and dr. Maurits Allessie.

Finally, I would like to express my sincere thanks to drs. A.V.G. Bruschke, C.A.P.L. Ascoop, J.M.P.G. Ernst, F.J. Slooff and N.M. van Hemel, who gave me the opportunity to visit several outstanding cardiology departments in the United States and also offered me the time to study clinical biostatistics during my training in cardiology at the St. Antonius Hospital, Utrecht. 



\section{CHAPTER 1}

\section{INTRODUCTION}

The clinical application of cardiac pacing has evolved and expanded since the introduction of endocardial stimulation in the early 1960s (1-4). At present permanent cardiac pacing is employed in patients with symptomic conduction disorders as well as in patients with certain types of tachyarrhythmias.

In this dissertation some aspects of cardiac pacing in patients with symptomatic conduction disorders are presented. Permanent pacing in patients with supraventricular or ventricular tachycardias is beyond the scope of this work.

\section{Patients with symptomatic conduction disorders}

In this chapter the clinical manifestations of sinus node dysfunction and atrio-ventricular (AV) block are cliscussed. In addition, the clinical evaluation and management of patients with these conduction disorders will be presented. For the sake of clarity, the two types of conduction disorders are discussed as isolated clinical problems. In general this separation reflects reality, however in a minority of patients, sinus node dysfunction and $\mathrm{AV}$ block may be present simultaneously.

\section{SINUS NODE DYSFUNCTION}

\section{Clinical manifestations}

Sinus node dysfunction is associated with a variety of nonspecific signs and 
symptoms. In 1974 Ferrer (5) presented a completely understandlable picture of the complex clinical problem encountered in patients with dysfunction of the sino-atrial node. She was the first to group the following electrocardiographic observations under the title "Sick Sinus Syndrome":

a. persistent, or unexpected sinus bradycardia ( 50 beats $/ \mathrm{min}$ or less);

b. short periods of sinus-arrest leading to profound episodes of cardiac asystole (3-10 seconds);

c. inability of the heart te resume sinus rhythm after DC cardioversion from atrial fibrillation or atrial flutter;

d. chronic atrial fibrillation occurring with a slow ventricular response that cannot be related to the effects of digitalis; the slow ventricular rate is due to coexisting atrio-ventricular node dysfunction, producing various degrees of atrio-ventricular block;

e. episodes of sino-atrial exit block not related to drugs;

f. bradycardia alternating with supra-ventricular tachycardia.

\section{Clinical evaluation}

\section{History}

The clinical symptoms related to sinus node dysfunction are: syncope, dizziness, lightheadedness and dyspnea. Syncope, dizziness and lightheadedness express cerebral hypoperfusion, whereas dyspnea in this setting is an expression of heart failure. Information on the duration and severity of these complaints, together with information gathered about other medical problems that may cause episodic dizziness or syncope, are the cornerstones of subsequent decision making. Table I shows a classification of the common causes of recurrent dizziness and syncope. In addition information is obtained on pharmacologic therapy, that may adversely affect sinus node function. It is established that antiarrhythmic drugs such as quinidine, flecainide, procainamide, disopyramide, cardiac glycosides, amiodarone, beta-adrenergic and calcium entry blocking agents, can severely depress sinus node function (6). In addition, lithium and antihypertensive agents such as clonidine, alphamethyldopa, reserpine and guanethidine may also depress sinus node function (7).

\section{Physical Examination}

Although self-evident, it is essential that a complete physical examination 


\section{TABLE I*}

\section{CLASSIFICATION OF CAUSES OF RECURRENT WEAKNESS, FAINTNESS AND DISTURBANCES OF CONSCIOUSNESS}

1. CIRCULATORY

A. CARDIAC

- BRADYCARDIA : SINUS NODE DYSFUNCTION, AV BLOCK, CAROTID SINUS HYPERSENSITIVITY

- TACHYCARDIA : VENTRICULAR OR SUPRAVENTRICULAR TACHYCARDIAS

- HYPERTROPHIC OBSTRUCTIVE CARDIOMYOPATHY

- AORTIC STENOSIS, ATRIAL MYXOMA, ATRIAL THROMBUS

B. PERIPHERAL

- POSTURAL ORTHOSTATIC HYPOTENSION

- PSYCHOGENIC SYNCOPE

2. OTHER CAUSES

A. METABOLIC AND BIOCHEMICAL

- HYPOGLYCAEMLA

- HYPERVENTILATION

- INTERNAL HEMORRHAGE, HYPOVOLEMIA

- DRUGS: CERTAIN SEDATIVES AND ANTIHYPERTENSIVE AGENTS

B. CEREBRAL

- EPILEPSY

- CEREBRAL VASCULAR DISTURBANCES

- EMOTIONAL DISTURBANCES

- Modified after R.D. Adams and T. R. Harrison (69).

may offer clues to causes of recurrent dizziness and syncope (Table 1). With regard to sinus node dysfunction no specific signs exist.

\section{Carotid sinus stimulation}

Recently several reports appeared about an association between hypersensitive carotid sinus syndrome and sick sinus syndrome.

Mandel et al. (8) observed in their series of 31 patients with suspected sinus node dysfunction a hypersensulive carotid sinus response (sinus pause $>3$ seconds) in 7 patienis ( $23 \%$ ). Similar findings were reported by Thormann et al. (9) and Morley et al. (10). Although carotid sinus hypersensitivity originally connoted a rather specific clinical entity, it is now viewed by these investigators as having a considerable broader meaning. Nevertheless, we would like to emphasize that the clinical relevance of this finding remains unclear, since a marked bradycardia response to carotid sinus mas- 
sage may occur in patients without clinical symptoms or prior suspicion of carotid sinus hypersensitivity (11).

From a diagnostic and therapeutic standpoint differentiation between the two syndromes is important. In patients with sinus node dysfunction, pacemaker therapy is likely to alleviate symptoms. In patients with clinical evidence of carotid sinus hypersensitivity, pacemaker therapy is only effective in the subset of patients with the cardio-inhibitory type of carotid sinus hypersensitivity. In patients with the vasodepressor type or mixed type (cardio-inhibitory and vasodepressor) the value of pacemaker therapy has not been unequivocably proven (12).

\section{4-Hour Holter recording and ECG transmission via telephone}

The most definitive method to diagnose sinus node dysfunction is to document an inappropriate sinus bradycardia, sinus arrest, sinus atrial block or bradycardia alternating with tachycardia. At present, ambulatory monitoring and ECG transmission via the telephone have become the most important tools to demonstrate the presence or absence of a relationship between symptoms and ECG abnormalities.

\section{Exercise testing}

Although the purpose of exercise testing is to evaluate the ability of the sinus node to accelerate in an appropriate fashion in response to physical stress, it is still unclear if an abnormal heart rate response to exercise will facilitate the identification of patients with sinus node dysfunction (13).

\section{Pharmacologic testing}

The effects of the autonomic nervous system on sinus node function has led some investigators to recommend that heart rate reponse to sympathomimetic, sympatholytic, vagotonic an vagolytic drugs must be employed routinely in the clinical evaluation of patients suspected of sinus node dysfunction due to the effects of the autonomic nervous system, Jose et al. $(16,17)$ have described a technique to determine the intrinsic sinus rate, i.e. the rate of spontaneous sinus node=depolarization independent of the effects of the autonomic nervous system. To obtain pharmacologic denervation, atropine $(0.04 \mathrm{mg} / \mathrm{kg})$ and propranolol $(0.2 \mathrm{mg} / \mathrm{kg})$ are intravenously administered, and the sinus rate representing the intrinsic heart is 
measured. The intrinsic heart rate is age dependent and it can be defined by the following regression equation: IHR $=117.2(0.53 \times$ age $)$. A depressed intrinsic heart rate will be observed in patients with sinus node disease, whereas in patients with a normal intrinsic heart rate the documented bradycardia is attributed to a disturbance of autonomic regulation $(16,17)$. Since this test may accurately identify patients who have sinus node disease, it is interesting from a diagnostic standpoint. The meaning of this test in terms of management and pacemaker therapy however is unclear.

\section{Invasive electrophysiologic evaluation}

Over the past decade, a number of invasive electrophysiologic techniques have been developed to evaluate sinus node function. Two possible pathophysiologic mechanisms underly sinus node dysfunction. First, disturbances of sinus node automaticity and second, disturbances of sino-atrial conduction. Sometimes both abnormalities exist simultaneously.

The tests used to assess sinus node automaticity and sino-atrial conduction lime will be discussed. In addition, the value of recording the sinus node electrogram and the assessment of sinus nodal refractoriness will be presented.

\section{- Simus node antomaticity}

Determination of the sinus node recovery time (SNRT) was originally described by Mandel et al. (18). Atrial pacing is initially performed at a rate approximately 20 beats/min faster than the spontaneous sinus rate. Pacing is continued for 30,60 , or 180 seconds (s) at which time it is abruptly terminated. SNRT is measured in milliseconds (ms) as the time elapsing from the last paced $P$ wave to the first spontaneous beat of sinus origin (Fig. 1, $A, B, C)$. Pacing trials are comprised of atrial pacing at progressively faster rates, often in rates with increments of 20 beats $/ \mathrm{min}$ up to a rate of 170 beats $/ \mathrm{min}$.

To control for differences in spontaneous sinus rate, many authors use the corrected SNRT in assessing sinus node automaticity. The corrected SNRT is defined as the difference between the SNRT and the spontaneous sinus cycle length $(19,20)$. Although accurate definition of the upper limit of normal for SNRT is essential for a correct interpretation, many studies offer a wide range of normal values, i.e. $1200 \mathrm{~ms}$ to $1750 \mathrm{~ms}$ voor SNRT and $375 \mathrm{~ms}$ to $550 \mathrm{~ms}$ for corrected SNRT $(19,20)$. 


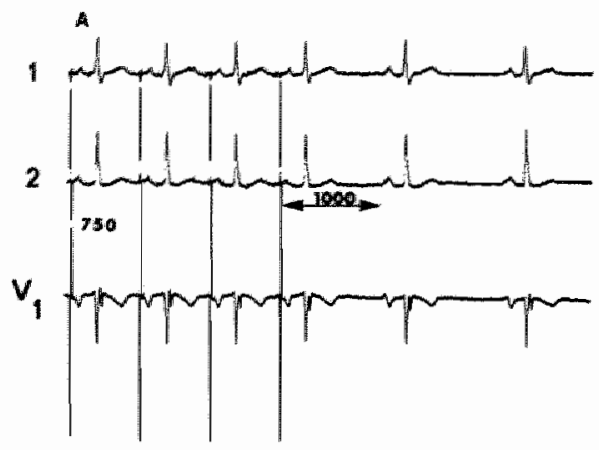

B

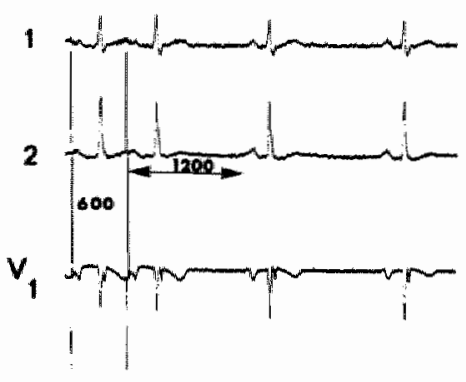

C

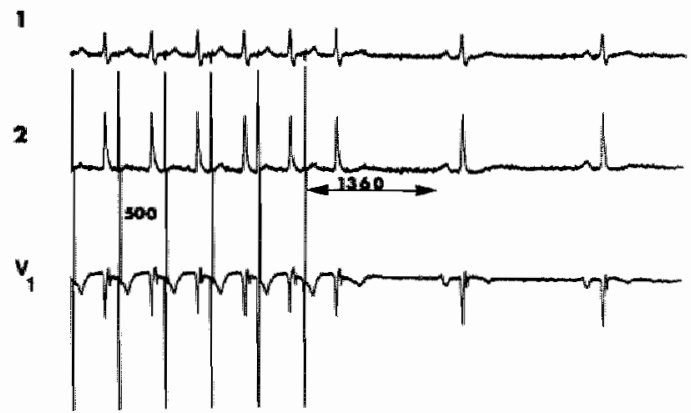

Fig. 1. Sinus Node Recovery Time.

a. The atrium is paced at a rate of 80 beats $/ \mathrm{min}$. When atrial pacing is abruptly terminated the SNRT is measured in $\mathrm{ms}$ as the time elapsing from the last paced $\mathrm{P}$ wave to the first spontaneous atrial beat of sinus origin. A SNRT is measured of $1000 \mathrm{~ms}$.

b. Atrial pacing at a rate of 100 beats/min. A SNRT is measured of $1200 \mathrm{~ms}$.

c. Atrial pacing at a rate of 120 beats $/ \mathrm{min}$ and a SNRT of $1360 \mathrm{~ms}$.

Pacing the atrium at approximately 120 beats/min for at least $15 \mathrm{~s}$ results in reproducible SNRTs (18). 
In patients with prolonged recovery times, Chadda et al. (21) have also suggested measuring SNRTs and calculating the corrected SNRTs after autonomic blockade has been achieved according to Jose's pharmacologic denervation technique (16). When SNRTs remain pathogically prolonged after pharmacologic denervation sinus node function is disturbed, whereas autonomic dysregulation of the sinus node is present when subsequently normal SNRTs are measured.

In patients with normal recovery times, Reiffel et al. (22) have emphasized that sinus node function is normal only when one can demonstrate the absence of atrio-sinus entrance block. Reiffel and coworkers were the first to note that maximum SNRTs in patients with sinus node dysfunction frequently occurred at rates much slower than those seen in normal subjects. To explain this finding they suggested that in patients with sinus node dysfunction, atrio-sinus entrance block also occurred at relatively slower atrial pacing rates than in normal subjects.

When atrial pacing trials are performed at different pacing rates, according to Mandel's description (18), atrio-sinus entrance block will always be recognized. On the other hand, when atrial pacing is performed at only one pacing rate, the presence of atrio-sinus entrance block might not be appreciated and the time elapsing from the last paced beat to the first spontaneous sinus beat may erroneously be interpreted as a normal SNRT.

\section{- Sino-atrial conduction time}

\section{(1) Premature atrial stimulation}

Analysis of the sinus node response to atrial premature beats was originally described by Strauss et al. (23). Fig. 2 illustrates the various types of sinus node response to premature atrial stimuli. Fig. 3 illustrates the calculation of the unidirectional sino-atrial conduction time (SACT). Reported normal values for calculated SACTs vary from $50 \mathrm{~ms}$ to $120 \mathrm{~ms}(24,25)$.

\section{(2) Acrial overdrive pacing}

Narula et al. (26) have described an alternative method to determine SACT, utilizing atrial overdrive pacing. This method assumes that pacing the atrium at a rate slightly faster than the spontaneous sinus rate will not result in suppression of sinus node automaticity, but that the pacing beats will gradually achieve capture and reset the spontaneous sinus cycle. The atrium is paced at a rate $<10$ beats $/ \mathrm{min}$ faster than the spontaneous sinus rate for 8 consecutive beats. The interval from the last paced beat to the 


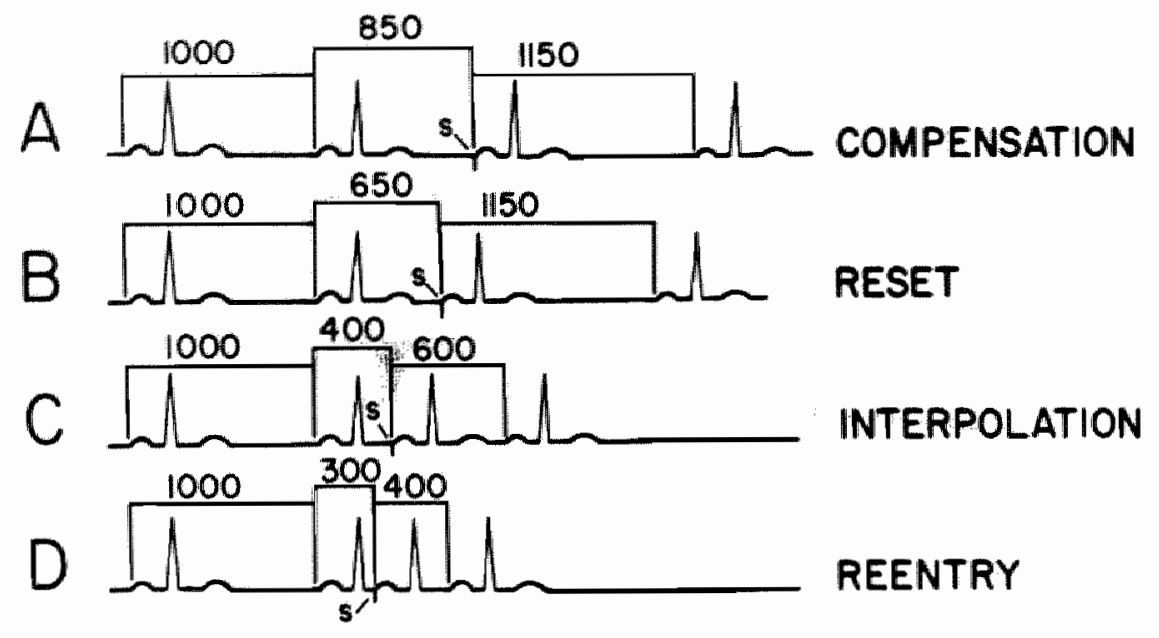

Fig. 2. Simus node response to atrial extrastimuli.

a. Compensation. An atrial extrastimulus is delivered with a coupling interval of $850 \mathrm{mms}$. This premature beat is followed by a spontaneous sinus beat after a pause of $11150 \mathrm{~ms}$. Since $850+1150=2000 \mathrm{~ms}$ and $2000 \mathrm{~ms}$ is exactly two times the basic sinus cycle lengrth, the compensalory pause is complete.

b. Resetting. An atrial extrastimulus is delivered with a coupling interval of $650 \mathrm{~ms}$. The premature beat is followed by a spontaneous simus beat after a pause of $1150 \mathrm{~ms}$. Since $650+1150<2000 \mathrm{~ms}$, the compensatory pause is incomplete. Therefore the sinus node has been depolarized by the atrial premature beat causing the next sinus depolarization to occur earlier.

c. Interpolation. An atrial extrastimulus is delivered with a coupling interval of $400 \mathrm{~ms}$. The premature beal is followed by a spontaneous sirus beat after a pause of $600 \mathrm{~ms}$. Since $400+600=1000 \mathrm{~ms}$ and $1000 \mathrm{~ms}$ is exactly the basic sinus cycle length, the normal sinus discharge rate is not effected by the atrial premaure beat.

d. Reentry. An atrial extrastimulus is delivered with a coupling interval of $300 \mathrm{~ms}$ and is followed by an early spontaneous discharge of the sinus node. The sum of the two intervals $700 \mathrm{~ms}(300+400)$, is less than the spontaneous sinus cycle length.

Provided that the first atrial beat following the atrial premature beat is of simus origin, this beat is ealled a sinus node echo beal.

(From Jordan et al. refference 20. By permission of the publisher.)

first return sinus beat is taken as the time (T) representing the sum of retrograde sino-atrial conduction time (RSACT), sinus cycle length (SCL) and anterograde sino-atrial conduction time (ASACT). Assuming that RSACT equals ASACT, unidirectional SACT equals (T-SCL)/2. This assumption has not been proven. Since there may be differences between anterograde and retrograde conduction velocities in the $\mathrm{AV}$ node, His bundle, accessory pathways and Purkinje fibers, why should the anterograde and retrogracle conduction time be the same in the sino-atrial node (27)? 


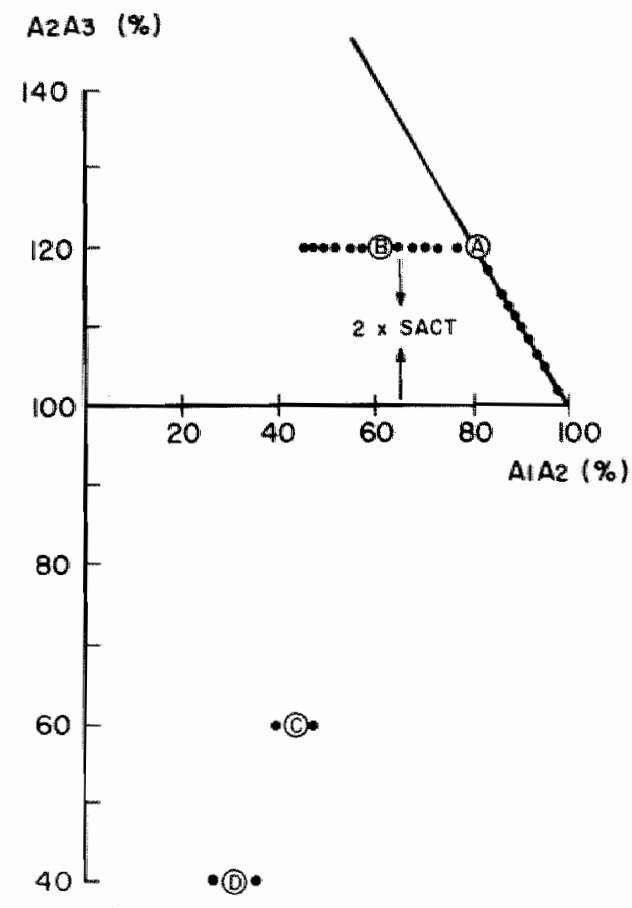

Fig. 3. Sino Atrial Conduction Tíme (SACT).

The horizontal axis represents the coupling interval of atrial extrastimuli with the preceding spontaneous sinus beats expressed as a percentage of the spontaneous sinus cycle length. The vertical axis represents the intervals between the atrial premature beat and the following spontaneous sinus beat, also expressed as a percentage of the spontaneous sinus cycle length. $A, B, C$ and D correspond with the atrial extrastimuli delivered at resp. $850 \mathrm{~ms}, 650 \mathrm{~ms}$, $400 \mathrm{~ms}$ and $300 \mathrm{~ms}$ as explained in Fig. 2. SACT is calculated as follows: The A2A3 interval during resetting of the spontaneous discharge of the sinus node is $1150 \mathrm{~ms}$. The spontaneous sinus cycle length is $1000 \mathrm{~ms}$ (A1A1). A2A3 - AlA1 $=2 \times \mathrm{SACT}$. SACT $=1150 / 2-$ $1000 / 2=150 / 2=75 \mathrm{~ms}$, provided that the atrio-sinus conduction time equals the sino-atrial conduction time.

(From Jordan et al., reference 20 . By permission of the publisher.)

SACTs calculated with this method are reproducible and are comparable to those calculated according to the method of Strauss. The advantage of this method is that complex equipment and laborious calculations required for the Strauss method became superfluous. A disadvantage of this technique as well of the Strauss method is, that SACTs are determined indirectly. Although SACT can be precisely and directly measured using the microelectrode technique, this can only be performed in the experimental animal laboratory. 


\section{- Recording of the sinus node electrogram}

At present it is unclear whether direct sinus nodal recordings can separate patients with normal from those with abnormal sinus node function (28).

\section{- Sinus node refractoriness}

Goldreyer and Damato (29) suggested that critically coupled atrial premature impulses that become interpolated are caused by sinus node refractoriness. Kerr and Strauss (30) verified this contention on isolated rabbit sinoatrial preparations with the microelectrode technique and concluded that the sudden transition between the zone of reset and the zone of interpolation was a good indication of the sinus node refractory period. They extended their observations to man and demonstrated a clear difference in sinus nodal refractoriness between normal individuals and patients with sinus node dysfunction (31). However this is the only reported study in man and additional studies of this nature are necessary to establish the role of this parameter in the diagnosis of sinus node dysfunction.

Do invasive electrophysiologic studies give additional information on patients suspected of sinus node dysfunction?

In terms of underlying pathophysiologic mechamisme the answer is yes. Electrophysiologic testing before and after autonomic blockade will aid in separating true sinus node dysfunction from sinus node dysfunction due to autonomic effects in patients with prolonged SNRTs. In contrast, the value of SNRT and CSNRT as tests to establish a diagnosis of sinus node dysfunction, is only rarely of clinical benifit. Sensitivity and specificity as statistical indexes of the efficiency of these tests have been calculated $(18,19$, 23-25). Almost all patients with a pathologically prolonged SNRT or CSNRT have sick sinus syndrome. However, in the majority of patients with sick sinus syndrome no abnormal prolongation of SNRT and CSNRT have been found $(18,19,24)$. Since the purpose of the test is to identify patients with sinus node dysfunction, a positive result (prolonged SNRT and CSNRT) will only be observed in a minority of cases.

The incidence of an abnormal prolongation of SACT in patients with sick sinus syndrome varied in different series from 29 to 38 percent, whereas calculated SACT of ostensibly normal subjects was prolonged in 15 to 22 percent $(22-25)$. Therefore, SACT calculation is also of limited value to identify patients with sinus node dysfunction. Even when the results of the 2 tests are combined (SACT and SNRT), as was done in a study by Seipel et 
al. (24), the diagnostic value is small.

In addition, it is not yet known if assessment of sinus node refractoriness or recording of the sinus node electrogram will offer useful clinical information.

\section{Management}

Pacemaker therapy for sinus node dysfunction is only indicated when a relationship between symptoms and ECG abnormalities characteristic for sinus node dysfunction can be documented, either by ECG, Holter recording, monitoring by telemetry or ECG transmission via telephone. A thorough medical and neurologic work-up is also essential. Such a work-up should include a detailed medical and pharmacologic history, routine laboratory examination, neurologic consultation and carotid sinus stimulation during continuous ECG monitoring (9-11).

Only when central nervous system symptoms or dyspnea have been shown to be associated with episodes of sinus node dysfunction and failure of subsidiary pacemakers to escape, then cardiac pacing will be succesful in eliminating these symptoms (32). Regardless whether the bradycardia is due to intrinsic sinus node dysfunction or autonomic dysregulation of the sinus node function, pacemaker implantation is indicated in symptomatic patients.

There is no further need to perform exercise tests, to administer drugs to assess the influences of the autonomic nervous system on sinus nodal function or to determine SNRTs and SACTs (Fig. 4).

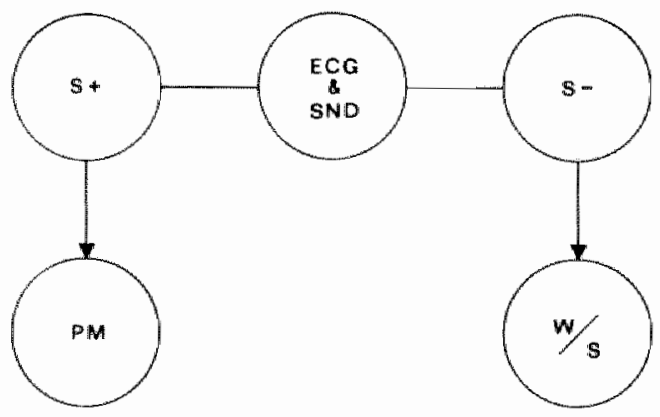

Fig. 4. Decision making tree in patients with sinus node dysfunction.

$\mathrm{EGG} \& \mathrm{SND}=$ patients with electrocardiograms characteristic for sick sinus syndrome; $S_{+}=$subset of symptomatic patients; $S-=$ remaining patients without symptoms; $P M=$ Pacemaker Implantation; $W / S=$ wait \& see. 
With regard to pacemaker selection, it is important to assess if anterograde and retrograde AV conduction are intact (33-37). Pacemaker selection will be discussed in the last section of this chapter. Assessment of anterograde and retrograde conduction will be discussed in Chapter 2 .

\section{ATRIO-VENTRICULAR BLOCK}

\section{Clinical manifestation}

Atrio-ventricular (AV) block is an electrocardiographic diagnosis. It is customary to distinguish 3 types of heart block:

- first degree AV block, which means prolonged but not blocked AV conduction. Propagation of the atrial impulse to the ventricle is delayed at the level of the AV node, common His bundle or both;

- second degree AV block, which means that some but not all atrial impulses originating either in the sinus node or within the atrium reach the ventricle;

- third degree AV block or complete heart block, which means a complete faillure of impulse propagation from the atrium to the ventricle. This is attributed to the inability of the AV conduction system to transmit atrial impulses in anterograde direction.

AV block may be either functional and potentially reversible or may be fixed, due to intrinsic disease of the AV conducting system. Complete heart block may occur to congenital or acquired lesions.

\section{Clinical evaluation}

\section{History}

The clinical symptoms related to AV block vary from recurrent syncope, dizziness or dyspnea to no complaints at all (42). Unfortunately, while symptoms may be completely lacking in patients with first and second degree AV block, they may also be absent in patients with third degree AV block.

It is also important to obtain information on drug therapy, since several drugs may severely depress AV conduction (43). In general, antiarrhythmic and anti-ischemic drugs that adversely affect sinus node function, may also depress anterograde AV conduction. The drugs most likely to compromize AV conduction are: digitalis, amiodarone, beta-adrenergic and calcium 
entry blocking agents. Some of the patients in whom these agents must be continued for clinical reasons, require a permanent pacemaker because of drug induced heart block.

\section{Physical Examination}

The presence of regular $A$ and $V$ in the jugular venous pulse, a stable loudness of the first heart sound and regular diastolic filling sounds all establish AV synchrony. Intermittent cannon waves, varying loudness of the first heart sound and intermittent diastolic filling sounds suggest $\mathrm{AV}$ dissociation. If this occurs in patients with a slow heart rate, AV block is likely. In patients with a fast heart rate these findings suggest ventricular tachy. cardia.

\section{ECG}

The ECG may indicate the site of the AV block. In patients with first degree $A V$ block a narrow QRS complex $(<0.10 \mathrm{~s}$ ) is highly suggestive for an AV nodal localization $(43,50)$.

Second degree $A V$ block is subdivided into 3 types: Type I, Type II and advanced second degree AV block (2:1 or 3:1 AV conduction). Type I block is characterized by a progressive lengthening of the PR interval before conduction of a $P$ wave to the ventricle is blocked.

Different patterns of PR intervals may be noted before AV block occurs. However, the PR interval following the non conducted $P$ wave is always shorter than de PR interval of the preceding beat.

Type I second degree AV block is most commonly localized in the AV node $(45,47)$. Type II block is characterized by the absence of PR interval lengthening before $\mathrm{AV}$ block occurs. The site of type II block is almost entirely limited to the His bundle or bundle branches.

For many years, it was generally accepted that Type I second degree AV block would not lead to sudden asystole, as escape pacemakers within the common His bundle were usually adequate to protect the patient. In contrast, patients with second degree AV block Type II would have a worse prognosis, since they have to rely on less stable escape pacemakers localized in the distal His Purkinje system. It has generally been accepted that second degree AV block type II is a harbinger of asystole as a result of the sudden onset of third degree AV block $(43,47-49,52)$.

Recently, Shaw et al. (48) presented data which challenged the correctmess 
of these long held concepts. These investigators showed that 3 and 5 years survival rates in unpaced patients were similarly poor regardless of the type of second degree AV block. Based on this evidence these investigators suggested that electrocardographic features can no longer be used to separate high and low risk patients with second degree AV block. The main limitation however of this study is its design. The investigators collected ECGs that were taken in the past of patients with second degree AV block and studied the follow-up of the paced and non paced patients from data in the patient's records. Retrospective studies may be clinically important, however they are the most unproductive methods devised for studying the natural history of a disease $(60)$.

Advanced second degree AV block (2:1 or $3: 1 \mathrm{AV}$ block) may be a variant of either Type I or Type II block $(47,52)$. Unfortunately the site of block can not be predicted by means of the ECG alone.

In third degree $A V$ block, QRS complexes can either be narrow or wide. Narrow QRS complexes (0.08-0.10 s) are only shown in patients with heart block localized in the AV node or common His bundle. Wide QRS complexes (0.10-0.12 s) may be present in AV nodal as well as infranodal block. However bizarre broadened QRS complexes with a width of $>0.12 \mathrm{~s}$ are almost exclusively observed in patients with AV block localized below the His bundle.

\section{Carotid sinus stimulation}

Carotid sinus massage may sometimes give a clue to the site of the anterograde AV block. When this maneuver aggravates the conduction disorder i.e. a progression of first or second degree AV block to third degree AV block, the block is most likely localized in the AV node. In some patients a decrease in block is observed. In these cases it is important to measure the spontaneous sinus rate. Slowing of the sinus rate may result in improved AV nodal as well as infranodal conduction (43), since both AV nodal and infranodal second degree AV block may be rate dependant. In this setting, carotid sinus massage does not give a clue to the site of AV block. However, when the spontaneous sinus rate does not decrease, improved AV conduction suggests an infranodal site of the AV block. Carotid sinus pressure has very little effect on AV conduction in patients with complete heart block, regardless of its site (44). 


\section{4-Hour Holter recording and ECG transmission via the telephone}

Although these techniques are often employed in patients with a history of unexplained syncope, they rarely document intermittent symptomatic third degree AV block. On the other hand, it is not uncommon to observe intermittent asymptomatic first or second degree AV block due to increased vagal tone e.g. during the night in patients with apparently intact AV conduction $(45,46)$. If this is the only time, that second degree AV block is documented, pacemaker therapy is certainly not recommended.

\section{Exercise testing}

Exercise testing may be a helpful diagnostic tool to assess the site of the AV block. When improvement of AV conduction occurs during exercise i.e. from second degree or third degree AV block to 1 : 1 AV conduction the block is most likely localized in the AV node, since AV nodal conduction improves due to sympathetic drive.

In contrast, when exercise increases the AV block i.e. from first or second degree AV block to third degree AV block, heart block is more likely localized in the His bundle or bundle branches due to an increase of atrial impulses reaching the abnormal His Purkinje System (43).

The potential reversibillity of AV block was demonstrated in young athletes (47). In these healthy individuals AV block on the rest ECG is an expression of increased vagal tone. The effects of exercise on the reversibility of AV block has not been systematically studied in elderly patients with second or third degree AV block. This is to be expected, as the majority of these patients are physically limited at the time a diagnosis of the AV block is established. As a consequence, limited date are available on the reversibility of AV block and on the physical work capacity of these patients during exercise $(50,51)$.

\section{Pharmacologic testing}

As opposed to sinus node dysfunction, sympathomimetic, sympatholytic, vagotonic and vagolytic drugs have not been routinely employed in the clinical evaluation of patients with first, second or third degree AV block. The administration of an anti-cholinergic drug like atropine may offer a clue to the site of block. When AV conduction temporarily improves after the administration of atropine, AV block is localized in the AV node. On 
the other hand, when atropine aggrawates the AV conduction disturbance, block is localized below the AV node. In rare cases, like bradycardia dependant infranodal block the opposite is true. In these patients atropine may abolish AV block despite its infranodal localization $(42,43)$.

\section{Invasive electrophysiologic study}

The site of AV block can be demonstrated by ellectrophysiologic study. In addition, invasive study allows $(43,52)$ further elucidation of the underlying mechanism of the conduction disorder. Fig. 5 shows the different

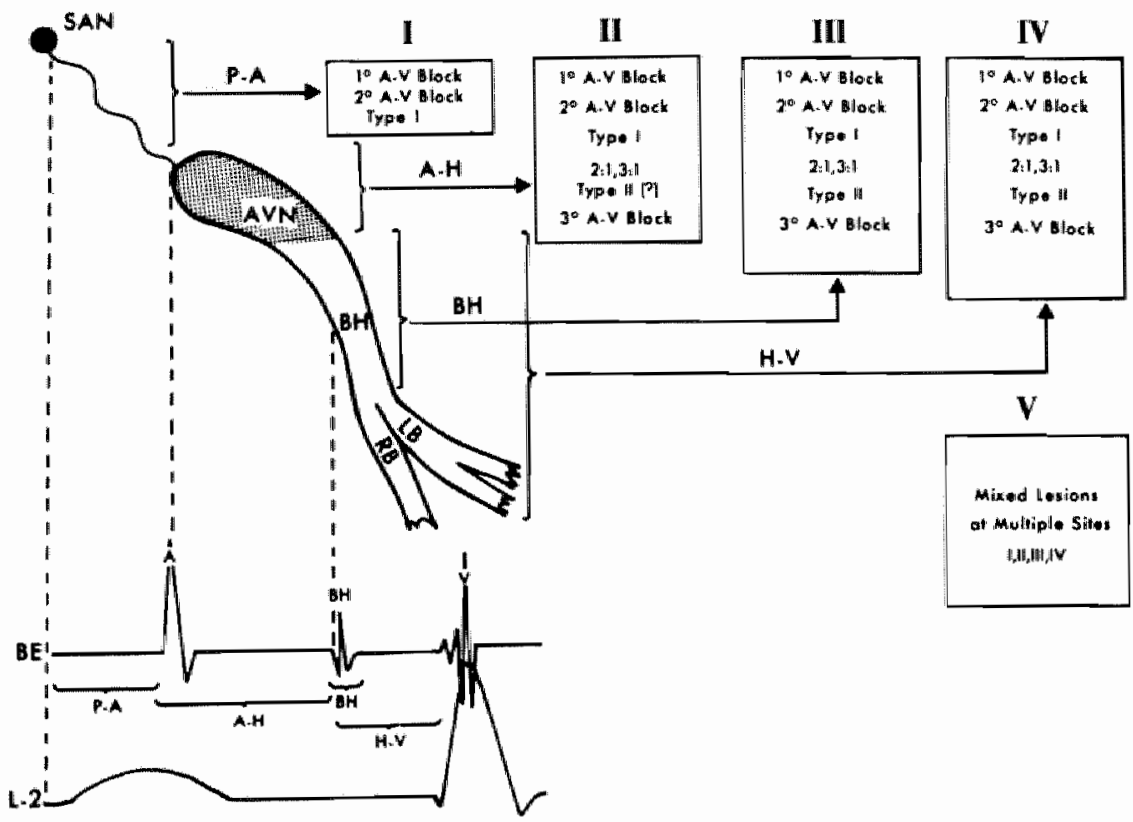

Fig. 5. Localization of AV block.

Diagrammatic representation of the AV conducting system shows different varieties of AV black.

Abbreviations: $S A N=$ Sino atriall node, $A V N=A V$ node, $B H=$ bundle of His, $L B=$ left bundle branch, $\mathbb{R B}=$ right bundle branch, $B E=$ His bundle electrogram, $L-2=$ lead II of the standard $\mathrm{ECG}, \mathrm{P}-\mathrm{A}=$ intra-atrial conduction time, $\mathrm{A}-\mathrm{H}=\mathrm{AV}$ nodal conduction time, $H \cdot V=$ infra-nodal conduction time. (From Narula et al. Atrioventricular block localization and classification by His bundle recorings. Am J Med $50 ; 146,1971$. By permission of the publisher.) 
varieties of $A V$ block as a result of lesions in different segments of the $A V$ conducting system.

\section{- First degree $A V$ block}

In the majority of cases ( $>80$ percent) AV nodal delay causes PR prolongation $(>0.21$ s) $(52,53)$. First degree AV block may be associated with a wide or narrow QRS complex. Patients with a wide QRS complex especially those with a left bundle branch block have a very high incidence (50-90 percent) of concomitant infranodal conduction delay (HV interval $>65 \mathrm{~ms})(52)$.

\section{- Second degree $A V$ block}

Second degree AV block may be localized in or below the AV node. Puech et al. (53) observed, that chronic Type I second degree AV block (Mobitz Type $\mathbb{1}$, Wenckebach type) was localized in 72 percent of the cases in the AV node and in 28 percent in the His bundle of bundle branches. Those cases that meet the strict criteria of Type II second degree AV block (Mobitz Type II) were almost invariably localized in the His bundle or bundle branches.

Advanced second degree AV block (high grade AV block with conduction ratios $2: 1,3: 1)$ may be Type I or Type II variants. Narula et al. (52) observed that the site of conduction block in patients with advanced second degree AV block was localized in the AV node in 33 percent, in the His bundle in 17 percent and in the bundle branches in the remaining 50 percent.

\section{- Third degree AV black}

In different series, the incidence of third degree AV block ranges from 16 to 25 percent in the AV mode, 14 to 20 percent in the His bundle and 5610 68 percent in the bundle branches $(52,53)$.

Another aspect of electrophysiologic investigation is the evaluation of retrograde AV conduction. With regard to presently available pulse generators, evaluation of retrograde conduction is of major clinical importance $(37,54-56)$. The clinical evaluation of retrograde AV conduction in patients with second or third degree $\mathrm{AV}$ block is elaborated upon in Chapter 5. 


\section{Management}

For the present, all authorities would agree that symptomatic patients with second or third degree $\mathrm{AV}$ block should be offered permanent cardiac pacing. However, no consensus has been reached on whether symptomatic patients with first degree AV block or some subgroups of patients with documented infranodal conduction delay should be paced $(43,44,47,49$, 57-61).

Generally, the following guidelines are suggested:

Pacemaker implantation is not indicated in asymptomatic patients with first, second or third degree AV block (49). In symptomatic patients with second or third degree AV block pacemaker implantation is indicated.

- When first degree $A V$ block is present on the ECG of a patient with syncopal episodes, electrophysiologic study is performed to determine the level of conduction delay. In addition, programmed electrical stimulation may be performed to rule out arrhythmias that might cause syncope. In patients with a prolonged AH interval ( $>160 \mathrm{~ms}$ ) but a normal $\mathrm{HV}$ interval ( $<65 \mathrm{~ms}$ ) either during baseline recording or during incremental atrial pacing at rates of at least 120 beats $/ \mathrm{min}$, no further action is usually required. The patient is followed in the outpatient clinic and depending on further symptoms 24-hour holter recordings are repeated. When a significantly prolonged $\mathrm{HV}$ time $(>65 \mathrm{~ms})$ is documented during baseline recording or infranodal block occurs during incremental atrial pacing at rates less than 120 beats/min, pacemaker therapy is indicated (43, 58, 62) (Fig. 6). The value of stressing the His-Purkinje system by Vaughan Williams class I antiarrhythmic drugs as suggested by Fisher (61) is still unknown;

- When second degree $A V$ block is present on the ECG of patients with symptoms of syncope or dizzines, irrespective of the site of block pacemaker therapy is indicated $(52,58)$ (Fig. 7);

- Symptomatic patients with third degree heart block are also candidates for permanent pacemaker insertion irrespective of the site of lesion (Fig. 7). In the setting of complete heart block in acute myocardial infarction, temporary pacing might be indicated when deterioration of haemodynamic performance is present.

Permanent pacing is rarely indicated in patients with inferior wall myo- 


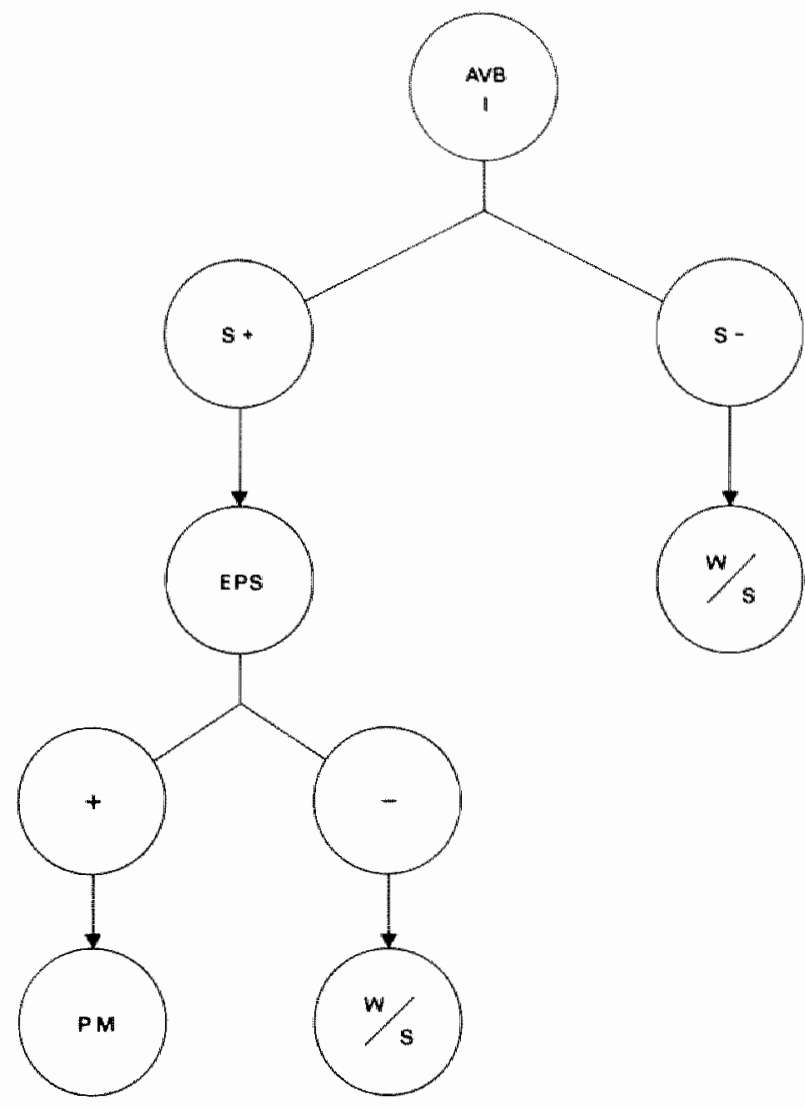

Fig. 6. Decision making tree In patlents with first degree AV block.

AVB I represents with first degree AV block. $S+=$ patients with symptoms of syncope or dizziness and first degree AV block; $\mathrm{S}$ - = asymptomatic patients with first degree AV block; $W / S=$ wait \& see; EPS = Electrophysiologic Study; $+/$ - infranodal conduction delay is present or absent; $P M=$ pacemaker implantation.

cardial infarctions, since the conduction abnormality is usually of functional origin due to increased vagal tone and hence is reversible during evolution of the infarction.

The conduction abnormality in anterior wall myocardial infarction is usually not reversible and a permanent pacemaker may be implanted. Unfortunately, pacemaker therapy rarely improves the prognosis of these patients. The major cause of death is pump failure, whether or not a pacemaker is implanted (64). 


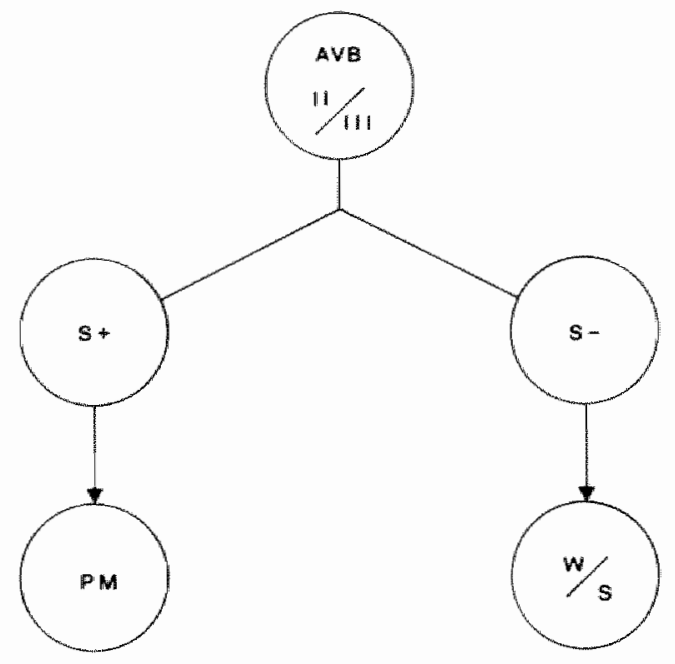

Fig. 7. Decision making tree in patients with second or third degree $A V$ block. (For abbreviations see Fig. 4 and 6 .)

- Symptomatic patients with bifascicular block (LBBB, or RBBB + LAHB/LPHB) and symptomatic patients with trifascicular block (bifascicular block + PR prolongation $>0.20 \mathrm{~s}$ ) are candidates for electrophysiologic study, provided that other causes for syncope have been excluded. When during baseline recording a prolonged HV interval ( $>65 \mathrm{~ms}$ ) is found or second degree infranodal block occurs during incremental atrial pacing at pacing rates less than 120 beats $/ \mathrm{min}$, pacemaker implantation is indicated $(57,63)$. In addition programmed electrical stimulation is performed to document or to rule out other causes of recuarent syncope, like ventricular taychyarrhythmias.

In patients with anexplained syncope and a normal ECG electrophysiologic evaluation is indicated, provided that other causes for dizziness or syncope have been excluded.

In these patients electrophysiologic study may reveal underlying infranodal conduction disease (65), however such a finding is rather exceptional. Patients who are found to have infranodal conduction disease are candidates for permanent pacing. In addition, programmed electrical stimulation may be performed to rule out or document arrhythmias that might cause syncope. 
A discussion on the value of programmed electrical stimulation with regard to the initiation of supraventricular or ventricular tachycardias in patients without clinical documentation of the arrhythmia is beyond the scope of the clinical evaluation of AV block, although it still is an important part of the evaluation of the patient with unexplained syncope.

\section{PACEMAKER SELECTION}

In this section, the most commonly used pacemakers for patients with sinus node dysfunction and patients with AV block will be discussed. In addition the concept of rate responsive pacing is introduced.

A
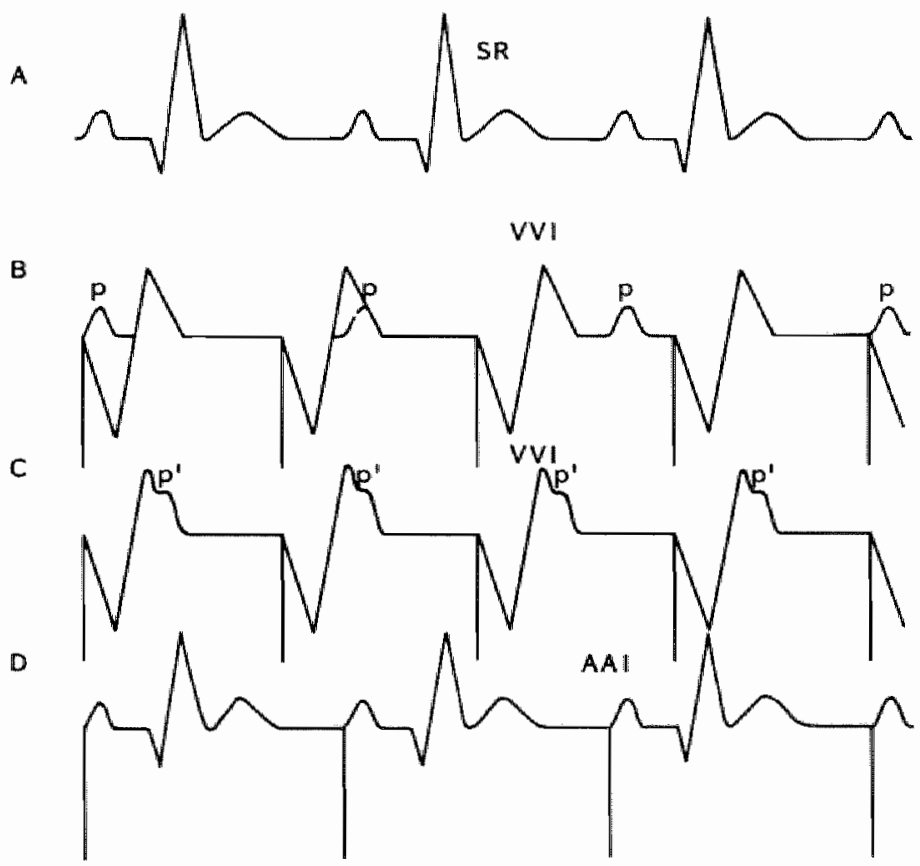

Fig. 8. Schematic representation of the ECG during sinus thythm and during atrial and ventricular on demand pacing in the patient with sinus node dysfunction.

a. Sinus rhythm with intact $A V$ conduction.

b. Ventricular pacing in a patient without retrograde $A V$ conduction results in $A V$ dissociation.

c. Ventricular pacing in a patient with intact retrograde $A V$ conduction results in atrial contraction against closed mitral and tricuspid walves.

d. Atrial pacing in a patient with intact $\mathrm{AV}$ conduction results in preservation of $\mathrm{AV}$ syrchrony. 


\section{Ventricular demand pacing}

For more than 2 decades, this was the only available permanent pacing system. Over the years several reports appeared in the literature emphasizing the disadvantages of this pacing mode, based on haemodynamic studies performed in the catheterization laboratory $(33,34)$. Certainly, one of the major shortcomings of ventricular pacing is that appropriate AV synchrony is lost either as a result of $\mathrm{AV}$ dissociation or as a consequence of retrograde atrial conduction (Fig. 8). Another dimitation especially in patients with sinus node dysfunction and intact anterograde AV conduction is that ventricular depolarization and ventricular contraction during ventricular pacing is different from and haemodynamically inferior to ventricular activation during normal $\mathrm{AV}$ conduction (39).

On the other hand, the majority of patients with symptomatic conduction disorders in whom a ventricular unit was implanted, did remarkably well, since ventricular demand pacing prowed to be successful in alleviating cerebral symptoms $(32,47)$. At present, ventricular demand pacemakers are still the most commonly used pacemakers in patients with symptomatic conduction disease (66).

\section{Atrial demand pacing}

Atrial pacing may be used with sinus node dysfunction and intact anterograde AV conduction. In patients with $\mathrm{AV}$ block, atrial pacing is contraindicated. From a haemodynamic standpoint, this pacing mode is superior to on demand ventricular pacing (35). So far, permanent atrial pacing has never gained a great popularity. This is partly due to the fact that only recently reliable atrial leads have become available for clinical application, but it also relates to the restraint of many clinicians to implant a pacing system which is inadequate if heart block would occur during follow-up.

\section{AV universal (DDD) pacing}

A DDD pacemaker operates as an atrial demand unit as long as anterograde AV conduction is intact. However when the natural AV conduction time exceeds a programmed interval ( $A V$ interval) the ventricle is paced. Therefore, during DDD pacing AV synchrony is preserved (38-40). Fig. 9 schematically illustrates the differences between ventricular and AV synchronous pacing. At present, DDD pacers are implanted, especially in pa- 

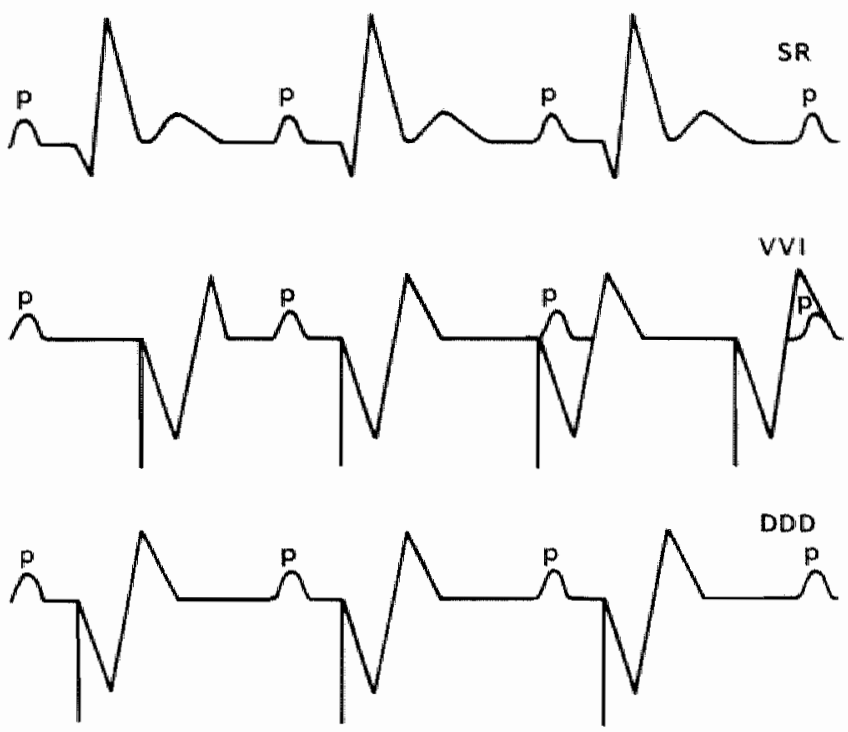

Fig. 9. Schematic representation of the ECG during normal sinus rhythm, during ventricular and $\mathrm{AV}$ synchronous pacing.

Upper tracing: sinus rhythm with intact $A V$ conduction.

Middle tracing: ventricular pacing by a single chamber pacemaker.

Lower tracing: AV' synchronous pacing by a dual chamber pacemaker.

tients who were physically active before the onset of $\mathrm{AV}$ block, irrespective of their age (70, Chapter 5).

Initially, AV synchrony was thought to play a more important role in maintaining cardiac output in the failing heart than in the normal heart (66). Recently, Wirtzfeld et al. (70) demonstrated that atrial contribution to stroke volume is relatively greater in patients with pulmonary capillary wedge pressures less than $20 \mathrm{mg} \mathrm{Hg}$ than in patients with wedge pressures greater than $20 \mathrm{~mm} \mathrm{Hg}$. Based on these results these investigators suggested, that it is more likely that the opposite is true.

The benefits of DDD pacing are: AV synchrony is preserved at rest in contrast to ventricular demand pacing; during exercise not only $\mathrm{AV}$ synchrony is maintained, but in addition the sinus node of the patient determines the AV synchronous pacing rate. In other words as long as the sinus node normally accelerates with exercise or during conditions of increased metabolic demand, a physiologic rate response occurs $(40,41,70)$. Criticall to a pacing system that uses the native $P$ wave as a trigger for ventricular pacing is the proper and consistent recognition and discrimination of the $\mathbf{P}$ wave 
from both other intracardiac signals and extracardiac sources of interference (71).

A poor rate increase is provided by the pacemaker in patients with either sinus node dysfunction or patients treated with drugs that may suppress sinus node function.

\section{Rate responsiwe pacing}

One can define rate responsive pacing as pacing to optimize cardiac output to meet metabolic needs in the absence of normal atrial control (72). Control is achieved by sensing some physiologic variable that is correlated to actual physiologic need. The pacing rate is increased or decreased, dependant on the sensed parameter value. Several sensors have now been developed to adjust the atrial or ventricular pacing rate to metabolic demand (41). The ideal form of pacing is one that responds to the body's need for varying cardiac output in a way a normal sinus node would respond while maintaining AV synchrony (70). Table II lists the physiologic sensors available for rate responsive pacing, which are presently available in singel chamber pacing systems.

TABLE II*

PHYSIOLOGIC SENSORS PROPOSED FOR RATE RESPONSIVE PACING

\begin{tabular}{lc}
\hline PARAMETER & YEAR** \\
\hline RESPIRATION RATE & 1975 \\
BLOOD pH & 1977 \\
CENTRAL BODY TEMPERATURE & 1978 \\
QT INTERVAL & 1981 \\
O2 CONTENT OF VENOUS MIXED BLOOD & 1981 \\
ASYNCHRONOUS ATRIAL RATE & 1982 \\
MUSCLE NOISE & 1983 \\
RV STROKE VOLUME & 1984 \\
RIGHT ATRIAL PRESSURE & 1984 \\
\hline
\end{tabular}

- Fron A. Wirzfeld el al. (70).

** First publication in the medical fiterature.

\section{- Rate responsive atrial pacing}

As far as sinus nodal function is concerned, neither ventricular and atrial on demand pacing nor AV synchronous pacing correct for a blunted sinus 
node response to exercise, emotion or metabolic demand. A rate responsive atrial pacing system would be a substitute for a failing sinus node in the subgroup of patients with sinus node dysfunction and intact AV conduction $(67,68)$.

\section{- Rate responsive ventricular pacing}

When patients are allowed to increase heart rate and maintain AV synchrony by use of AV synchronous pacing, a statistically significant increase in exercise capacity has been demonstrated in comparison with fixed rate ventricular pacing $(50,51)$.

Is this increase in exercise capacity a result of the chronotropic response of the ventricle alone or a result of the maintainance of AV synchrony during the chronotropic response of the ventricle?

Fananapazir et al. (73) studied this subject and observed that the chronotropic response of the ventricle is the primary determinant in enhanching exercise capacity. These investigators demonstrated that a similar heart rate response with or without atrial synchrony appeared to allow a similar entancement of exercise capacity over ventricular demand pacing. Rate responsive ventricular pacing therefore has, similar to DDD pacing, the potential for improved exercise capability in comparison with ventricular demand pacing at a constant rate.

\section{- Rate responsive $A \boldsymbol{V}$ synchronous pacing}

As mentioned before, a limitation during AV synchronous pacing is that an inadequate rate increase will occur during exercise in patients with sinus node dysfunction or patients treated with drugs that may suppress sinus node function. Rate responsive $A V$ synchronous pacing might substitute for this default with preservation of AV synchrony. With the development of appropriate sensors, rate responsive pacing may open a completely new field of investigation for the treatment of cardiac conduction disorders (67, 68,70 ).

Two decades ago syncope due to complete heart block was the primary indication for permanent cardiac pacing. At present, pacemakers are implanted not only to prevent recurrent syncope but also with the objective to improve the patient's working capacity and feeling of well-being (70). 


\section{REFERENCES}

1. Escher, D.J.W.: Historical aspects of pacing. In Cardiac Pacing. Edited by Samet. New York \& London, Crune \& Stratton, pp 1-5, 1973.

2. Schechter, D.C.: Exploring the origins of electrical cardiac stimulatio Minneapolis, Medtronic Inc., 1983.

3. Lagergren, H.: How it happened: My recollection of early pacing. Pace 1; 14 1978.

4. Furman, S., Schwedel, J.B.: An intracardiac pacemaker for Stokes-Ada seizures. N Eng J Med 261; 943, 1959.

5. Ferrer, I.M.: The Sick Sinus Syndrome. Futura Publishing Company, Mou1 Kisco, New York, 1974.

6. Strauss, H.C.. Scheinman, M.M., LaBarre, A. et al.: Review of the sign ficance of drugs in the sick sinus syndrome. In The Sinus Node, structur function and clinical relevance. Edited by F.I.M. Bonke. The Hague \& Bosto \& London, Martinus Nijhoff Medical Division, pp 103-J11, 1978.

7. Wellens, H.J.J., Cats, V.M., Dueren, D.R.: Symptomatic sinus node at normalities following lithium carbonate therapy. Am J Med 59; 285, 1975.

8. Mandel, W.J., Hayakawa, H., Allen, H.N., et al.: Assessment of sinus nod function in patients with the sick sinus syndrome. Circulation 46; 761, 1972

9. Thormann, J., Schwarz, F., Ensslen, R. et al.: Vagal tone, significance o electrophysiologic findings and clinical course in symptomatic sinus node dys function. Am Heart J 95; 725, 1978.

10. Morley, C.A., Perrins, E.J., Grant, P., et al.: Carotid sinus syncope treated b pacing. Analysis of persistent symptoms and role of atrioventricular sequentia pacing. Br Heart J 47; $411,1982$.

11. Lown, B., Levine, S.A.: The Carotid Sinus. Clinical value of its stimullation Circulation 23; 766, 1961.

1.2. Sedziwy, L., Szezepkowski, J., Driatkowiak, A., et al.: Clinical and thera peutic considerations of carotid sinus syndrome. Pace 6; Abstract 19, 70, 1983

13. Abbott, J.A., Hirschheld, D.S., Kumkel, F.W., et al.: Graded exercise testing in patients with sinus node dysfunction. Am J Med 62; 330, 1977.

14. Jordan, J.L., Yamaguchi, I., Mandel, W. J.: The sick sinus syndrome patho physiology, significance and treatment. Cardiol Dig 12; 11, 1977.

15. Gaffney, J.B., Wasserman, A.G., Rotsztian, A., et al.: Sick Sinus Syndrome 
Mechanisms and management. In Cardiac Arrhythmias - Mechanisms and Management. Edited by A. Castellanos, Philadelphia „F.A. Davis, p 25, 1980.

16. Jose, A.D.: Effect of combined sympathetic and parasympathetic blockade on heart rate and cardiac function in man. Am J Cardiol 18; 476, 1966.

17. Jordan, J.L., Yamaguchi, L. Mandel, W.J. : Studies on the mechanism of sinus node dysfunction in the sick sinus syndrome. Circulation 57; 217, 1978.

18. Mandel, W.J., Hayakawa, H., Danzig, R. et al.: Evaluation of sino-atrial node function in man by overdrive suppression. Circulation 44;59, 1971.

19. Pop, T., Fleischmann, D.: Measurement of sinus node recovery time after atrial pacing. In The Sinus Node, structure, function and clinical relevance. Edited by F.I.M. Bonke. The Hague \& Boston \& London, Martinus Nijhoff Medical Division, pp 23-35, 1978.

20. Jordan, J.L., Yamaguchi, I., Mandel, W.J.: Function and dysfunction of the sinus node: clinical studies in the evaluation of simus node function. In The Sinus Node, structure, function and clinical relevance. Edited by F.I.M. Bonke. The Hague \& Boston \& London, Martinus Nijhoff Medical Division, pp 3-22, 1978.

21. Chadda, K.D., Banka, U.S., Bodenheimer, M.M., et al.: Corrected sinus node recovery time: Experimental physiologic and pathologic determinants. Circulation 51; 797, 1975,

22. Reiffel "J.A., Gang, E., Bigger, J.T., Jr., et al.: Sinus node recovery time related to paced cycle length in normals and patients with sinoatrial dysfunction. Am Heart J 104; 746, 1982

23. Strauss, H.C., Bigger, J.T., Jr., Saroff, A.L., et al.: Electrophysiologic evaluation of sinus node function in patients with sinus node dysfunction. Circulation $53 ; 763,1976$.

24. Seipel, L., Breithardt, G., Leuner, C.: Programmed atrial stimulation used for calculation of sinoatrial conduction time (SACT) in man. In The Sinus Node, structure, function and clinical relevance. Edited by F.I.M. Bonke. The Hague \& Boston \& London, Martinus Nijhoff Medical Division, pp 36-45, 1978.

25. Breithardt, G., Seipel, L., Loogen, F.: Sinus node recovery time and calculated sinoatrial conduction time in normal subjects and patients with sinus node dysfunction. Circulation $56 ; 43,1977$.

26. Narula, O.S., Shanta, N., Vasquez, M. et al.: A new method for measurement of sinoatrial conduction time. Circulation 58; 706, 1978.

27. Levine, P.A.: Personal Communication.

28. Reiffel, J.A., Gang, E., Glicklich, J., et al.: The human sinus node electrogram: A transvenous catheter technique and comparison of directly measured and indirectly estimated sinoatrial conduction time in adults. Circulation 62; $1324,1980$.

29. Goldreyer, B.N., Damato, A.N.: Sinoatrial node entrance block. Circulation 44; 789, 1971.

30. Kerr, C.R., Prystowsky, E.N., Browning, D. J., et al.: Characterization of refractoriness in the sinus node of the rabbit. Circ. Res. 47; 742, 1980.

31. Kerr, C.R., Strauss, H.C.: The measurement of sinus node refractoriness in man. Circulation $68 ; 1231,1983$. 
32. Chokshi, D.S.: Treatment of sinoatrial rhythm disorders with perman cardiac pacing. Am J Cardiol 32;215, 1973.

33. Wirtzfeld, A., Himmler, F.Ch., Prauer, H.W., et al.: Atrial and ventric pacing in patients with the sick sinus syndrome. In Proceedings of the $W$ World Symposium on Cardiac Pacing. Edited by C. Meere, Montreal, PAC SYMP, Chapter, 15-5, 1979.

34. El Gamal, M.I.H., and Van Gelder, L.M.: Chronic ventricular pacing n ventriculo-atrial conduction versus atrial pacing in three patients with sym tomatic sinus bradycardia. Pace 1; 100, 1981.

35. Ogawa, S., Dreifus, L.S., Shenoy, P.A., et al.: Hemodynamic consequen of atrio-ventricular and ventriculo-atrial pacing. Pace 1; 8, 1978.

36. Van Mechelen, R., Hagemeijer, F. De Boer, H. et al.: Atrio-ventricular a ventriculo-atrial conduction in patients with Symptomatic Sinus Node D function. Pace 6;13, 1983.

37. Van Mechelen, R., Hagemeijer, F., De Jong, J. et al.: Responses of an , universal (DDD) Pulse Generator to programmed single ventricular ext stimuli. Pace 7; 215, 1984.

38. Nathan, D.A., Center, S., Wu. C.Y., Keller, W.: An implantable synchronc pacemeker for the long term correction of complete heart block. Am J Card 11; 362, 1963.

39. Samet, P., Castillo, C., Bernstein, W.H.: Hemodynamic sequelae of atri ventricular and sequential atrioventricular pacing in cardiac patients. A Heart J 72; 725, 1966.

40. Sutton, R., Perrins, J., Citron, P.: Physiological cardiac pacing. Pace 3; 20 1980.

41. Rickards, A.F., Donaldson, R.M.: Rate responsive pacing. Clin Prog Paci Electrophysiol 1; 12, 1983.

42. Furman, S.: Cardiac pacing and pacemaker. I. Indications for pacing brad arrhythmias. Am Heart J 93; 523, 1977.

43. Narula, O.S., Shanta, N.: Atrioventricular block: Clinical Concepts and $f$ Bundle Electrocardiography. In Cardiac Arrhythmias, their mechanism diagnosis \& management. Edited by W.J. Mandel. Philadelphia \& Toront J.B. Lippincott Company, pp 437-453, 1980.

44. Schuilenburg, R.M., Durrer, D.: Problems in recognition of conduction d turbances in the His bundle. Circulation $51 ; 68,1975$.

45. Brodsky, M., Wu, D. , Denes, P., et al.: Arrhythmias documented by $24-h o$ continuous electrocardiographic monitoring in 50 male medical students wit out apparent heart disease. Am J Cardiol 39; 390, 1977.

46. Van Mechelen, R., Hagemeijer, F.: Antegrade AV conduction in patients wi sinus node dysfunction after atrial pacemaker implantation. In: Cardi: Pacing. Electrophysiology \& Tachyarrhythmias. Edited by F. Perez Gome Madrid, Editorial Grouz, pp 643-648, 1985.

47. Varriale, P., Niznik, J., Naclerio, E.A.: Indications for permanent cardia pacing. In Cardiac Pacing, a Concise Guide to Clinical Practise. Edited by I Varriale and E.A. Naclerio. Philadelphia, Lea Febiger, pp 83-96, 1979.

48. Shaw, D.B., Kekwick, C.A., Veale, D. et al.: Survival in second degree atrix 
ventricular block. Br Heart J 53; 587, 1985.

49. Frye, R.L., Collins, J.J., Desanctis, R.W. et al.: Guidelines for permanent cardiac pacemaker implantation, May 1984: A report of the Joint American College of Cardiology / American Heart Association Task force on Assessment of Cardiovascular Procedures. Circulation 70: 331A-339A, 1984.

50. Karlof, I.: Haemodynamic effect of atrial triggered versus fixed rate pacing at rest and during exercise in complete heart block. Acta Med Scand 197; 195, 1975.

51. Kruse, I., Ryden, L.: Comparison of physical work capacity and systolic time intervals with ventricular inhibited and atrial synchronous ventricular inhibited pacing. Br Heart J 46; 129, 1981.

52. Narula, O.S., Scherlag, B.J., Samet, P., et al.: Atrioventricular block: localization and classification by His bundle recordings. Am J Med 50; 146, 1971.

53. Puech, P., Grolleau, R., Guimond, C.: Incidence of different types of A-V block and their localization by His bundle recorings. In The Conduction System of the Heart. Edited by H.J.J. Wellens, K.I. Lie, and M.J. Janse. Leiden, H.E. Stenfert Kroese, pp 467-484, 1976.

54. Schuilenburg, R.: Patterns of V-A conduction in the human heart in the presence of normal and abnormal A-V conduction. In The Conduction System of the Heart. Edited by H.J.J. Wellens, K.I. Lie, and M. Janse. Leiden, H.E. Stenfert Kroese, pp 485-503, 1976.

55. Den Dulk, K., Lindemans, F.W., Wellens, H.J.J.: Management of pacemaker circus movement tachycardias. Pace 7; 346, 1984.

56. Den Dulk, K. Lindemans, F.W., Băr, F.W., et al.: Pacemaker related tachycardias. Pace $5 ;$ 476, 1982.

57. Rosen, K.M., Loeb, H.S. Gunnar, R.M. et al.: Mobitz type II block without bundle branch block. Circulation 44; 1111, 1971.

58. Rosen, K.M., Dhingra, R.C., Loeb, H.S. et al.: Chronic heart block in adults. Arch. Intern. Med. 131;663, 1973.

59. Dhingra, R.C., Denes, P., Wu, D., et al.: Syncope in patients with chronic bifascicular block. Significance, causative mechanisms and clinical implication. Ann Intern Med 81; 302, 1974.

60. Dorn, H.: Some applications of biometry in the collection and evaluation of medical data. J. Chron. Dis. I: 638, 1955.

61. Fisher, J.D.: Role of electrophysiologic testing in the diagnosis and treatment of patients with known and suspected bradycardias. Prog. Card. Vas. Dis. 24; $1,25,1981$.

62. Denes, P., Dhingra, R.C., Wu, D., et al.: Chronic H-V interval in patients with bifascicular block, right bundle branch block and left anterior hemiblock. Clinical, electrocardiographic and electrophysiologic correlations. Am J Cardiol 35; 23, 1975.

63. Dhingra, R.C., Palileo, E., Strasberg, B. et al.: Significance of H-V interval of 51.7 parients with chronic bifascicular block. Circulation $64 ; 1265,1981$.

64. Lie, K.1., Durrer, D.: Conduction disturbances in acute myocardial infarction. In Cardial Arrhythmias: Electrophysiology, Diagnosis and Management. Edited by O.S. Narula. Baltimore, Williams and Wilkins, pp 140-163, 1979. 
65. Altschuler, H., Fisher, J.D., Furman, S.: Significance of isolated H-V interval prolongation in symptomatic patients without documented heart block. Am Heart J 97; 19, 1979.

66. Samet, P., Bernstein, W.H., Nathan, D.A., et al.: Atrial contribution to cardiac output in complete heart block. Am J Cardiol 16; 1, 1965.

67. Rossi, P., Rognoni, G., Ochetta, E., et al.: Respiration dependant ventricular pacing compared with fixed ventricular and $\mathrm{AV}$ synchronous pacing: Aerobic and Haemodynamic Variables. JACC 6; 646, 1985.

68. Rickards, A.F.: Non atrial synchronous rate responsive pacing. In Cardiac Pacing. Electrophysiology \& Tachyarrhythmias. Edited by F. Perez Gomez. Madrid, Editorial Grouz, pp 755-764, 1985.

69. Adams, R.D., Harrison, T.R.: Faintness, syncope and episodic weakness. In Principles of Internal Medicine. Edited by T.R. Harrison. New York, McGraw-Hill Book Company, Fifth Edition, p 194, 1966.

70 Wirtzfeld, A., Stangl, K., and Schmidt, G.: Physiological Pacing: AV synchrony and rate control. In Cardiac Pacing Electrophysiology \& Tachyarrhythmias. Edited by F. Perez Gomez. Madrid, Editorial Grouz, p 886, 1985.

71. Levine, P.A.: $P$ Wave synchronous (VVD or VAT) Pacing. In Pacing Therapy. A Guide to Cardiac Pacing for optimum Hemodynamic Benefit. Edited by P.A. Levine and R.C. Mace. Mount Kisco, New York, Future Publishing Company, p 134, 1983.

72. Gillette, P.: Critical Analysis of Sensors for Physiological Responsive Pacing. Pace 7; 1263, 1984.

73. Fananapazir, L., Brunett, D.H., Monks, P.: Atrial synchronized ventricular pacing: Contribution of the chronotropic response to impaired exercise performance. Pace 6; 601, 1983. 


\title{
Atrioventricular and Ventriculo-Atrial Conduction in Patients with Symptomatic Sinus Node Dysfunction
}

\author{
ROB VAN MECHELEN, FRANS HAGEMEIJER. HANS DE BOER, and ADRI SCHELLING \\ From Department of Cardiology. Sint Franciscus Gasthuis, Rotterdam, and Thoraxcenter. Erasmus University. \\ Rotterdam. The Netherlands
}

VAN MECHELEN, R., ET AL: Atrioventricular and ventriculo-atrial conduction in patients with symptomatic sinus node dysfunction. In 14 patients with symptomatic sinus node dysfunction-sinus bradycardia, sino-atrial exit block, or sinus arrest-electrophysiological studies were performed before implantation of a pacemaker. In 8 patients incremental high right atrial pacing shawed AV-modal Wenckebach at pacing rates equal to or abave $130 / \mathrm{min}$ (group I); in 6 patients AV-nodal Wenckebach was reached at pacing rates less than $130 /$ min (group II). During ventricular pacing at a rate 10-15\% faster than the existing sinus rate, ventriculo-atrial (VA) conduction was present in all patients of group I. while VA conduction was present in only 2 patients of group $I I(p<0.05)$. Potients with symptomatic sinus node dysfunction but with intact $A V$ conduction frequently show $V A$ conduction during ventricular pacing and thus are particularly at risk for developing a pacemaker syndrome when a ventricular demand (VVI) pacemaker is implanted. This complication can be avaided by atrial demond (AAI) pacing or AV sequential (DVI) pacing. When adequate experience has been gathered with $A V$ universal (DDD) pacemakers, the indications for selection of a pacemaker in patients with symptomatic sinus node dysfunction will probably change. (PACE, Vol. 6, January-February, 1983)

pacemaker syndrame, permanent pacing, sick sinus syndrome, ventricula-atrial conduction

Ventriculo-atrial [VA] conduction may occur under a variety of circumstances. VA conduction has occasionally been demonstrated in patients with ventricular premature beats, ${ }^{1}$ sponlaneous or catheter-induced ventricular tachycardia ${ }^{2-4}$ complete AV block during ventricular pacing, ${ }^{s *}$ normal. AV conduction, and in a subset of patients with sinus node dysfunction undergoing ventricular demand pacing. ${ }^{*}$

The surface ECG is often helpful in identifying retrograde $P$ waves during ventricular pacing. but definite proof of $\mathrm{WA}$ conduction is only possible by electrophysiological investigation. However, electrophysiological studies are not employed routinely in patients with sinus node dysfunction and, therefore, the true incidence of VA conduction during ventricular pacing in these patients has not been established.

Address Tor reprink: Robvan Mechelen. M.D., Sint Franciscus Gisthilis, Kloiweg 500, 3045 PM Rotherdam. The NetherInters

Received November 13, 1981: revised Innuary 4, 1982 and Fubruary 16,1902 accepted for publication May 26, 1982.
Patients with sinus node dysfunction exhibiting VA conduction in response to ventricular pacing may be particularly sensitive to the loss of atrioventricular synchrony and may be inappropriate candidates for ventricular demand (VV1) pacing. ${ }^{9 \sim 14}$ We performed electrophysiological investigations in these patients to study VA conduction during ventricular pacing. In addition, sino-atrial, AV-nodal, and inframodal conduction were evaluated in order to select the most appropriate mode for permanent pacing.

Patients were divided into two groups, one with normal AV conduction (group I), and the other with impatred AV conduction (group $\mathbb{I}$. in order to study the rellationship between AV conduction and the capacity for 1:1 VA conduclion.

\section{Methods}

The decision to implant a pacemaker in patients with symptomatic sinus node dysfuriction was based upon the following conditions:

1. symploms of dizziness, dyspnea, and/or syn- 
cope in relation with sinus bradycardia. sinus arrest, or sino-atrial block documented by ambulatory electrocardiography or by talemetry:

2. absence of drug therepy (digitalis and betablockadel, that might impair sino-atrial function.

\section{Electrophysiologicol studies}

Patients who met these criteria underwent an electrophysiological investigation after having given informed consent, in order to study $V A$ conduction arud to evaluate sino-atrial, AV nodal, and infranodal conduction.

"Three catheters were introduced by puncture of the femoral vein. One quadripolar catheter was used to stimulate the atria and record a bipolar high right atrial [HRA] electrogram; one bipolar catheter was positioned across the tricuspid valve to record the His bundle electrogram [HBE]: and one bipolar catheter was used to stimulate the ventricles. If no adequate His bundle electrogram could be recorded within 10 minutes after introduction of the catheters. AV and VA conduction were studied using the atrial and wentricular catheters only. All recordings were made on a Meddars 300 catheterization laboratory computer (Honeywell*). An external pulse generator (Janssen SU2) was used for atrial and ventricular stimulation. Three $\mathbb{E C G}$ leads, a high right atrial and a His bundle electrogram were recorded simultaneously.

The AH incerval and HV interval were measured during sinus rhythm. Ventricular pacing was then initiated at a rate $10-15 \%$ faster than tho existing sinus rate. The effective ventricular refractory period (VERP) was determined with premature ventricular beats induced with regularly shortening degrees of prematurity. Criteria for the acceptance of 1:1 VA conduction during pacing were the following: [1] identical ventricular and atrial cycle length at the ventricular pacing rate: (2) constant VA conduction times af one and the same pacing rate: [3] a pause prior to the resumption of sirus rhythm

"Honaywell, Denver, Colorado, U.S.A. when ventricular pacing was abruplly integ. rupted (Figs. 1a, b).

Incremental ventricular pacing was also pen. formed up to a pacing rate of $160 / \mathrm{min}$ or up 10 i rate al which second degree VA block occurred.

The high right atrium was paced at an initil pacing rate slightry above the patient"s sinus of AV junctional rale.

The atrial pacing rate was increased in steps of $10 / \mathrm{min}$ until $1: 1 \mathrm{AV}$ conduction was lost arid second degree AV block occurred. A normal te. sponse to atrial pacing at incremental cates was defined as the development of Wenckebach periods all a heart rate of $130 / \mathrm{min}$ or higher, The development of Wenckebach block belowa heart rate of $130 / \mathrm{min}$ suggested impaired $A V$ conduction. An estimate of cardiac automaticity was obtained by pacing the atrium at approximately $120 / \mathrm{min}$ for a minimum of 30 seconds. Upon cessation of pacing, the interval from the last pacing impulse to the first sinus node re covery beat was measured [SNRT). The corrected sinus node recovery time (CSNRT) was calculated by subtracting the basic sinus. rhythm cycle length from the sinus node re. covery time. If asystole persisted for 5 seconds without escape rhythm, atrial pacing was tesumed.

Automatic tone was assessed by carotid sinus massage (CSM) and the intravenous adminis. tration of atropine, starting with $0.5 \mathrm{mg}$ ap to: maximum dose of $2 \mathrm{mg}$. A normal response ic atropine was defined as an increase of simus rale to greater than $90 / \mathrm{min}$, and an increase over the spontaneous rate of $20.50 \%$.

"These data were used to sub-divide our pu tient population into two categories: Group I: pa tients with normal AV conduction with $A$ nodal Wenckebach occurring at a HRA pacin rate of al least $130 / \mathrm{min}$; Group II: patients will impaired AV conduction with AV noda Wenckebach occurring at a HRA pacing ral slower than $130 / \mathrm{min}$.

Policy for pacemaker implantation and follow up

In patients with normal $\mathrm{AV}$ conduction, a: atrial demand pacemaker (AAI) was implanted In patients with impaired AV conduction a ven 

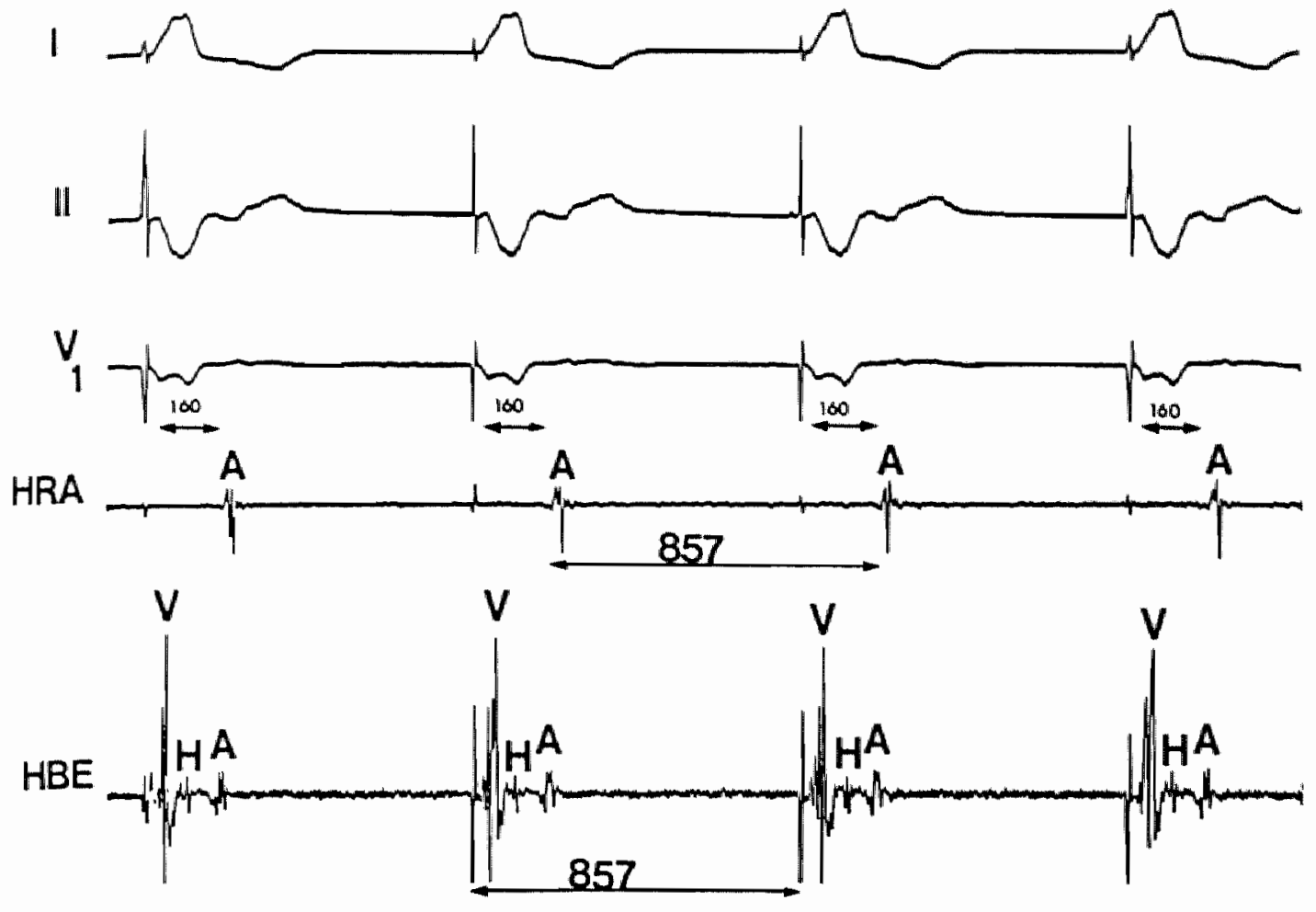

Figure 1a. Criteria for 1:1 VA conduction at ventricular pacing. The ventricles are driven at a rate of $70 / \mathrm{min}$ (CL, $857 \mathrm{~ms}$ ). Atrial and ventricular cycle lengths are equal; VA conduction time is constant ( $160 \mathrm{~ms}$ ). The His bundle electrogram (HBE) shows retrograde His bundle depolorizations during ventricular pacing. The VA interval is measured from the ventricular spike to the onset of atrial depolarization in the HRA lead.

Iricular demand pacemaker (VVI) was implanted when VA conduction was absent during ventricular pacing at rates $60-100 / \mathrm{min}$. In patients with impaired $A V$ conduction but intact VA conduction during ventricular pacing, an $A V$ sequential (DVI) pacemaker was implanted. Patients were discharged from the hospital 7 days after pacemaker implantation. Pacemaker follow-up included analysis of impulse duration. impulse frequency, impulse amplitude, and impulse form. Patients came to the outpatient clinic the tenth day, one month, three months, and six months after discharge from the hospital, and thereafter every six months.

\section{Results}

\section{Patient choracteristics}

During a two-year period from september 1979 through Seplember 1981, 14 patients were admitted to our department because of symptomatic sinus node dysfunction. The clinical and electrocardiographic data are listed in Table

\section{Sino-atrial conduction}

Table II shows the results of electrophysiological studies. The response to CSM was nor- 


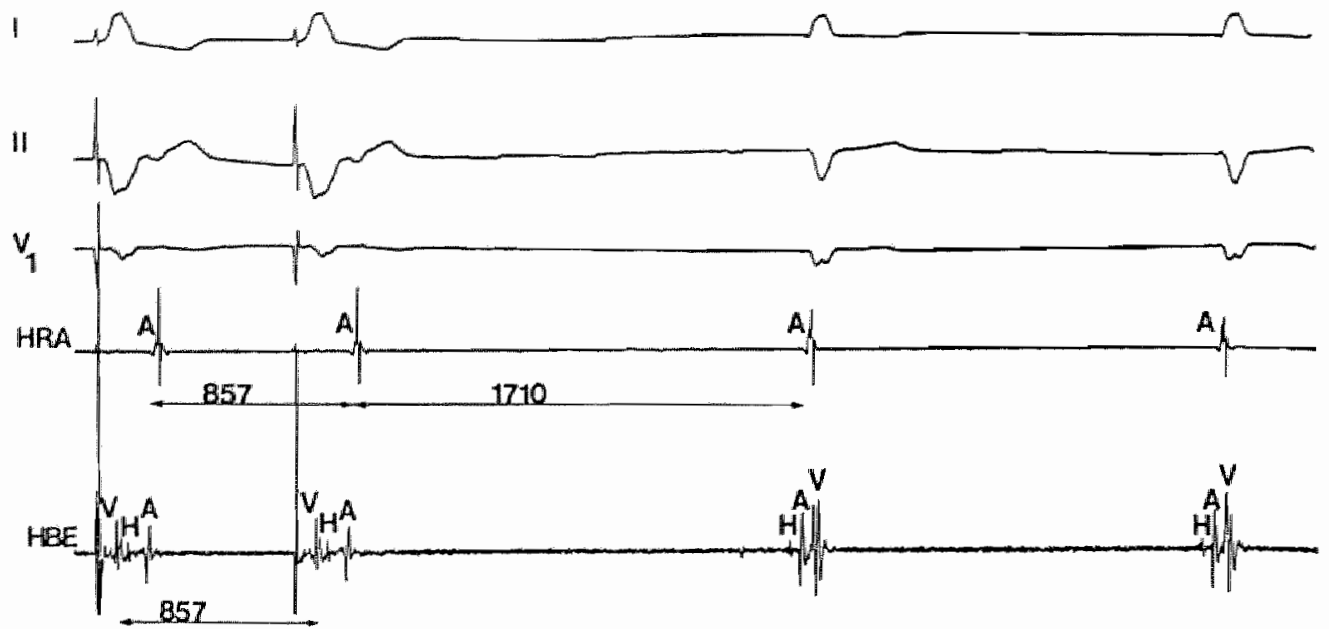

Figure 1b. Criteria for 1:1 WA conduction at the termination of ventriculor pacing. After the second paced beat, electrical stimuli are abruptly terminated. A 1.7 s pause results before the first atrial depolarization of $A V$ junctional origin occurs. The first atriat depolarization of sinus origin in this patient appeared after a pause of $5.5 \mathrm{~s}$.

mal in all patients. The response to alropine was blunted in 10 patients $\mid 71 \%)$. Sinus node recovery time (SNRT) and corrected sinus node racovery time (CNSRT) are also listed in Table II.

\section{AVmodal conduction}

The AH interval during sinus rhythm was normal in 7 patients and prolonged in 4 patients. "The HV inlerval during sinus rhythm was normal in 11 patienis. In 3 palients His potentials could not be recorded. Second degree AV block during HRA pacing was always proximal to the His bundle in patients in whom an adequate His bundle depolarization could be recorded. In 8 patients AV Wenckebach developed during pacing from the HRA at rates ranging from $130 / \mathrm{min}$ to $160 / \mathrm{min}$ (Group I). Six patients developed AV nodal Wenckebach during HRA pacing at rates below $130 / \mathrm{min}$, tranging from $50 / \mathrm{min}$ to $120 / \mathrm{min}$. Of these 6 patients there were 4 who had prolonged $\mathrm{AH}$ intervals $(\geqslant 140 \mathrm{~ms}$ ) during sinus rhythm, or at atrial pacing slightly above the spontaneous rate.

\section{infranodal conduction}

There were 3 patients with intraventricular conduction defects, 1 patient with right bundle branch block and left axis deviation, and 2 patients with left anterior hemiblock. The HV interwal was normal ( $\leqslant 60 \mathrm{~ms}$ ) in three patients.

\section{VA conduction}

VA conduction was present in 10 patients and absent in 4 patients (Table III]. VA intervals measured from the stimulus artifact to the onsel of atrial depolarization in the HRA lead ranged from $120-230 \mathrm{~ms}$ at ventricular pacing rates 10 $15 \%$ faster than the sinus rate. VA Wenckebact was present in all 10 palients: in 7 at ventricular pacing rates equal to or greater than $100 / \mathrm{min}$ (ranging from $100-150 / \mathrm{min}$ ) and in 3 patients at ventricular rates slower than $100 / \mathrm{min}[90 / \mathrm{min}]$. 
Titable 1 .

Clinicall and Electrocardiographic Data

Elactrociardiogram

\begin{tabular}{|c|c|c|c|c|c|c|c|c|c|}
\hline Patient & $\begin{array}{l}\text { Age } \\
\text { (yrs) }\end{array}$ & Sex & $\begin{array}{l}\text { Arrhythmila } \\
\text { prior to pacing }\end{array}$ & $\begin{array}{l}\text { Spontaneous } \\
\text { Silnus pause } \\
\text { (toc) }\end{array}$ & $\begin{array}{c}\mathrm{HR} \\
(\mathrm{bpm})\end{array}$ & $\underset{(\sec )}{\mathrm{PR}}$ & $\begin{array}{l}\text { aAs } \\
(\text { ac) }\end{array}$ & other & Symptoms \\
\hline 1. J.B. & 73 & $f$ & AVJ, SB & 3.5 & $50-120$ & 0.16 & 0.06 & - & syncope \\
\hline 2. L.B. & 67 & $\mathrm{~m}$ & AVJ, SE & - & $30-100$ & 0.18 & 0.08 & - & dizzlnesis \\
\hline 3. D.L. & 75 & $f$ & SB, PSVT & - & $35-140$ & 0.18 & 0.06 & - & dilzziness \\
\hline $4_{n}$ A.V. & 40 & $f$ & SAB, PVST & 4.2 & $70-140$ & 0.16 & 0.06 & - & $\begin{array}{l}\text { dyspnead } \\
\text { dizziness }\end{array}$ \\
\hline 5. A.L & $7 B$ & $m$ & PSVT, SB, AVJ & - & $40-150$ & 0.14 & 0.08 & - & dizziness \\
\hline 6. J.C. & 81 & $\mathrm{~m}$ & SB, PAF, SA & 5.5 & $50-120$ & 0.16 & 0.06 & - & syncope \\
\hline 7. A.E. & 85 & $\pi$ & SB, AWJ & - & $37-140$ & 0.18 & 0.08 & - & dizziness \\
\hline 8. M.R. & 83 & \# & $S B, A W J$ & - & $40-60$ & 0.22 & 0.14 & $\begin{array}{l}\text { RBBB } \\
\text { LAHB }\end{array}$ & dlzziness \\
\hline 9. E.S.M. & 77 & $\#$ & SB, AVJ & - & $40-100$ & 0.18 & 0.10 & LAHB & dizziness \\
\hline 10. J.S.K. & 73 & $\sharp$ & SB, AWJ & - & 28- 60 & 0.16 & 0.06 & - & $\begin{array}{l}\text { syncope, } \\
\text { dizziness }\end{array}$ \\
\hline 11. G.D. & 81 & $f$ & $S B_{n} A V B I I$ & - & $40-80$ & 0.20 & 0.06 & - & dizzinasus \\
\hline 12. D.P. & 83 & 1 & $\mathrm{SB}_{\text {"AVBII }}$ & - & $40-80$ & 0.20 & 0.110 & LAHB & $\begin{array}{l}\text { dyspnea, } \\
\text { dizziness }\end{array}$ \\
\hline 13. G.E. & 71 & 1 & $S A_{x} S B$ & 4.5 & $40-60$ & 0.16 & 0.06 & - & $\begin{array}{l}\text { dizziness" } \\
\text { syncope: }\end{array}$ \\
\hline 14. A.J. & 67 & $\mathrm{~m}$ & PAF, AVJ & - & $16-100$ & 0.18 & 0.08 & - & dizziness \\
\hline
\end{tabular}

Abbreviations: $A V j=A V$ Junctional rhythm; $S B=$ sinus bradycardia; $P S V T=$ paroxysmal supraventricular tachycardia; $S A B=$

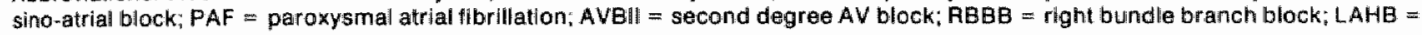
left anterior hemibiack.

VA conduction was present in all patients of group $I_{n}$ but in only 2 patients of group $\mathbb{I I}$ $(p<0.05)$ (Table IV).

Pacemaker therapy and follow-up

All patients were discharged from the hos pital within 7 days after pacemaker implantation. Eight patients had an AAI unit, 4 patients had a VVI unil, and 2 patients had a DVI pacemaker. All patients could be folllowed for at least 3 months. The follow-up data are listed in Table V. None of the patients with an AAI pacemaker developed impaired AV conduction. There were no pacemaker-related complicalions during the observed follow-up period; in particular, there were no symptoms suggestive of pacemaker syndrome. All patients are alive.

\section{Discussion}

Ventriculo-altrial conduction was studied in patients with tachyarrhythmias by Goldreyer a.. ${ }^{\%}$ in 1970. These investigators could demonstrate an $89 \%$ incidence of VA conduction in patients with normal $A V$ conduction, compared with an $8 \%$ incidence of VA conduction in patients with impaired AV conduction.

Schuilenburg ${ }^{15}$ could demonstrate a $38 \%$ incidence of $V A$ conduction in patients with normal AV conduction and a $44 \%$ incidence of $V A$ con duction in patients with impaired $A V$ conduction.

In comparison with the vast literalure on the subject of AV conduction accumulated in recent years, the number of studies in which ante. gade and retrograde $A Y$ conduction were compared systematically is relatively small, ${ }^{10 * 2 s}$ 
Table II:

Results of Electrophysiological Studies

\begin{tabular}{|c|c|c|c|c|c|c|c|c|c|}
\hline \multirow[b]{2}{*}{ Patient } & & & & & & \multicolumn{2}{|c|}{$\begin{array}{l}\text { Atrial Owerdrive } \\
\text { Alesponse }\end{array}$} & \multicolumn{2}{|c|}{$\begin{array}{c}\text { Respones to } \\
\text { atropine }\end{array}$} \\
\hline & \multicolumn{2}{|c|}{$\begin{array}{c}\text { HA and Rhythm } \\
\text { during study } \\
\text { (bpm) }\end{array}$} & $\underset{(\mathrm{me})}{\mathrm{AH}}$ & $\begin{array}{l}\text { HV } \\
\text { (ms) }\end{array}$ & $\begin{array}{l}\text { AVN-W } \\
\text { (bpm) }\end{array}$ & $\begin{array}{l}\text { SNAT } \\
\text { (ms) }\end{array}$ & $\begin{array}{c}\text { CSNAT } \\
\text { (ms) }\end{array}$ & $\begin{array}{c}\text { MF: } \\
\text { (bpm) }\end{array}$ & $\begin{array}{l}\text { Incrioase in } \\
\text { rate (\%) }\end{array}$ \\
\hline 1. U.B. & SA & 50 & 100 & 50 & 160 & 2000 & 350 & 70 & 10 \\
\hline 2. L.B. & $\mathrm{SP}$ & 70 & 110 & 55 & 140 & - & - & 87 & 15 \\
\hline 3. D.L. & SA & 50 & 80 & 50 & 130 & 2000 & 600 & 50 & 10 \\
\hline 4. A.V. & SP: & 42 & - & - & 130 & - & - & 70 & 16 \\
\hline 5. A.L. & AWs & 50 & 150 & 50 & 110 & 3000 & 1100 & 100 & 50 \\
\hline 6. J.C. & $\mathrm{SFI}$ & 80 & - & - & 140 & 4000 & - & 130 & 60 \\
\hline 7. A.E. & AWJ & 45 & - & - & 70 & 4500 & 500 & 45 & 0 \\
\hline 8. M.A. & $S A$ & 40 & 180 & 60 & 100 & 1100 & 500 & 70 & 12 \\
\hline 9. ESM & SA & 60 & 100 & 50 & 130 & 1400 & 450 & - & - \\
\hline 10. J.S.K. & $A V J$ & 40 & 130 & 50 & 130 & 1800 & 350 & 40 & 0 \\
\hline 11. G.D. & $S A_{,} A V B_{\|}$ & 40 & 140 & 50 & 60 & 1600 & 250 & 60 & 10 \\
\hline 12. D.P. & $S A_{11} A_{V B}$ & 30 & 180 & 55 & 50 & 5800 & 350 & 80 & 12 \\
\hline 13. G.E. & SP & 60 & 110 & 45 & 120 & 8400 & 560 & 100 & 50 \\
\hline 1.4. A J & AVid & 45 & 90 & 50 & 150 & 5500 & 250 & 40 & 0 \\
\hline
\end{tabular}

Abbreviations: $S$ F = sinus rhythm; AVJ = AV Junctional rhythm; AVBUl = second degree AV nodal block." AVN-W = AV nodil Wenckebach blocki SNAT = sinus mode recovery time; CSNAT = corrected sinus node recowery time.

Wirtzfeld ${ }^{a}$ observed in 50 patients with sinus node dysfunction a $40 \%$ incidence of VA conduction during permanent ventricular pacing. However, antegrade and retrograde AV conduction were not compared systematically. Morley el al ." observed an $89 \%$ incidence of VA conduction in 42 patients with sick sinus and carotid sinus syndrome and normal antegrade AV conduction.

In 14 patients with symptomatic sinus node dysfunction, we observed a $100 \%$ incidence of VA conduction in patients with intact AV conduction and a $33 \%$ incidence of VA conduction in patients with impaired $\mathrm{AV}$ conduction $(p<0.05)$. For patients who require permanent pacing these alectrophysiological findings may have important practical implications. During vantricular pacing VA conduction will result in contration of the atria against closed mitral and tricuspid valves. As a consequence systemic and pulmonary vein pressures will increase and arterial blood pressure will fall. The symptoms of this so called pacemaker syndrome are in some patients, so disabling that their ventricular demand pacemaker has to be explanted. ${ }^{12-14}$ We, therefore, believe that evaluation of retro. grade conduction is mandatory, when one considers the implantation of a ventricular demand pacemaker in these patients.

In patients with normal $A V$ conduction, but with intact VA conduction, atrial demand pacing will prevent a pacemaker syndrome. This pacing mode has been recommended $d^{0,13,44}$ and we have used atrial demand [AAI] pacemakers succesfully in $B$ of our patients. If, however, AV conduction deteriorates at a later stage, a new lead placement and a new pacemaker implantation might be required. AV sequential (DVI) pacing will also avoid the risk of a pacemaker syndrome and may anticipate the deterioration of AV conduction at a later stage. Unfortunately. many of the available units have an AV delay. which is too short to respect normal AV conduction, and artificial ventricular pacing occurs in 
Tiable 111.

Results of Electrophysiological Studies

GROUP:

\begin{tabular}{lcccc}
\hline $\begin{array}{l}\text { patients with } \\
\text { normal AV conduction }\end{array}$ & $\begin{array}{c}\text { VERP } \\
\text { (ms) }\end{array}$ & VAC & $\begin{array}{c}\text { VAW } \\
\text { (bpm) }\end{array}$ & $\begin{array}{c}\text { VACT } \\
\text { (ms) }\end{array}$ \\
\hline I. J.B. & 280 & + & 110 & 150 \\
2. L.B. & 210 & + & 120 & 200 \\
3. D.L. & 240 & + & 100 & 160 \\
4. A.V. & 280 & + & 150 & 180 \\
6. J.C. & 300 & + & 140 & 130 \\
9. E.S.M. & 310 & + & 90 & 160 \\
10. J.S.K. & 260 & + & 110 & 230 \\
14. A.J. & 220 & + & 90 & 120 \\
\hline
\end{tabular}

\section{GROUP II}

\section{patients with impaired}

AV conduction

\begin{tabular}{|c|c|c|c|c|}
\hline 5. A.L. & 260 & + & 120 & 150 \\
\hline 7. AE. & 240 & - & - & - \\
\hline B. M.F. & 280 & - & - & - \\
\hline 11, G.D. & 240 & - & - & - \\
\hline 12. DP. & 320 & - & - & - \\
\hline 13. G.E. & 300 & + & 90 & 150 \\
\hline
\end{tabular}

Abbreviations: WERP = effective refractory period at ventricular pacing rates ranging from $60 \mathrm{~m} / \mathrm{min}$ to $90 /$ min.; $V A C=V A$ conduction; VAW $=$ VA Wenckebach pacing rate; VACT = VA conduction time. VA inter val was measured from the stimulus artifact to the onset of AHRA.

\section{Tablo: IV.}

VA. conduction in patients with normal and Impaired AV comduction

\begin{tabular}{lcc} 
& $\begin{array}{c}\text { VA } \\
\text { conduction } \\
\text { prasent }\end{array}$ & $\begin{array}{c}\text { VA } \\
\text { conduction } \\
\text { absent }\end{array}$ \\
\hline $\begin{array}{l}\text { GROUPI } \\
\text { patilents with } \\
\text { mormal AV } \\
\text { conduction }\end{array}$ & 8 & 0 \\
$\begin{array}{l}\text { GROUP I } \\
\text { patients with } \\
\text { impaired AV } \\
\text { conduction } \\
\text { Total }\end{array}$ & & \\
& & \\
\hline
\end{tabular}

"two-sided Fisher exact test.(22) spite of normal AV conduction. Another prob. lem with these units is that the initial slew rate of the sensed ventricular depolarization may be loo slow, and the result is a lusion beat or even artificial pacing very late in a spontaneous QRS complex in spite of normal ventricular semsing. For this reason programmabllty of the AV delay with this form of pacing will allow greater flexibility.

In patients with impaired $A V$ conduction. atrial demand (AAI) pacing is contraindicaled. In 2 of our patients with impaired AV conduction but with intact VA conduction, retrograde conduction was precluded by pacing the atria and ventricles sequentially. In these patients an AV sequential (DVI) pacemaker was implanted.

Initially, when we started our study, the atrial synchronous ventricular inhibited [VDD] pace- 
Table $W$.

Pacemaker therapy and follow-up

\begin{tabular}{|c|c|c|c|c|c|c|}
\hline \multirow{2}{*}{ Pattient: } & \multicolumn{2}{|c|}{ AV conduction } & \multicolumn{2}{|c|}{ VA conduction } & \multirow{2}{*}{ PM } & \multirow{2}{*}{$\begin{array}{c}F-U \\
\text { (months:) }\end{array}$} \\
\hline & w. & IMP. & $P$. & A. & & \\
\hline 1. LB. & + & & + & & AAl & 3 \\
\hline 2. L.B. & + & & + & & AAl & 4 \\
\hline 3. D.L. & + & & + & & AA! & 8 \\
\hline 4. A, W. & + & & + & & $A, A_{1} I$ & 13 \\
\hline 5. A.L. & & + & $*$ & & DWI & 16 \\
\hline 6. J.C & + & & + & & AAl & 7 \\
\hline 7. A.E. & & + & & + & VVI & 3 \\
\hline 8. M.R. & & + & & + & WVI & 18 \\
\hline 9. E.SM & + & & + & & AAI & 14 \\
\hline 10. J.S.K. & + & & + & & AAI & 6 \\
\hline 11. G.D. & & + & & + & W'I & 7 \\
\hline 12. D.P. & & + & & + & WI & 10 \\
\hline 13. Q.E. & & + & + & & DWI & 9 \\
\hline 14. A.J. & + & & + & & A.AII & 24 \\
\hline
\end{tabular}

Abbreviations: $N=$ normal; $I m p .=$ mpaired; $P=$ present; $A=$ absent: $P M=$ pacemalker type; $F-U=$ followup.

maker and the AV universal (DDD) pacemaker were not available. However, these units are avaliable at present. The VDD unit is not indicated in patients with sinus node dysfunction, because normal sino-atrial function is a prerequisite for its application. The DDD unit might be used in palients with symptomatic sinus node dysfunction, but when VA conduction is intact, this unit should be programmed in a DVI mode. The reason to choose the DVI mode of pacing rather than the DDD pacing mode is that in the latter $V A$ conduction might induce a rementry lachycardia, in which the retrograde arm of the circuit is provided by the VA conducthon pathway and the antegrade arm by the atrial synchronous ventricular pacing pathway." By programming the unil in a DVI mode,

\section{References}

1. Kistin, $\mathrm{A}, \mathrm{D}$. and Landowne, M.: Retrograde conduction from premature ventricular contracthons: A common occurrence in the human heart. Circulation, 3738, 1951.

2. Kistin, A.D.: Retrograde conduction to the atria in ventricular bradycardia. Circulation, 24:236, 1961.

3. Massumi, R.A., Tawakkal, A.. and Kistin. A.D.:
VA conduction will not result in an atrial synchronous ventricular response and thereby not initiate a re*entry tachycardia.

In canclusion. patients with symptomatic sinus node dysfunction, in particular patients with normal AV conduction, will frequently evidence VA conduction during wentricular pacing. "These patients may develop a pacemaker syndrome after implantation of a ventricular demand (VVI) pacemaker. "This complication can be avoided by atrial demand [AAl] pacing or AV sequential [DVI] pacing. When adequate experience has been gained with $A V$ universal (DDD) pacemakers, the indications for selection of a pacemaker in patients with symptomatic sinus node dysfunction will probably change.

Reevaluation of the electrocardiographic and bedside criteria for diagnosis of ventricular tachycardia. Circulotion, 36:628, 1967.

4. Kistin, A.D., Tawakkol, A., and Massumi, R.A.: Atrial rhythm in ventricular tachycardia occurring during cardiac catheterization. Circulation, $35: 10,1967$.

5. Scherf, D., Cohen, I., and Orphanus, R.P.: Retro- 
grade activation of the alria in atrioventricular block. Am. I. Cardiol., 13:219, 1964 .

6. Louvros, $N_{\text {.., }}$ and Costeas, $F$.: Retrograde activation of atria in atriowentricular block. Arch. Intern. Med., 116778. 1965.

7. Castillo, C., and Samet, P.: Retrograde conduction in complete heart block. Br. Heort J., 29:553, 1967.

8. Barold, S., Linhart. J., and Samet "P.: Reciprocal beating induced by ventricular pacing. Circulation, 38:330" 1968 .

9. Wirtzfeld A.. Himmler, F.Ch., Präuer, H.W., et al.: Atrial and wentricular pacing in patien ts with the sick sinus syndrome. In C. Meere (Ed.): Proceedings of the Vith World Symposium on Cardiac Pacing. Montreal. PACESYMP, 1979, Chap. $15-5$.

10. Ogawa, S. Dreifus" L.S. Shenoy, P.A., et al.: Hemodynamic consequences of atrioventricular and ventriculo-atrial pacing. PACE, 1:8, 1978.

11. Johnson, A.D., Laiken, S.L., and Enhler, R.L.: Hemodynamic compromise associated with ventriculo-atrial conduction following transwenous pacemaker placement. Am. I. Med. 65:75, 1978.

12. Alicandri. C., Fonad, F.M. "Tarazi, R.C., et al.: Three cases of hypotension and syncope with ventricular pacing: Possible role of atrial retlexes. Am. J. Cardiol. 42:137, 1978 .

13. Amikam, S., and Riss, E.: Untoward hemodynamic consequences of permanent ventricular pacing associated with ventriculo-atrial conduction. In C. Meere (Ed.): Proceedings of the Vith World Sympasium on Cardiac Pacing, Montreal, PACESYMP, 1979. Chap. 15-6.
14. El Gamel. M.I.H., and Van Gelder, I. M.: Chronic ventricular pacing with ventriculo-atrial conduction versus atrial pacing in three patients with symptomatic sinus bradycardia. PACE. 1:100, 1981 .

15. Rosen, K.M., Loeb, H.S., Ziad Sinno, al.: Cardiac conduction in patients with symptomatic sinus node disease. Circulation. 43:836, 1971.

16. Narula, O.S.: Atrioventricular conduction den fects in patients with sinus bradycardia. Cirm culation, 44:1096, 1971.

17. Goldreyer, B.N, and Bigger, ]: Ventricula-atrial conduction in man. Circulation, 61:935, 1970.

18. Schuilenburg, R.M.: Patterns of VA conduction in the human heart in the presence of normal and abnormal AV conduction. In HIJ. Wellens. K.1. Lie, and M.]. Janse (Eds.): The Conduction System of the Heart. Structure, Function and Clinical Implications. Philadelphia: Lea \& Febiger, 1976, 485-503.

19. Akhtar, M., Damato, A.N., Caracta, A.R., ot al: A comparative analysis of antegrade and retro. grade conduction patterns in man. Circulation. $52: 766,1975$.

20. Narula, O.S.: Retrograde pre-excilation. Comparison of antegrade and retrograde conduction intervals in man. Circulation, 50:1129, 1974.

21. Mortey, C., Sutton, R., Perrins, I., et al.: Importance of retrograde atrioventricular conducion in physiological cardiac pacing. PACE, 3:A-60, 1981.

22. Armitage, P.: Statistical Methads in Madical Me search. (Second printing), Blackwell Sxi. Publ. Oxford. 1973 . 


\title{
Serial electrophysiologic studies after single chamber atrial pacemaker implantation in patients with symptomatic sinus node dysfunction
}

\author{
R. WAN MEHFIEN, A. SEGERS AND F. HAGEMEUER

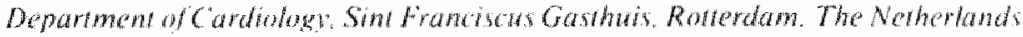

KEY WORDS: Anterograde AV conduction, antiarthythmic drugs, atrial pacing, symptomatic sinus node dygfunction

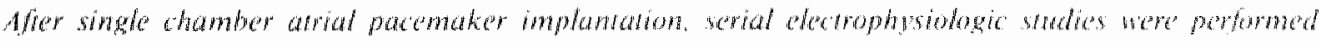

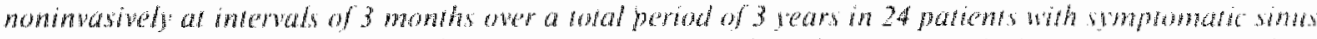

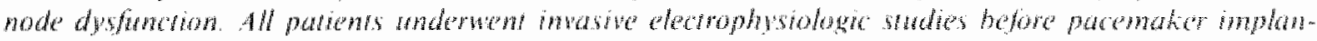

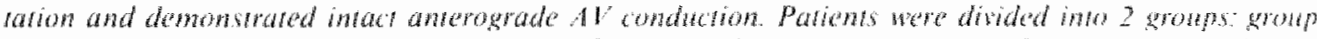

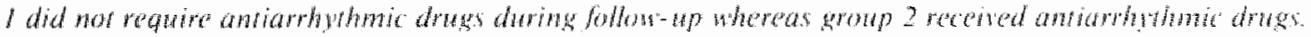

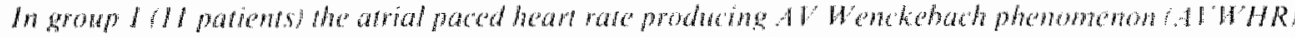

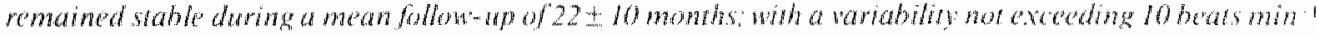

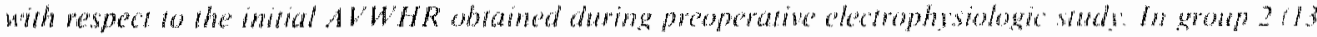

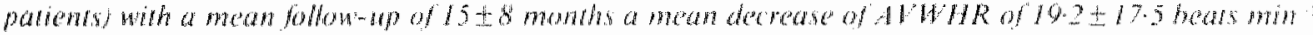

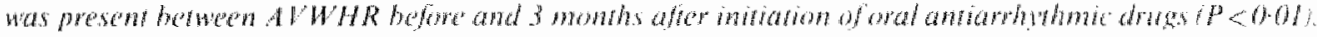

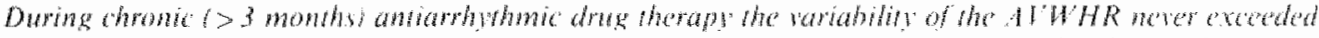

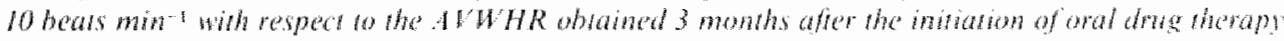

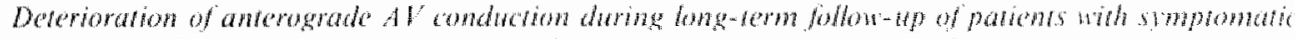

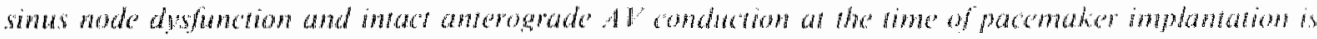

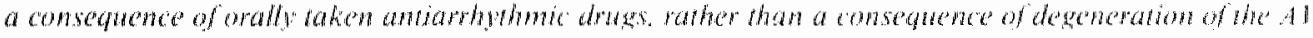
condhothys wylem.

\section{Introduction}

Single-chamber atrial pacing in patients with symptomatic sinus node dysfunction and intact anterograde $A V$ conduction at the time of pacemaker implantation is still a controversial issuc. Fenerdit Rosen af al and Nallall have suggested that sinus node dystunction is a part of a dithuse disease of the AV conducting sytem. They assumed that, although anterograde $A V$ conduction may be intact at the time of pacemalker implantation, deterioration during lollown is likely, as a result of degeneration of the AV conducting system. Howewer, since antiathyth mic drugs are lrequently used in these, patients to treat coexisting tachyorthyth. mids or other medical problems w deterionation of

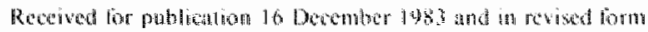
22 March 1934

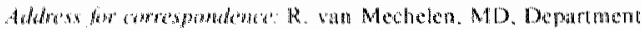

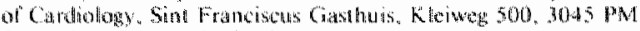
Rotherditm. "The Netheriands anterograde $A V$ conducion may also be a result of the electrophysiologic effects of these agents on the AV conducting system.

The aim of our study, was lo determine the relative importance of these two factors on deterioration of anterograde A $V$ conduction during followup of patients with symptomatic sinus node dystunction and intact anterograde AV conduction at the time of single-chamber atrial pacemaker implantation.

\section{Methods}

PATHET SHILCTION

Pationts with symptomatic sinus node dysluncdion and intact anterograde $A V$ conduction were selected for this study. The diagnosis of symplomatic sinus node dysfunction was based upon symptoms of dizziness, dyspnoed or syncope with: (a) sinus bradycardia $\left(<50\right.$ beats min $\left.^{-1}\right)$, sinus arrest $(\geqslant 45)$ and/or sino-atrial block $(\geqslant 4$ s). documented by Holter tracing and/or telemetry; 


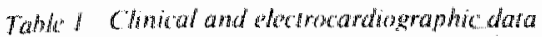

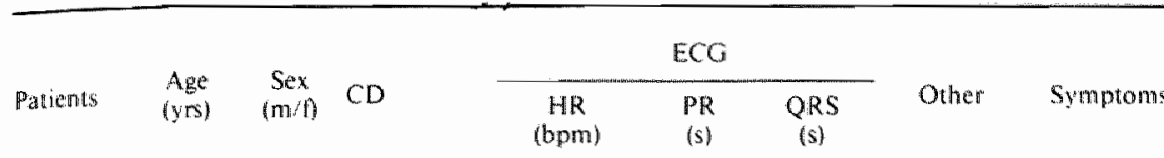

\begin{tabular}{|c|c|c|c|c|c|c|c|c|}
\hline 1 & 8.4 & i & 58 & $40-50$ & 0.18 & 0.08 & - & duziness \\
\hline 2 & 75 & $\overline{\mathrm{f}}$ & SA. SB & $50-120$ & 0.16 & 0.08 & - & syncope \\
\hline 3 & 70 & $\mathrm{~m}$ & $S B$ & $30-100$ & 0.18 & $0-08$ & - & syncope \\
\hline 4 & 77 & $\mathrm{f}$ & $S B$ & $42-70$ & 0.18 & 0.08 & - & dizziness \\
\hline 5 & 94 & $i$ & SB & $40-70$ & 0.24 & $0 \cdot 08$ & - & dizziness \\
\hline 5 & 73 & i & $\mathrm{SB}$ & $40-60$ & $0 \cdot 116$ & 0.08 & - & dizziness \\
\hline 7 & 84 & $\mathrm{f}$ & SB, AVIR & $30-50$ & 0.20 & 0.08 & - & dizziness \\
\hline 8 & 76 & $\mathrm{f}$ & $S A . S B$ & $20-60$ & $0 \cdot 18$ & 0.08 & - & syncope \\
\hline 9 & 61 & $\mathrm{~m}$ & $5 B$ & $35-50$ & 0.20 & 0.08 & - & syncope \\
\hline 10 & 82 & $i$ & SB, AVJR & $40-50$ & 0.18 & 0.08 & - & diziness \\
\hline 11 & 76 & $m$ & $S A$ & $10-90$ & 0.18 & 0.08 & - & syncope \\
\hline 12 & 75 & $i$ & SB. AVJR & $28-60$ & 0.16 & 0.08 & LVH & syncope \\
\hline 13 & 71 & $\mathrm{~m}$ & $\mathrm{SB}$ & $40-60$ & 0.14 & 0.08 & - & dizxiness \\
\hline 14 & 78 & 1 & SB, AVUR & $40-70$ & 0.18 & 0.08 & - & dizziness \\
\hline 15 & 75 & $\mathrm{f}$ & SB, PAF, VT & $30-140$ & $0 \cdot 18$ & 0.08 & - & syncope \\
\hline 16 & 76 & i & SAB, SB & $45-70$ & 0.20 & 0.08 & - & dizziness \\
\hline 17 & 85 & f" & $\mathrm{SA}$ & $30-140$ & $0 \cdot 18$ & 0.08 & - & syncope \\
\hline 18 & 65 & $i$ & SB, PAFI & $40-150$ & 0.16 & 0.08 & - & dimziness \\
\hline 19 & 83 & $\mathrm{~m}$ & SA & $30-90$ & 0.20 & $0 \cdot 10$ & AMI & dizziness \\
\hline 20 & 78 & i & SA & $15-75$ & $0 \cdot 16$ & 0.08 & AMI & syncope \\
\hline 21 & 85 & $m$ & $\mathrm{SB}$ & $30-70$ & $0 \cdot 20$ & 0.08 & - & syncope \\
\hline 22 & 80 & i & SB & $30-65$ & 0.18 & 0.08 & - & dizziness \\
\hline 23 & 73 & $\mathrm{~m}$ & SB & $30-90$ & 0.20 & $0 \cdot 12$ & $\mathbb{R B B B}, \mathrm{AMI}$ & syncope \\
\hline 24 & 55 & f & $\mathrm{SB} \cdot \mathrm{PAF}$ & $40-180$ & 0.14 & 0.08 & - & dizziness \\
\hline
\end{tabular}

$\mathrm{CD}=$ conduction disorder; $\mathrm{SA}=$ sinus arrest; $\mathrm{SB}=$ sinus bradycardia. $\mathrm{SAB}=$ sino-atrial block; $\mathrm{A} V \mathrm{~V} \mathrm{R}=\mathrm{AV}$ junctional rhythm; $P A F=$ paroxysmal atrial fibrillation; $P A F L=$ paroxysmal atrial flutter; $V T=$ ventricuIar tachycardia: $\mathrm{LVH}=$ left ventricular hypertrophy: $\mathrm{AMI}=$ anterior myocardial infarction; $\mathrm{RBBB}=$ right bundle branch block.

(b) the absence of orall drug therapy that might impair sino-atrial function $\{$ s- 7 .

The clinical and electrocardiographic data are listed in Table 1. The presence of intact anterograde AV conduction was assessed during electrophysiologic study prior to pacemaker implantation.

\section{ER HCTROPHYSIOLOGIC STUDHES}

Aiter informed consent was obtained, patients underwent an electrophystologic study according to previously described catheter techniques ${ }^{2,3,8]}$. Cardiowactive drugs were withheld for at leasi $48 \mathrm{~h}$ prior to the study.

Intact anterograde AV conduction was defined as:

1. normal HV interval ( $\leqslant 60 \mathrm{~ms}$ ) during baseline recording:

2. persistence of $1: \| \mathrm{AV}$ conduction during incremental high right atrial pacing at rates equal to or greater than 120 beats min 1 (Table 2).

In all patients with intact anterograde $\mathrm{AV}$ con. duction a single chamber atriall pacemaker was implanted (Medtronic 5985, 5977 or 8423). This particular pulse generator was selected because the programmability of the pacing system allowed us to perform limited electrophysiologic studies noninvasively during follow-up. With this pacemaker the atrial paced rate producing AV Wenckebach phenomenon was determined at intervals of 3 months after hospital discharge. The latter was assessed by increasing the atrial pacing rate in steps of 10 beats min ${ }^{-1}$, until $1: 1 \mathrm{AV}$ conduction was lost and second-degree AV block occurred. Each pacing period lasted \& min. Studies were recorded on a ECG machine with a paper speed of $50 \mathrm{~m} \mathrm{~m} \mathrm{~s}^{-1}$ (Fig. 1). 
Table 2 Electrophysislogic smodies priar to pacemaker implantation

\begin{tabular}{|c|c|c|c|c|c|c|}
\hline \multirow{2}{*}{ Patierats } & \multicolumn{4}{|c|}{ Baseline } & \multirow{2}{*}{$\begin{array}{c}\text { SNRT } \\
\text { (ms) }\end{array}$} & \multirow{2}{*}{$\begin{array}{c}\text { ANWH } \\
\text { (bpm) }\end{array}$} \\
\hline & Rhyithm & $\begin{array}{c}\text { HR } \\
\text { (bpm) }\end{array}$ & $\begin{array}{l}\mathrm{AH} \\
\text { (ms) }\end{array}$ & $\begin{array}{l}\mathrm{HV} \\
\text { (ms) }\end{array}$ & & \\
\hline 1 & $S R$ & 42 & - & - & - & 130 \\
\hline 2 & $\mathrm{SR}$ & 50 & 100 & 50 & 2000 & 160 \\
\hline 3 & $S R$ & 70 & 110 & 50 & - & 160 \\
\hline 4 & AVJR & 50 & - & 50 & 2000 & 140 \\
\hline 5 & - & - & - & - & - & $\geq 140$ \\
\hline 6 & $S R$ & 45 & 80 & 50 & 2300 & 150 \\
\hline 7 & $\mathrm{SR}$ & 50 & - & - & 8700 & 170 \\
\hline 8 & AVJR & 30 & - & 40 & $>6000$ & 120 \\
\hline 9 & $\mathrm{SR}$ & 55 & 130 & 45 & 2100 & 130 \\
\hline 10 & AVJR & 50 & - & - & 3500 & 150 \\
\hline 11 & $\mathrm{SR}$ & 60 & 80 & 50 & 1400 & 140 \\
\hline 12 & AVJR & 40 & - & 50 & 1800 & 130 \\
\hline 13 & $\mathrm{SR}$ & 50 & 70 & 40 & 1700 & 170 \\
\hline 14 & AVUR & 50 & - & 50 & $>5000$ & 190 \\
\hline 15 & SR & 70 & 90 & 50 & - & $\geqslant 160$ \\
\hline 16 & $\mathrm{SR}$ & 50 & 100 & 50 & 5600 & 120 \\
\hline 17 & $S R$ & 70 & 90 & 60 & - & 140 \\
\hline 18 & $\mathrm{SR}$ & 70 & 80 & 40 & 1200 & 180 \\
\hline 19 & $S R$ & 90 & - & - & 900 & 190 \\
\hline 20 & $\mathrm{SR}$ & 60 & 130 & 50 & 4600 & 130 \\
\hline 21 & $S R$ & 50 & 90 & 50 & - & 120 \\
\hline 22 & $S R$ & 70 & - & - & 1400 & 140 \\
\hline 23 & $\mathrm{SR}$ & 70 & - & - & 1500 & 120 \\
\hline 24 & $S R$ & 65 & 60 & 40 & 1300 & 180 \\
\hline
\end{tabular}

$H R=$ heart rate: $A H=A H$ intervat $H V=H V$ interval. SNRT = sinus node recovery time; $A V W H R=$ atrial pacing rate producing $A V$ Wenckebach phenomenon: $S R=$ sinus thythm: $A V J R=A V$ junctional rhythm.

\section{PATIENT HOLLOW-UP}

After initial study and pacemaker implantation, patients were prospectively followed in the outpatient clinic at intervals of 3 months. The first petient entered the study in September 1980 and the last patient entered the study in April 1983. Every pacemaker check-up visit included the history, physical examination, 12-lead ECG, and a noninvasive determination of the atrial paced heart rate producing AV Wenckebach phenomenon (AVWHR). One 24-h Holter recording was performed routinely during the first 6 weeks atter hospital discharge and thereafter when history suggested transient brady- or tachy-arrhythmias.

When "follow-up was completed in September 1983, patients were divided into 2 groups; group 1 patients had not received antiarrhythmic drugs during follow-up and group 2 patients were taking antiarthythmic drugs. Group 2 consisted of patients who were taking antiarthythmic drugs in hospital, and patients in whom antiarrhytlmic drugs were prescribed during follow-up.

\section{STATISTICAL ANAL.YSIS}

Each patient served as his or her own control. Differences between values were compared by means of the two-tailed paired Student's $z$-test. All data are presented as means \pm s.d.

\section{Resulits}

There were II patients (group 1) who did not require antiarrythmic drug therapy after pacemaker implantation during a mean" follow-up of $22 \pm 10$ months. The mean age of group 1 patients was $77 \pm 9$ years. Previous to pacemaker implanta. tion the electrocardiogram showed a normal PR. interval $(<0.20 \mathrm{~s})$ in 8 patients $(73 \%)$. In all 

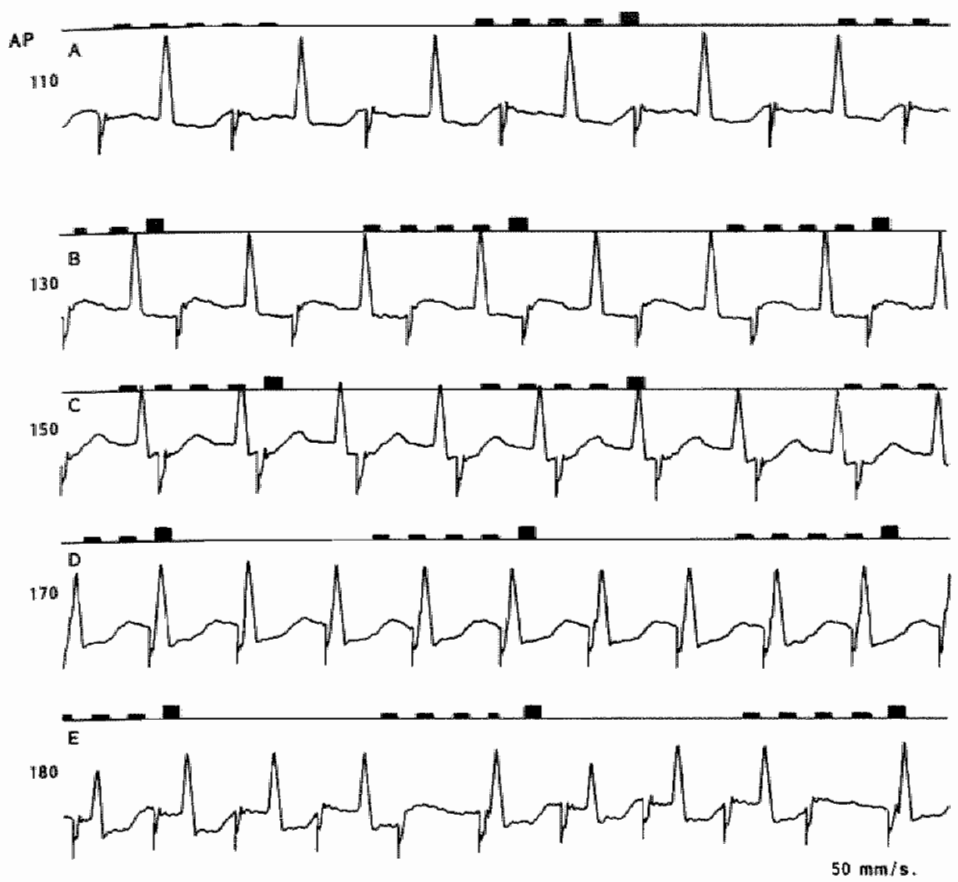

Figure 1. The atrial paced heart rate producing AV Wenckebach phenomenon is determined during incremental atrial pacing (AP).

patients of group I the QRS complex was narrow $(\leqslant 0.10 \mathrm{~s})$. The permanent atrial pacing rates ranged from 70 to 80 beats min": The mean atrial pacing rate producing AV Wenckebach phenomenon (AVWHR) during preoperative electrophysiologic studies was $144 \pm 17$ beats $\min ^{-1}$. Table 3 shows the results of serial electrophysiologic testing at intervals of 3 months after hospital discharge. The variability of AVWHR was equal to or less than 10 beats $\mathrm{min}^{-1}$, with respect to the initial AVWHR obtained during preoperative electrophyslologic study. One patient (no. 1) demonstrated transiently an increase of the AVWHR of more than 10 beats min -14 months after pacemakep implantation.

Group 2 consisted of $\| 3$ patients, in whom a variety of antiarrhythmic drugs were prescribed after pacemaker implantation, to treat cardiac failure or coexisting tachyarrhythmias. Table 4 shows the specific agents that were taken orally and the date these drugs were prescribed during follow-up of each patient.

The mean follow-up of group 2 was $15 \pm 8$ months. The mean age was $75 \pm 8$ years. Prior to pacemaker implantation the electrocardiogram showed a normal PR interval in 9 patients $(69 \%)$. In 12 patients ( $92 \%$ ) the QRS complex was narrow. In one patient the QRS duration was $0.12 \mathrm{sec}$. Permanent atrial pacing rates ranged from 70 beats/ min $^{-1}$ to 80 beats min ${ }^{-1}$. The mean AVWHR during preoperative electrophysiologic studies was $151 \pm 29$ beats min ${ }^{-1}$. Table 5 shows the results of serval electrophysiologic testing during follow-up observations in the outpatient clinic. A mean decrease of the AVWHR of $19.2 \pm 17.5$ beats min $^{-1}$ oceurred between the AVWHR before and 3 months after initiation of oral antiarrhythmic therapy $(P<0.01)$.

In patient no. 20 no lall of the AVWHR was observed after 3 months of oral quinidine sullate $(200 \mathrm{mg}$ t.id.). In all other patients of group 2 either receiving digoxin, beta-blocking agents, verapamil or amiodarone, a drop of the AVWHR was noted after 3 months of oral drug therapy. Patient no. 16 complained of dizziness and latigue during the first 3 months of amiodarone therapy $(600 \mathrm{mg}$ daily). with a concomitant drop of the AVWHR from 120 beats $\min ^{-1}$ to 80 beats $\mathrm{min}^{\sim 1}$. The ECG showed 


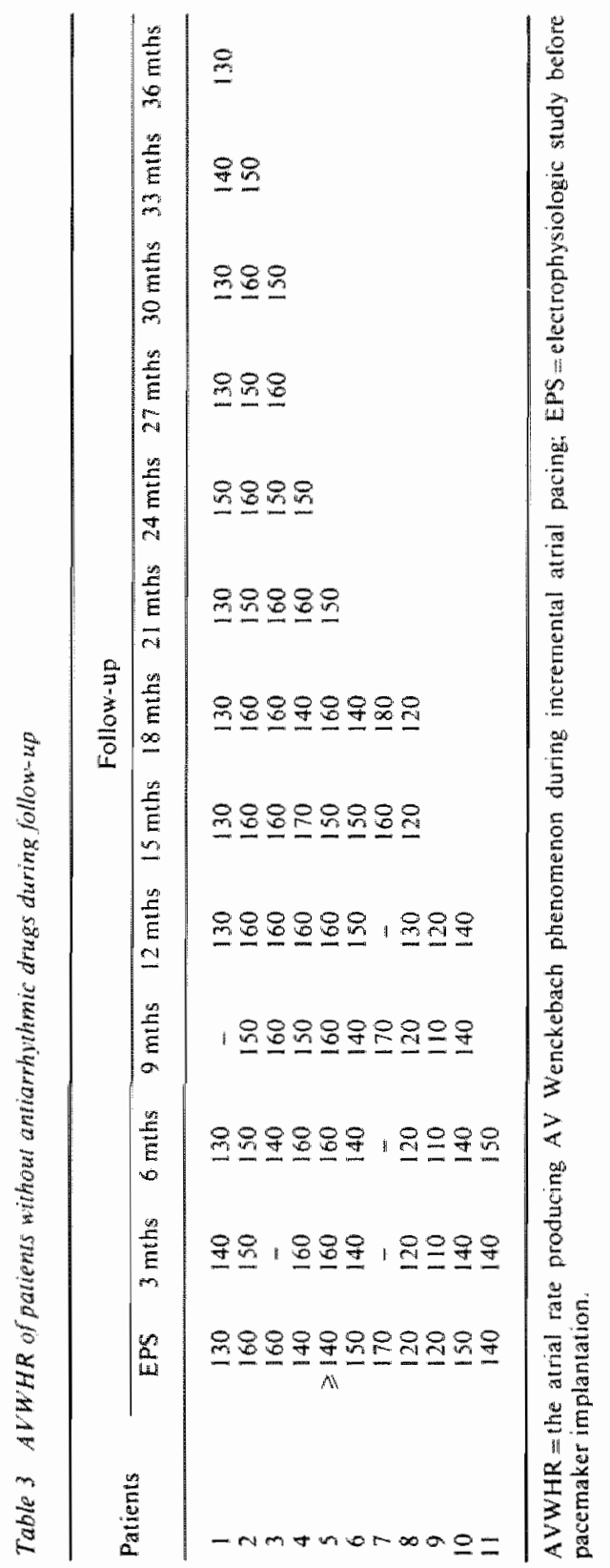


Toble 4 Antarhythmic drates during follow-up

\begin{tabular}{|c|c|c|c|}
\hline Panients & $\begin{array}{l}\text { Initiation } \\
\text { (mths of FU) }\end{array}$ & Indication & $\begin{array}{c}\text { Drugs } \\
\text { (mg/day }{ }^{-1} \text { ) }\end{array}$ \\
\hline 12 & 6 & PAT & $\begin{array}{l}\text { digoxin } 0.125 \\
\text { metoprolol } 50\end{array}$ \\
\hline$\sharp 3$ & 3 & $\mathrm{CHF}$ & digon in 0.125 \\
\hline 14 & 1 & PAT & $\begin{array}{l}\text { digoxin } 0.125 \\
\text { metoprolol } 50\end{array}$ \\
\hline 15 & 3 & $V T, P A F$ & $\begin{array}{l}\text { propranolol } 80 \\
\text { digoxin } 0.625\end{array}$ \\
\hline 16 & $\begin{array}{l}1 \\
3\end{array}$ & PAFI & $\begin{array}{l}\text { amiodarone } 600 \\
\text { amiodarone } 200\end{array}$ \\
\hline 17 & 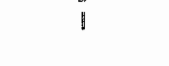 & PAT & $\begin{array}{l}\text { digoxin } 0.125 \\
\text { netoprolol } 50\end{array}$ \\
\hline 18 & 1 & PAFI & $\begin{array}{l}\text { digoxin } 0.25 \\
\text { verapamil } 240\end{array}$ \\
\hline 19 & 1 & $\begin{array}{l}\mathrm{CHF} \\
\mathrm{AP}\end{array}$ & $\begin{array}{l}\text { digoxin } 0.125 \\
\text { atenolol } 100\end{array}$ \\
\hline 20 & 1 & PAF & quinidine 600 \\
\hline $2 \|$ & $i$ & $\mathrm{CHF}$ & digoxim $0 \cdot 125$ \\
\hline 22 & 1 & $\mathrm{CHF}$ & digosin 0.125 \\
\hline 23 & 1 & $\mathrm{VT}$ & $\begin{array}{l}\text { amiodarone } 200 \\
\text { digoxin } 0.0625\end{array}$ \\
\hline 24 & 1 & PAF & metoprolol 200 \\
\hline
\end{tabular}

PAF = paroxysmal atrial fibrillation; $C H F=$ congestive heart lailure; $\mathrm{PAF}=$ = paroxysmal at rial flutter: $\mathrm{PAT}=$ paroxysmal atrial tachycardia; $\mathrm{AP}=$ angina pectoris; $\mathrm{VT}=$ ventricular tachycardia; $\mathrm{MO} / \mathrm{FU}=$ months of follow-up.

second degree AV block (type 1) at the permanently programmed atrial pacing rate of 80 beats $\mathrm{min}^{-1}$. The amiodarone dosage was reduced to $200 \mathrm{mg}$ daily and she remained asymptomatic during further follow-up. This patient was the only one of group 2 in whom the dosage of antiarthythmic drug therapy was changed during follow-up. No other patient of group 2 showed signs or symptoms of second or third-degree AV block. During chronic (>3 months) antiarmythmic drug therapy the variability of the AVWHR of group 2 patients was equal to or less than 10 beats min" 10. the AVWHR obtained 3 months after the initiation of oral drug therapy.

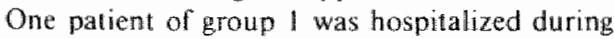
follow-up because of a transient ischaemic altack and 2 patients of group 2 were hospitalized because of anginal pain. None of our patients developed chronic atrial fibrillation and all patients were alive and well when follow-up evaluations were completed in September 1983.

\section{Discussion}

There has been considerable reluctance in the past to implant atrial demand pacemakers in patients widh symptomatic sinus node dysfunction. Ventricular demand or dual chamber pacemakers have been used in preference because of a concern about deterioration of anterograde $\mathrm{A} V$ conduction during lollow-up.

Several investigators ${ }^{[1-11]}$ have reported an increased risk of second or third-degree $A V$ block during long-term follow-up of patients with an atrial demand pacemaker. Others $[12 n]$ obserwed a very low incidence of impaired anterograde AV conduction during long-term follow-up.

Our results suggest that deterioration of anterom grade $A V$ conduction was related 10 the use of antiarhythmic drugs during follow up, rather than to degeneration of the $\mathrm{AV}$ conducting system.

In our II patients, who did not require antiarrhythmic drug therapy, the development of second- 


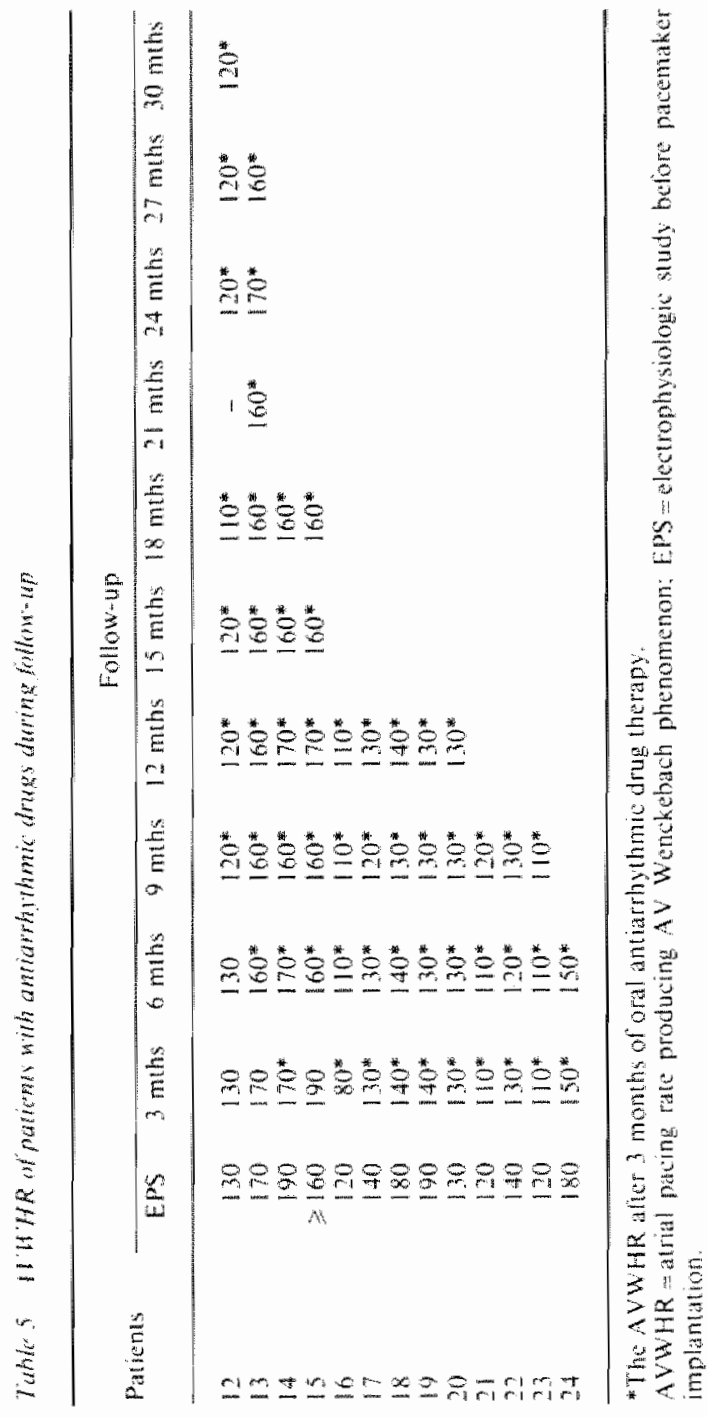


or third-degree AV block was not observed during long-term follow-up. In one patient of otar 13 patients who did require chronic antarthythmic during therapy symptomatic second-degree (type If $A V$ block occurred as a consequence of a miodarone therapy. In all other patients on chronic antiarrhythmic drug therapy no symptoms or signs of second- or thirdodegree AV block developed.

Several factors may explain the discrepancy belween our results and those of other investigators:

\section{(1) Wariability in patient population chosen for} suldy: Since the diagnostic criteria for smus nod: dysfunction are necessarily broad $[1\}$, it is understandable that our candidate population was different from the patient population of other

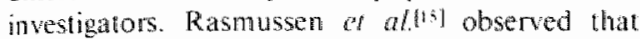
more than $50 \%$ of patients with sinus node dysfunction demonstrated some kind of atrio-ventricular conduction disease. However, a prolonged sinus node recovery time was used as the sole criterion for defining an abnormal sinus node dystunction.

(2) Criteria for anial pacemaker inplantation. In our series we based the decision to implant an atrial demand pacemaker on two electrophysiologic criteria, a nomal HV interval during baseline recording and the persistence of $1: 1$ AV conduction during incremental thigh right atrial pacing at a rate of at least 120 beats min-1 In the study of

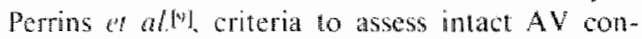
duction prior to pacenatker implantation were not mentioned. In the study of Berthotet al aril complete electrophysiologic studies were performed in only 6 out of 26 patients. It is therefore concevable that these investigators thad included in their study patients with already impaired AV nodal or infra modal conduction.

The presence of a nomal PR interval $(<0.20 \mathrm{~s})$ and a narrow $Q R S$ complex $(<0 \cdot \| 0)$ on the electron cardogram or Holter tracing can also be used an an indication of intaci $A V$ condrction. Unforturately. there would appear to be no definitive criterion. since nomal intervals are no absolute guarantee of inact AV conduction and prolonged intervals may nol always indicale impared $\mathrm{AV}$ conduction when compared wh invasive elcetrophysiologic sudies?

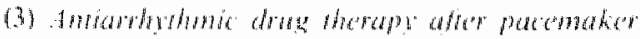
imalanatow. Cerlatin antiarthythmic drugs are known to adversely allect $A V$ nodal function in individuals with intact anterogade A $V$ conductron $[16: 2]$. However, the exact influence of these drugs on anterograde AV conduction in patients with symptomatic sinus node dysfunction has not been systematically studied. Dekker of alli1] followed 104 patients with symptomatic sinus node dysfumction for at least 28 months after singlem chamber atrial pacemaker implantation. A progressive impament of AV conduction was noted especially in patients with supraventricular atrhythmas after pacemaker implantation, a finding not confrmed by other investigatorston. These conflicting observations may result from differences in choice and dosage of antiarthythmic agents that may impain anterograde AV conduction.

In conclusion, our data suggest that deterioration of anterograde $A V$ conducion may be more related to the use of antiarnhythmic drugs, rather than to degeneration of the $\mathrm{AV}$ conducting system. In patients with symptomatic sinus node dysfumetion but intact anterograde $\mathrm{AV}$ conduction at the initial electrophysiologic study single chamber atrial pacemaker proved to be safe, even when antiarthythmic drug therapy was used. Further studies with a long period of follow-up will be necessary to confirm the safety of atrial pacing in patients with apparently intact AV conduction.

The authors would like to thank Wima wam Hassel for typing the manuscript. Hans de Boer and Tjerk de Boer for their technical assistance, and Jan G. P. Tijssen for the stabtistical analysis.

\section{References}

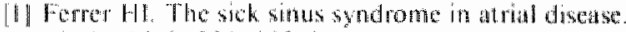
JAMA 1968: 206:645-6.

[2] Rosen KM, Loeb HS. Sinno MU ef at Cardiac bonduction in pationts with symptomate simus node

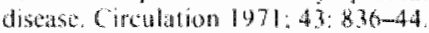

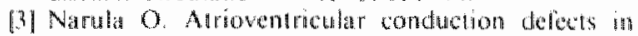

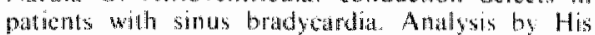
bunde recordings. Circulation $1971: 44: 1096-110$.

(4) Strase HS. Scheinman MM. La Barme A et at

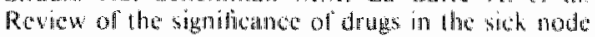
syndrome. In, Bonke, F. I. ed. The sirus node struc-

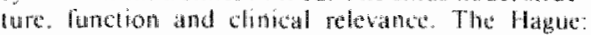
Marninus Nijhoti Medical Dawision. 197x: 103-11.

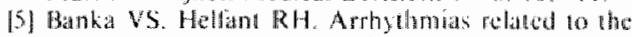

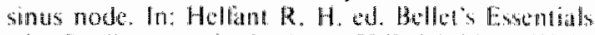
of Cardia Arrhythmias. Philadelphas W. B. Saunders $C 0.1480: 58-73$

[6] Apert MA. Sinomatrial blow and sinus arrest in a ardiac arrhythmids: A beside guide lo diagnosis and treatrent Chicago: Voar Booli. Modiagl Publishom. $1980: 128-43$. 
[7] Marnot HJL, Meyerburg R. Recognilion and treat mant of card hac arrhythmas and conduction dusturbances. In: Hurst JW, ed. The heart, Sth edition. New Vork MoGraw-Hil, 1982:519-55.

[5] Var Mechelen $R_{\text {, Hagemejer }} F_{\text {s }}$ de Bow $H$. al al Atrioventricular and ventriculo-atral conduction in patients with symptiomatic sinus node dysfunction. Pace 1983;6:13-21.

19] Perrins 1. Suton $\mathrm{R}$, Morley $\mathrm{C}$. at al Is atral pacing owt.moded? Pace $1981: 4: A-64$.

[10] Bertholet $M_{4}$ Dumoulin JC Foumy J et al. Natural evolution of atriowentricular conduction in patients. with sick sinus syndrome treated by atrial demand pacing. A study of 26 cases. Acta Cardiol. 1983; 38: $22 y-32$

[11] Dekker fm Aan Beek $\mathrm{R}$, van Hemel NM et al Atrioventricular conduction in sick sinus syndrome. Pace $1981: 4:$ : $4:$.

[12] Winte J, Bondke H, \& Dresster, L. The behaviour of atrioventricular conduction after implantation of alrial pacemakers. Pace 1983;6: A-1.

[13] Hayes D, Furman S. Progression to atrioverutricular block in patients with single chamber atrial pacing. Pace 1983:6: A-1.

[14] Ferrer MI. The sick sines syndrome. New York. Futura Publishing Company, 1974.
[15] Rasmussen K, Mybre ESP, Gunnes P, Wang H. Multhevel distase of the conduction system. Eut Heart 1 $1983: 4: 73-8$.

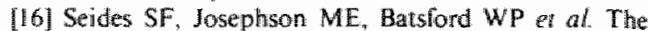
electrophysiology of propranolol in man. Am Hean J $1974: 88: 737-41$.

[17) Smithen $C S$, Balcon $R$, Sowton $\mathrm{GE}$, Use of bundle of His potentials to assess changes in atrioventricular condwction produced by a series of beta-adrenergic blocking agents. Br Meart J 1971; 33: 955-61.

[18] Mareus Fl. Current concepts of digoxin therapy. Mod. Concepts Cardiovase. Disease 1976:45: 77-82.

$19 \|$ Coodman DJ Rosen KM. Cannom DS a al. Effects of digoxin on atriowentricular conduction. Circulation $1975 ; 51: 25 \|-6$.

[20] Singh BN. The racional basis of antiarrhythmic therapy: the clinical pharmacology of commonly used antiarthythmic drugs. Anglology 1978; 29: $206-42$

[21] Joseplison ME Seides SF. The electroplysiologic effects of intramuseular quinidine on the atrioventricular conduction system in man. Am Heart J 1974 87: $55-64$.

[22] Roy PR, Spurrell RAJ, Sowton GE. The effects of verapamil on the conduction system in man. Postgrad Med J $1974: 50: 270-3$.

\section{Comment by K. Rasmussen (Tromso, Norway)}

Van Mechelen and coworkers have performed serial etectrophysiological measurements of the $A-V$ system, by a simple but adequate method, in patients with sinus node dysfunction. They have interpreted their results as indicating that, in most subjects with isolated sinus node disease, it is sufficient to perform simple atrial pacing. This message may be important since it permits us to simplify a pacing technology which has increasingly tended to overwhel $\mathrm{m}$ us.

These results are apparently opposed to the common concept of a generalized conduction disease which inevitably attacks various vevels of the conduction system, and in which A-V conduction disturbances are always threatening patients with sinus node disease. However, this discrepancy may be only apparent. The patients were selected as hawing no A-V conduction disease. It is not surprising that this did not emerge in the 11 patients followed from 6 to 36 months without drugs. In the presence of a generalized conduction disease progressing in a stepwise and random manner, a longer observation period in a larger number of patients would be needed in order to assess accurately the incidence of cases needing additional ventricular pacing.

Even the practical conclusions from this paper should be drawn with some caution. It is requred that the $A-V$ conduction system has been tested and found normal. The patients may need a more frequent and accutate follow up than was otherwise necessary. Furthermore, as is evident from the report, antiarthythmic drugs will have to be used cautiously in order not to unmask latent A-V conduction disease. If these requirements can be met, the authors are probably correct in saying that simple atrial pacing, as opposed to the more elaborate pacing systems, imposes very small additional risk on these patients. The conclusion is in accordance with a good general rule, treat what you know about and take care of progressions when they appear. 


\title{
Responses of an AV Universal (DDD) Pulse Generator (Cordis 233D) to Programmed Single Ventricular Extrastimuli
}

\author{
ROB VAN MECHELEN, FRANS HAGEMEIJER, JAN DE JONG and \\ HANS DE BOER \\ From the Department of Cardiology, Sint Franciscus Gasthuis, Rotterdam, The Netherlands
}

VAN MECHELEN, R., ET AL:: Responses of an AV universal (DDD) pulse generator (Cordis 233D) to programmed single ventricular extrastimuli. To evaluate factors playing a role in iniliation and perpetuation of pacemaker-mediated tachycardias (PMTs), 22 consecutive patients with symptomatic conduction disorders were studied after implantation of an AV universal (DDD) pulse generator [Cordis 233D). Patients were divided into two groups, depending upon the presence or absence of ventriculoatrial (VA) conduction during electrophysiological study [EPS] performed before pacemaker implantation. PMT's could be initiated in six of eight patients of Group I and in none of 14 patients of Group II. Initiation and perpetuation of PMTs during DDD pacing were dependent upon the capacity of the patient to conduct ventricular premature beats (VPBs) and subsequent paced ventricular beats retrogradely to the atria, and upon three programmable parameters of the pulse generator (AV delay period, upper rate limit, tachycardia response).

Programmed single ventricular extrastimulation demonstrated that: (1) merely the presence of VA conduction during EPS, although necessary, was not sufficient to induce PMTs after DDD pacemaker implantation; (2) VPBs introduced late rather than early in the cardiac cycle initiated PMTs in a different way; (3) the initiation of PMTs could be prevented during study by adjusting the programmable parameters (AV delay period, upper rate limit, tachycardia response); (4) one of the two available tachycardia responses of the pulse generator (gradual fall-back response) was able to terminate and initiate PMTs consistently.

These observations helped in understanding the responses of the Cordis $233 D$ pulse generator to ventricular premature beats. They indicate that additional refinement of the pulse generator is necessary to solve the problem of PMT. (PACE, Vol. 7, March-April 1984)

AV universal [DDD] pulse generator, pacemaker arrhythmias, pacemaker-mediated tachycardia, programmable pacemaker, ventriculo-atrial (VA) conduction.

\section{Introduction}

With the introduction of AV universal (DDD) pulse generators clinicians have a dual-chamber pacemaker att their disposal that can restore $\mathrm{AV}$ synchrony and/or could offer an atrial rate on demand. Therefore, these units have been applied to patients with symptomatic sinus node dysfunc-

Address for reprints: Rob van Mecheler, M.D. Department of
Cardiology. Sint Franciscais Gasthuis. Kleiweg 500 , 304 PM PM Rardiology, Sint Franciscins
Rotlerdam, The Nethurlands.

Received Augusiti 18, 1982; revision received May 18, 1989; accepted July $8,1983$. tion. with symptomatic second or third degree AV block, and with a combination of both conditions. Unfortunately, the DDD pacing mode in presently available AV universal (DDD) pulse genera. tors is not recommended for patients with ventriculo atrial (VA) conduction ${ }^{1,2}$ because blocked utrial premalure beats, ventricular premature beats and myopotentials sensed by the atrial channel may induce lachycardias mediated by the pulse generator. ${ }^{1-3}$ Also, the application of a magnet above a DDD pulse generator, or chest wall stimulation at a rate faster than the spontaneous sinus rate, may induce pacemaker-mediated tachycardias. ${ }^{4}$

As a consequence of this limitation, cllinicians must establish the presence or absence of VA con- 
duction in patients eligible for AV universal (DDD) pulse generators before deciding to apply the DDD pacing mode permanently.

The electrocardiogram is often of little help in establishing VA conduction before pacemaker implantation; only electrophysiological investigation is a relliable indicator. For this reason, all patients in this study underwent an electrophysiological investigation before an $\mathrm{AV}$ universal DDD pulse generator* was implanted. After pacemaker implantation, single ventricular extrastimuli were introduced during DDD pacing in order to demonstrate the consequences of ventricular premature beats for the DDD pacing mode of this unit.

\section{Material and Methods}

\section{Patients}

The decision to implant a DDD pulse generator in patients with symptomaticaconduction disorders was based upon: (1) atrial and ventricular electrophysiological function; (2) physical activity of the patient.

The unit was not used in patients with chronic atrial fibrillation, with paroxysmal supraventricular tachycardias, with known ventricular arrhythmias or in patients whose physical activity was limited even before the onset of conduction disorders.

\section{Electrophysiological Studies}

Following informed consent, electrophysiological studies were performed in patients who met the selection criteria. The patients received no medication prior to the study. Catheters were placed for both stimulation and recording of intracardiac electrograms at the right ventricular apex, tricuspid valve ring, and high lateral right atrium. Patterns of $\mathrm{AV}$ and VA conduction and refractory periods were determined using the extrastimulus technique during pacting from the high right atrium and right ventricular apex at several basic cycle lengths.

"Cordis 233D, Cordis Corp., Miami, Florida, U.S.A.
Incremental ventricular pacing at steps of $10 \mathrm{bpm}$ was initiated at a beginning rate $10-15 \%$ faster than the existing sinus rate, up to a pacing rate of $160 \mathrm{~d}$ min, or up to a rate at which second degree VA block occurred. Each period lasted one mimute. Criteria for determining the presence of $1: 1$ VA. conduction during pacing were: (1) atrial activation sequence from low right atrium (LRA) to high right atrium (HRA]; [2] identical ventricular and atrial cycle lengths at the ventricular pacing rate; (3) constant VA conduction times at one and the same pacing rate. Only data relevant to the DDD pacing mode of the AV universal pulse generator will be presented.

\section{Pulse Generator}

The microprocessor-based DDD unit consists of an atrial and a ventricular channel, with separate timing cycles, which operate in synchrony. The timing cycles of both channels are divided into two parts: an alert period and a refractory period. During the alert periods the pulse generator responds to spontameous atrial and ventricular events; during the refractory periods of either atrial ar ventricular chamel or both, the pulse generator will not produce output pulses to cardiac signals. A sub-part of the refractory period is the blanking period. This blanking period ( $50 \mathrm{~ms}$ ) will only be effective when an output pulse is delivered by the atrial or ventricular channel. During the blanking period atrial and ventricular sensing amplifiers are blocked to prevent cross-talk. The specifications of the pulse generator are listed in Table $I$.

\section{Atrial Tachycardia Responses}

To prevent atrial synchronous rates exceeding the upper rate limit of the pulse generator, two independent modes of response are available in this unit: the AV block response and the gradual fall-back response.

\section{AV Block Response}

When the pulse generator is programmed to the AV block response, the atrial refractory period equals the cycle length (ms) of the programmed maximum atrial synchronous pacing rate (Table 
Tabile I.

Specifications of the AV Universal (DDD) Pulse Generator

Prognammable specilications

Minimum rate, bpm

Maximum rate. bipm

Atral tachycardia response

Av delay period, ms

Atrial sensitivity, mV

Ventricuiar sensilivity, mV

Athal output, ms:

Ventricular output; $\mathrm{ms}$

Atrial refractory period, " ms

Nom-programmable specifications

Atrial refractory period, "ms

Wentricular refractory period, ms
$50,60,70,80$

$100,130,160,180$

2... 1 AV block, gradual fall back $^{\text {" }}$

$80,120,165,250$

$0.8,1.5,2.5$, off

$0.5,1.0,1.5, \mathrm{off}$.

$0.5,1.0,1.5,2.0$

$600,460,375,333$

305

305
$0.8,1.5,7.0,04$

When the pulse generator is programmed to gradual fall-back response the atriall refractory period is not programmable but fixed. For explanation of the gradual fall-back nesponse see text. "The atrial refractory period is only programmable when the $2: 1$ AV block response to atrial tachycardia is programmed. The atrial refractory period equals the cycle length of the programmed maxinum rate.

1). At atriall rates exceeding the maximum atrial synchronous pacing rate, the pulse generator shifts abruptly from a 1:1 AV synchronous pacing mode to a $2: 1$ AV synchronous pacing mode.

\section{Falli-back Response}

The fall-back response is aimed at a more gradbal slowing down of the ventricular rate when the maximum atrial synchronous pacing rate is excaeded. This mode is based on the computational power of the incorporated microprocessor. As the atrial rate exceeds the upper rate limit, the fallback algorithm allows up to 4 atrial synchronous ventricular pacing pulses (limited by a $190 / \mathrm{min}$ pace limit). After a pause, the pulse generator automatically shifts from atrial-synchronous pacing to ventricular demand pacing at a rate slightly below the programmed maximum rate (for a period of 3.6 seconds). The ventricular rate then gradually decreases until the programmed fall-back rate is achieved. When, during the gradual falli-back response, evidence exists of an atrial rate below the programmed upper rate limit, the fall-back routine is discontinued and AV synchronous pacing is resumed.

\section{Programmed Single Ventricular Extrastimulation}

After pacemaker implantation all pulse generators were programmed in the DDD pacing mode: upper rate limit, $180 / \mathrm{min}$; AV block response;

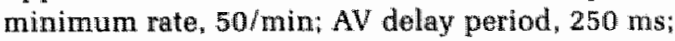
atrial sensitivity, $0.8 \mathrm{mV}$; ventricular sensitivity, $2.5 \mathrm{mV}$; atrial output, $1.5 \mathrm{~ms}$; ventricullar output, $2 \mathrm{~ms}$.

The studies were performed using a temponary bipolar catheter electrode already positioned in the right ventricular apex before pacemaker implantation, a programmable stimulator Janssen SU2) and an electrocardiograph. To avoid overcharging of the sensing amplifiers in the pulse generator and to prevent sensing of the stimulation pulse by the atrial amplifier [far-field sensing], the output voltage was set to an amplitude just above the diastolic threshold for ventricular stimulation (less than 0.75 V). Capture of the ventricular extrastimulus could be assured by adjusting pulse duration (greater than $0.5 \mathrm{~ms}$ ).

After every 8 atrial synchronous (paced) ventricular beats, a single ventricular extrastimulus was introduced at progressive prematurity in steps of $50 \mathrm{~ms}$ decrements, until ventricular refractoriness was reached. When a tachycardia was initiated, a magnet was applied over the pulse gener" ator to terminate the arrhythmia. Magnet application during pacemaker-mediated tachycardia produced asynchronous emission of both atrial and ventricular stimuli at the programmed minimum rate. The tachycardia zone was determined and the studies were repeated after reprogramming the AV delay period from $250 \mathrm{~ms}$ to $165 \mathrm{~ms}$ and 120 ms. respectively; after programming the upper rate limit of the pulse generator bellow the tachycerdia rate; and after programming the gradual fall-back response to atrial tachycardia instead of the AV block response.

\section{Results}

Patient data are shown in Table II; electrophysiological data are listed in Table III and Table IV.

\section{ECG Analysis}

When a ventricular extrastimulus was introduced late in the cardiac cycle, the subsequent spontaneous sinus beat could elicit a ventricular 
Table II.

Clinicual Date

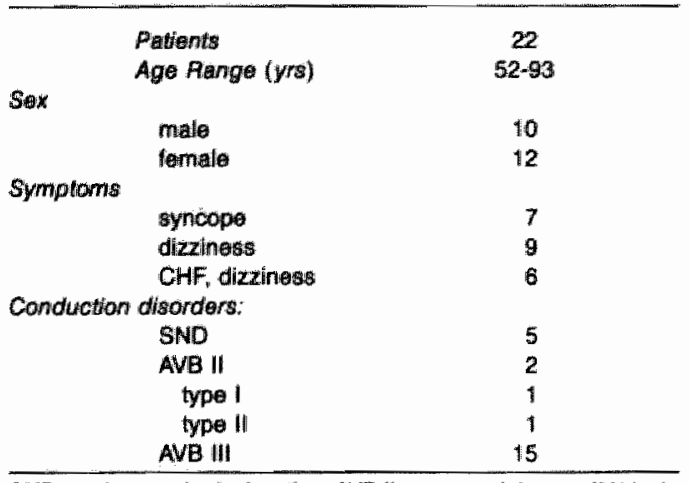

SND = sinue node olystunction; AVB I = second degree AV block; AVB IIll wird degrea AV block"CHF = congestive heart lailure. response from the pulse generator, but no nesponse from the ventricular myocardium because of refractoriness (Fig. 1a). With progressively premature ventricular extrastimuli the following sensed atrial event elicited a ventricular response from the pulse generator and the ventricular myocardium. In patients without VA conduction, ventricular extrastimuli did not influence the spontaneous cycle length. However, in patients with VA conduction the ventricular response of the pulse generator to the following spontaneous sinus beat induced ventriculo-atrial (VA) conduction, thereby initiating a pacemaker-mediated tachycardia (Fig. 1b). The retrograde limb of the artificial re-entrant tachycardia was provided by the VA conduction pathway and the anterograde limb was provided by the programmed AV delay period of the pulse generator.

Still shorter coupled ventricular extrastirnuli also initiated pacemaker-mediated tachycardias in patients with VA conduction. However, the sequence of initiation was different (Fig. 1C). When ventricular extrastimuli were introduced late in the car-

Table III.

Electrophysiological Data (I)

\begin{tabular}{|c|c|c|c|c|c|c|c|}
\hline $\begin{array}{c}\text { Patlente } \\
\text { whout VAC }\end{array}$ & $\operatorname{sex}$ & $\begin{array}{l}\text { age } \\
(y+s)\end{array}$ & $\mathrm{CD}$ & ECG & $\begin{array}{c}\text { AVC } \\
\text { (lbpm) }\end{array}$ & $\underset{(\mathrm{ms})}{\mathrm{AHH}}$ & $\begin{array}{l}\mathbb{H V} \\
\text { (ms) }\end{array}$ \\
\hline 1 & f & 77 & AVB \|\| & SR,AVUR & - & - & 40 \\
\hline 2 & 1 & 93 & AVE III & SR, VA & - & 100 & - \\
\hline 3 & it & 78 & $\begin{array}{l}\text { SND } \\
\text { AVB }\end{array}$ & SB,LAHB & $60-120$ & $250-340$ & 60 \\
\hline 4 & $\mathrm{~m}$ & 86 & AWB III & SA, NA & - & 110 & - \\
\hline 5 & $\mathrm{~m}$ & 60 & AVB III & SP,VA & - & 150 & - \\
\hline \multirow[t]{2}{*}{6} & $\mathrm{~m}$ & 89 & AVB ill & $\mathrm{SR}, \mathrm{VA}$ & - & 120 & - \\
\hline & & & AVB I & SA, $\angle B B B$ & $50-80$ & 120 & 100 \\
\hline 7 & $m$ & 72 & AVE III & $S R, V R$ & 一 & 140 & - \\
\hline a & f & 70 & AVE II & SR,RBBB & $70 \cdot 110$ & $90-100$ & 50 \\
\hline \multicolumn{8}{|c|}{ (type 2) } \\
\hline 9 & I & 80 & AVB II! & SR,VR & - & 100 & - \\
\hline 10 & $m$ & 73 & AVB $\|$ & SR, VR & - & 110 & - \\
\hline $1 \Downarrow$ & $m$ & 74 & AVB \|\| & $\sin , \vee R$ & - & 100 & - \\
\hline 12 & 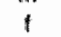 & 90 & AVB III & SR, VA & - & 140 & - \\
\hline 13 & $m$ & 52 & AVB III & SR,AWJA & - & - & 70 \\
\hline 14 & 1 & 68 & AVB $\| I$ & SP,VA & - & 100 & - \\
\hline
\end{tabular}

$V A C=V A$ conduction; $C D=$ conduction disorder: $S A=$ sinus thythm; $S B=$ sinus bradycardia: AWJR $A$ AV junctional thythm; $\mathrm{VA}=$ ventricular rhythm; $\mathrm{AVC}=$ range of 1.1 AV conduction during incremental atrial pacing; $\mathrm{LAHB}=$ left anterior hemiblock; $\mathrm{ABBB}=$ ight bundle branch block: $\mathrm{LBBB}=$ left bundle branch block; $\mathrm{AVB}$ I, II. III Ifrst, second and third degree AV block. 
Tabia IV.

Electrophysiological Data (ii)

\begin{tabular}{|c|c|c|c|c|c|c|c|c|c|}
\hline $\begin{array}{l}\text { Patlents } \\
\text { with VAC }\end{array}$ & $\operatorname{sex}$ & $\begin{array}{l}\text { age } \\
\text { (yrs) }\end{array}$ & $\mathrm{CD}$ & $\begin{array}{c}\text { ECG } \\
\text { findlings }\end{array}$ & $\begin{array}{l}\text { Avc } \\
\text { (bpm) }\end{array}$ & $\begin{array}{c}\text { AH } \\
\text { (ms) }\end{array}$ & HV & $\begin{array}{l}\text { VAC } \\
\text { (bpm) }\end{array}$ & $\begin{array}{l}\text { VACT } \\
\text { (ms) }\end{array}$ \\
\hline 15 & i & 77 & SND & SB,SAB,AVJR & $50-110$ & $110-170$ & 45 & $60-80$ & $200-210$ \\
\hline 16 & 1 & 72 & SND & SB,AW.JR,LAHB & $50-110$ & $90-190$ & 45 & $60-120$ & $180-230$ \\
\hline 17 & it & 73 & AVBB II! & SR,AVJA & - & - & 50 & $60-140$ & $180-200$ \\
\hline 18 & $\mathrm{~m}$ & 93 & AVB III & SR AVIIR & - & - & 55 & $80-150$ & $200-230$ \\
\hline 19 & $m$ & 70 & SND & SR, RBBB & $60-110$ & $180-250$ & 50 & $70-110$ & $270-300$ \\
\hline 20 & $f$ & 72 & SND & SAB, SB, A Flutter & $50-140$ & $110-170$ & 45 & 60 & 400 \\
\hline 21 & $\mathrm{~m}$ & 50 & $\begin{array}{l}\text { AVB III } \\
\text { NAVC }\end{array}$ & $\begin{array}{l}\text { SR,VR } \\
\text { SR,RBBB }\end{array}$ & $\overline{60-120}$ & $\begin{array}{c}100 \\
100-120\end{array}$ & $\overline{50}$ & $90-130$ & $200-230$ \\
\hline 22 & $t$ & 78 & AVB II (type I) & SR, RBBB & $60-80$ & 100 & 50 & $70-130$ & $170=180$ \\
\hline
\end{tabular}

VAC = VA conduction, range of $1: 1$ VA conduction during incremental ventricular pacing; $A V C=$ range of $1: 1$ AV conduction during incremental atrial pacing; $C D=$ conduction disorder; VACT $=$ VA conduction times meassured from the ventricular spike to the onse; of $\mathrm{A}$ HRA; $\mathrm{SB}=$ sinus bradycardia; $\mathrm{AV}$ JR = AV junctional rhythm; $S N D=$ sinus node dystunction; $S A B=$ sino-atria $\mid$ block; $L A H B=$ left anterior hemiblock; $R B B B=$ right bundle branch block; VR = ventricular thythm; AVB I, II, III = first, seicond and third degree AV block.

diac cycle, collision of these ventricular beats occurred with the following spontaneous sinus beat; the paced ventricular beat in response to this sinus beat could (when the retrograde pathway was no longer refractory] be conducted retrogradely to the atria, and initiate a pacemaker-mediated tachycardia. When ventricular extrastimuli were introduced more prematurely, VA conduction initiated a pacemaker-mediated tachycardia.

When ventricular extrastimuli were introduced during the refractory period of the ventricular channel, refractoriness of the ventricular myocardium was reached in 8 of 14 patients without VA conduction and in 5 of 8 patients with VA conduction. In patients without VA conduction these premature beats did not interfere with the spontaneous cardiac cycle. In patients with VA conduction the response of the pulse generator was dependent upon the presence of VA conduction at these short coupling intervals. Again, if VA conduction was present, artificial re-entrant tachycardias could be initiated; if VA conduction was absent, the spontaneous cardiac cycle was not influenced by these extrastimuli.

The cycle lengths of the tachycardias could be shortened (1) as long as $1: 1$ VA conduction was present by reducing the programmed AV delay period (Table $V$ and Fig. $2 a, b, c)$; (2) as long as the rates of the tachycardias did not exceed the upper rate limit of the pulse generator.

All tachycardias could easily be terminated by applying a magnet over the pulse generator (Fig. 3]. We also tested the responses of the pulse generator to atrial rates exceeding the maximum atrial synchronous pacing rate. By programming the upper rate limit below the tachycardia rate, in combination with the $\mathrm{AV}$ block response, all tachycardias could be terminated [Fig. 4]. It was, however, impossible to terminate these tachycardias by programming the fall-back response (Fig. 5). The reason for this was that if $1: 1$ VA conduction was present at a ventricular paced rate exceeding the upper rate limit of the pulse generator, $1: 1 \mathrm{VA}$ conduction was also present at ventricular pacing rates bolow that rate, unless the spontaneous atrial rate exceeded that particular ventricular pacing rate. As a consequence, atrial activity sensed by the atrial channel at a rate below the programmed upper rate limit terminated the fall-back response. AV synchronous pacing resumed and the upper rate limit was again exceeded. This, in turn, activated the fall-back tachycardia intervention program and the sequence was repeated perpetually as long as $1: 1$ VA conduction was present.

In 2 cases (patlients 15 and 20) with symptomatic sinus node dysfunction and $1: 1 \mathrm{AV}$ conduction 

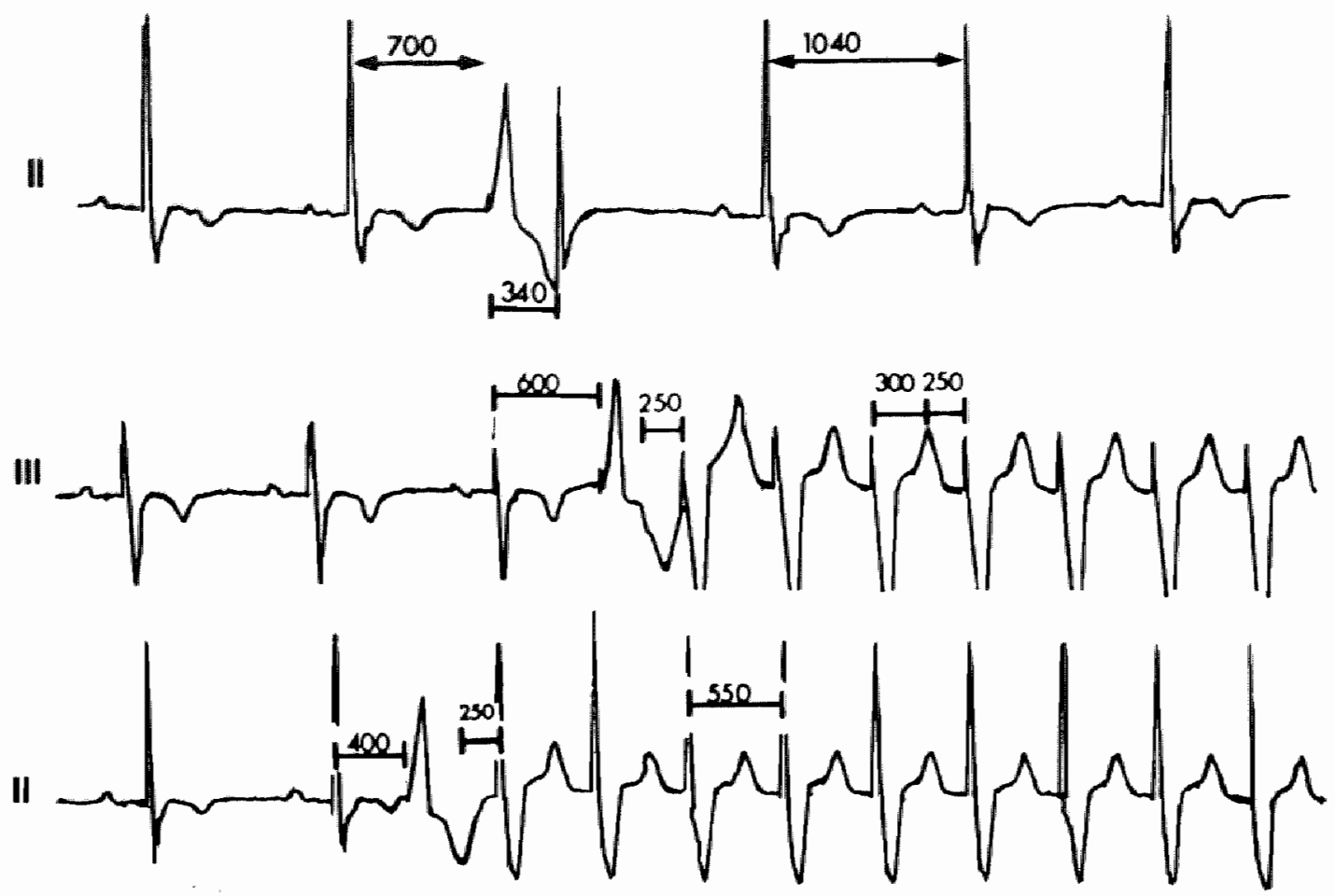

Figure 1. (A) During spontaneous sinus rhythm (CL $=1040 \mathrm{~ms}$ ) one ventricular extrastimulus was introduced with a coupling interval of 700 ms. The pulse generator was programmed in the DDD pacing mode; minimum rate $50 / \mathrm{min}_{\text {; }}$ upper rate limit $180 / \mathrm{min}$; AV delay period, 250 $\mathrm{ms}$; tachycardia response, AV block. A ventricular spike is produced by the pulse generator in the $T$ wave of the ventricular premature beat as a consequence of synchronization with a sinus beat hidden in the QRS complex of the premature ventricular beat. (B) A ventricular extrastimulus is introduced with a coupling interval of $600 \mathrm{~ms}$. A pacemaker-mediated tachycardia is initiated. Note the mechanism of initiation (see text). The tachycardia cycle length is $5.50 \mathrm{~ms}$ (110/min). Sensing of the retrograde $P$ wave occurs $300 \mathrm{~ms}(550-250)$ after the preceding ven* tricular pacer spike. (C) A ventricular extrastimulus is introduced with a coupling interval of 400 ms. A pacemaker-mediated tachycardia is initiated by VA conduction of the ventricular premature beat. Note the difference of tachycardia initiation with ventricular extrastimuli occurring very late during the cardiac cycle (see text).

during incrementatatrial pacing up to a rate of $110 / \mathrm{min}$ and $140 \mathrm{Lmin}$, VA conduction was only present during incremental ventricular pacing up to rate of $60 / \mathrm{min}$ and $80 / \mathrm{min}$ (Tables IV and V). In these patients, pacemaker-mediated tachycardia could not be initiated and VA conduction was not sustained during the ventricular extra- stimulus study, even at the largest programmed AV delay period of $250 \mathrm{~ms}$.

When ventricular extrastimuli were introduced during the atrial blanking period ( $50 \mathrm{~ms}$ ), a ventricular pacer spike was produced after termination of the programmed AV delay periods (Fig. 6).

Depending upon the presence or absence of $\mathrm{VA}$ 
Tablle V:

Pacemaksrmediated Tachycardias in Putients with VA Conduction

\begin{tabular}{|c|c|c|c|c|c|c|}
\hline Patlents & $\begin{array}{c}\mathrm{HR} \\
\text { (bpm) }\end{array}$ & $\begin{array}{c}\text { TR } \\
\text { (bpm) } \\
\text { AND } \\
250 \mathrm{~ms}\end{array}$ & $\begin{array}{c}\text { TR } \\
\text { (bpm) } \\
\text { AVD } \\
165 \mathrm{~ms} \\
\end{array}$ & $\begin{array}{c}\text { TA } \\
\text { (bpm) } \\
\text { AVD } \\
120 \mathrm{~ms}\end{array}$ & $\begin{array}{l}\text { VACT } \\
\text { (ms) }\end{array}$ & $\begin{array}{l}\text { VERP } \\
\text { (ms) }\end{array}$ \\
\hline 15 & $70-75$ & - & - & - & - & $300-350$ \\
\hline 16 & $80-82$ & 130 & 160 & - & 210 & $250-300$ \\
\hline 17 & 80 & 130 & 150 & 170 & $210-230$ & 250 \\
\hline 18 & $60-65$ & 140 & 170 & - & $180-190$ & 250 \\
\hline 19 & $50-55$ & 110 & 130 & - & 300 & 300 \\
\hline 20 & $80-90$ & - & - & - & - & 300 \\
\hline 21 & $70-80$ & 120 & - & - & 250 & 300 \\
\hline 22 & $70-80$ & 120 & 144 & 160 & 250 & 250 \\
\hline
\end{tabular}

$H A$ = heart rate during $D D D$ pacing; $T R=$ tachycandia rate; $A V D=$ programmed $A V$ de:lay pertad; VACT conduction times, calculated by subtracting the programmed AV delay pertod from the tachycardia cycle length (VACT $=$ TCL - AVD). Note: all pulse generators were programmed at an upper trate limit of $180 / \mathrm{min}$ in comm bination with AV block response to atrial tacthycardias exceeding the upper rate limit. Thils programming does not allow indiuction of tachycardias at rates exceeding $180 / \mathrm{min}$.

conduction the duration of these studies varied from 15 minutes to 30 minutes.

\section{Reprogramming of the Pulse Generator}

In patients without VA conduction, the DDD pacing mode was applied permanently. The AV delay period was adjusted depiending upon the presence of intact or impaired AV conduction, and the minimum rate of the pulse generator was adjusted according to the presence or absence of sinus node dysfunction.

In patients with VA conduction, either the DVI mode was used permanently, or the DDD mode was applied and programmed parameters were adjusted to prevent pacemaker-mediated tachycardia (AV delay period, upper rate limit, tachycardia response).

\section{A}

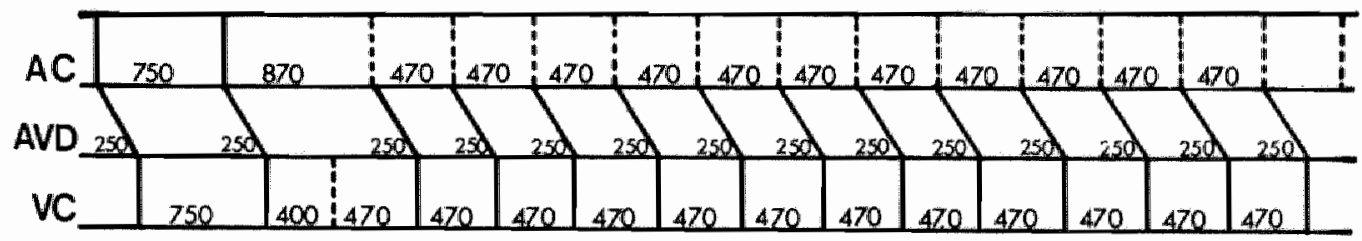

Figure 2a. A pacemaker-mediated tachycardia is induced by one ventricular extrastimulus. The first two retrograde $P$ waves are marked with an arrow. At a programmed AV delay period of $250 \mathrm{~ms}$, the rate of the tachycardia is $128 / \mathrm{min}(\mathrm{CL}=470 \mathrm{~ms}, \mathrm{VACT}=220 \mathrm{~ms})$, 


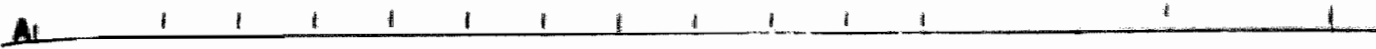

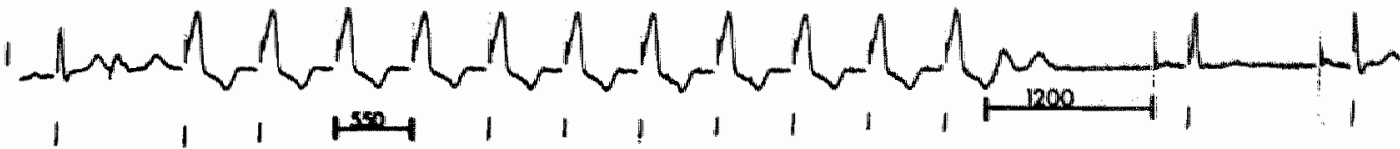

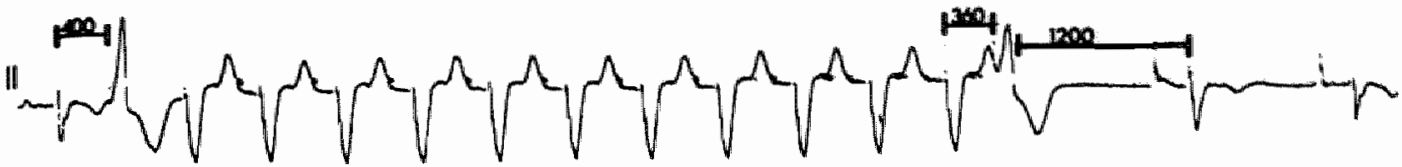

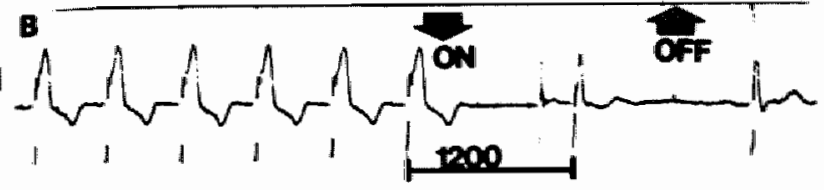

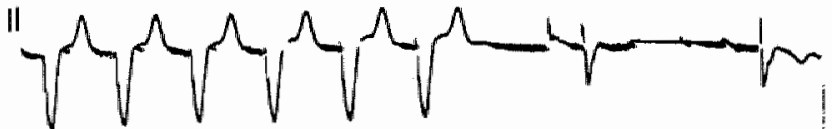

Figure 3. (A) Ventricular extrastimulus and tachycardia termination (same patient as in Fig. 1). A pacamakermediated tachycardic is terminated by 1 ventricular extrastimulus. The coupling interval with the preceding ventricular event is $360 \mathrm{~ms}$. Because VACT equals $300 \mathrm{~ms}$, the extrastimulus occurred (360-300) $60 \mathrm{~ms}$ after sensing of the retrograde $P$ wave (during the AV delay of the pulse generator). By shortening the AV delay to 60 ms, tachycardia is terminated by black in the retrograde limb of the circuit. (B) Magnet application and tachycardia termination. Magnet application during pacemaker-mediated tachycardia produces asynchronous emission of both atrial and ventricular extrastimuli at the programmed minimum rate.
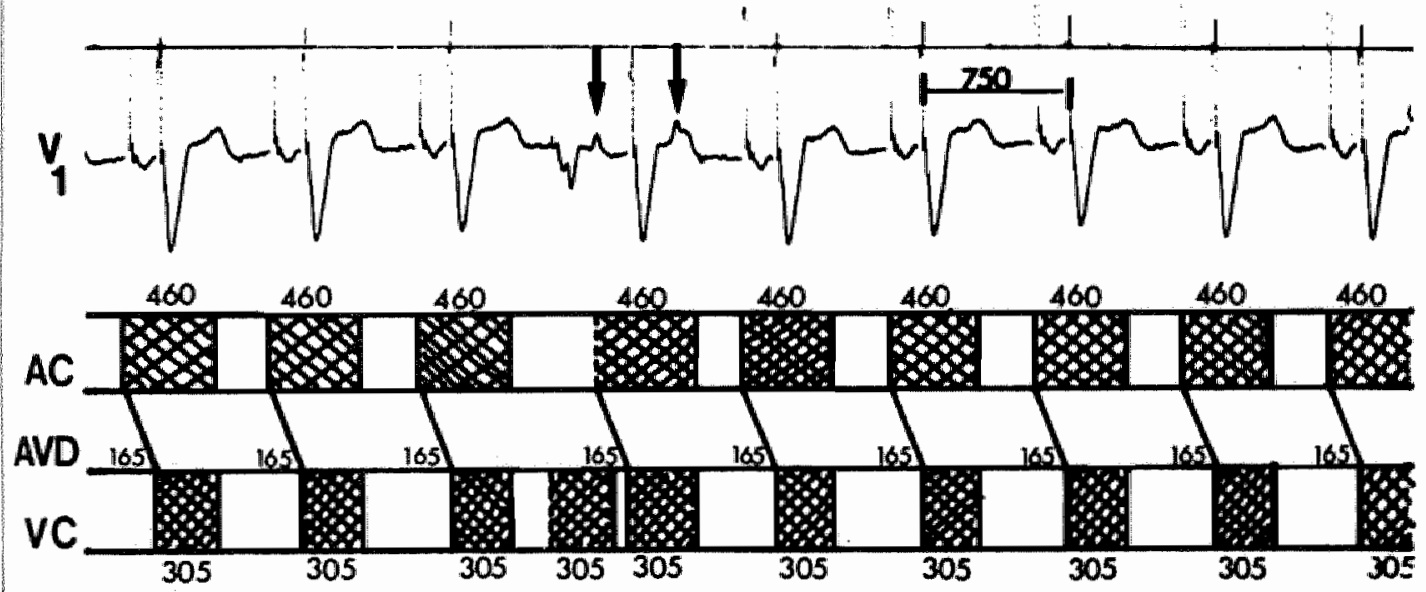

Figure 4. AV block response to pacemaker-mediated tachycardias. The upper rate limit of the pulse generator is programmed below the tactycardio rate. In this patient (same as in Fig. 26 ) a lachycardia could be induced with a rate of $150 / \mathrm{min}$ ( $C L=400 \mathrm{~ms}$ ) at a programmed AV delay of $165 \mathrm{~ms}$. The upper rate limit was programmed at $130 \mathrm{~min}$; the atrial refractory period of the pulse generator then equals the cycle length of the programmed upper rate, $460 \mathrm{~ms}$. The second retrograde $P$ wave occurs within the airial refractory period of the pulse generator and no tachycardia is induced. $A C=$ atrial channel of the pulse generator; $V C=$ ventricular channel of the pulse genterator: $A V D=A V$ delay period. Shaded areas repmesent refractory periods of atrial and ventricular channels. 
A

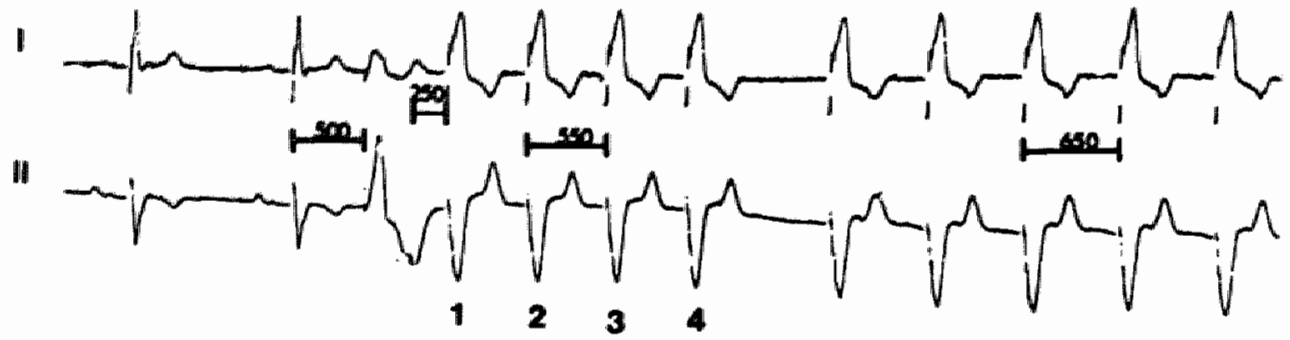

B

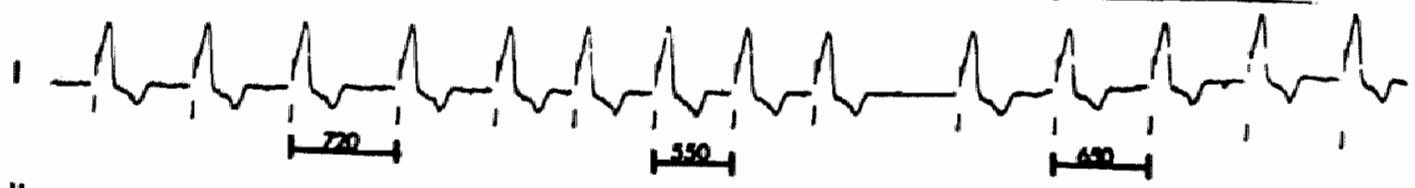

II

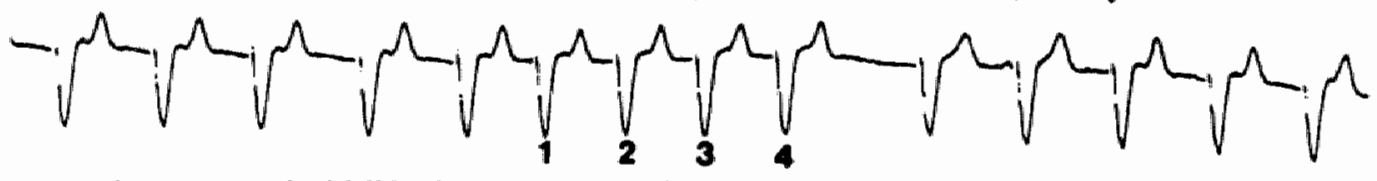

Figure 5. Gradual fall-back response to atrial tachycardias. In this patient with a pacemaker. mediated tochycardia of $110 / \mathrm{min}$ at a programmed AV delay of $250 \mathrm{~ms}$, the upper rate limit of the pulse generator is programmed to $100 / \mathrm{min}$. The tachycardia is initiated by a ventricular extrastimulus with a coupling interval of $500 \mathrm{~ms}$, and subsequent retrograde conduction to the atria. The pulse generator synchronizes with four atrial events, and after a pause, starts VVI. operating at a rate slightly below the programmed upper rate limit of $90 / \mathrm{min}$ (CL-650 ms) for a period of 3.6 seconds. One cycle is deliberately increased by $70 \mathrm{~ms}$ (CL-720 ms) to detect atrial activity that might occur during the atrial blanking period. The ventricular rate then gradually decreases until the programmed fall-back rate is achieved. However, if atrial events are sensed at an rate below the programmed maximum rate, AV synchronous pacing is resumed.

It is obwious that synchronization with atrial events after termination of the gradual fall-back response results in an atrial synchronous wentricular rate exceeding the programmed upper rate limit of the pulse generator; this in turn activates the fall-back tachycardia intervention program again. The sequence is repeated os long as 1:1 VA conduction is present.

pulse generator as Long as the programmed upper rate limit of the pulse generator was greater than that of the tachycardia. The cycle lengths of the tachycardias were determined by the patients' VA conduction times and by the programmed AV delay periods. The tachycardia cycle lengths varied

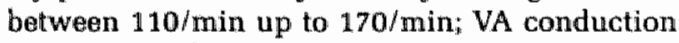
times ranged from $170 \mathrm{~ms}$ to $300 \mathrm{~ms}$ during tachy- cardia. In the remaining two patients with VA conduction it was impossible to initiate pacemaker tachycardia. This was due to the fact that sustained VA conduction, a prerequisite for pacemaker-mediated tachycardia., was not present during the study.

Initially, we programmed the pacer to the DVI mode in patients with VA conduction to avoid the 

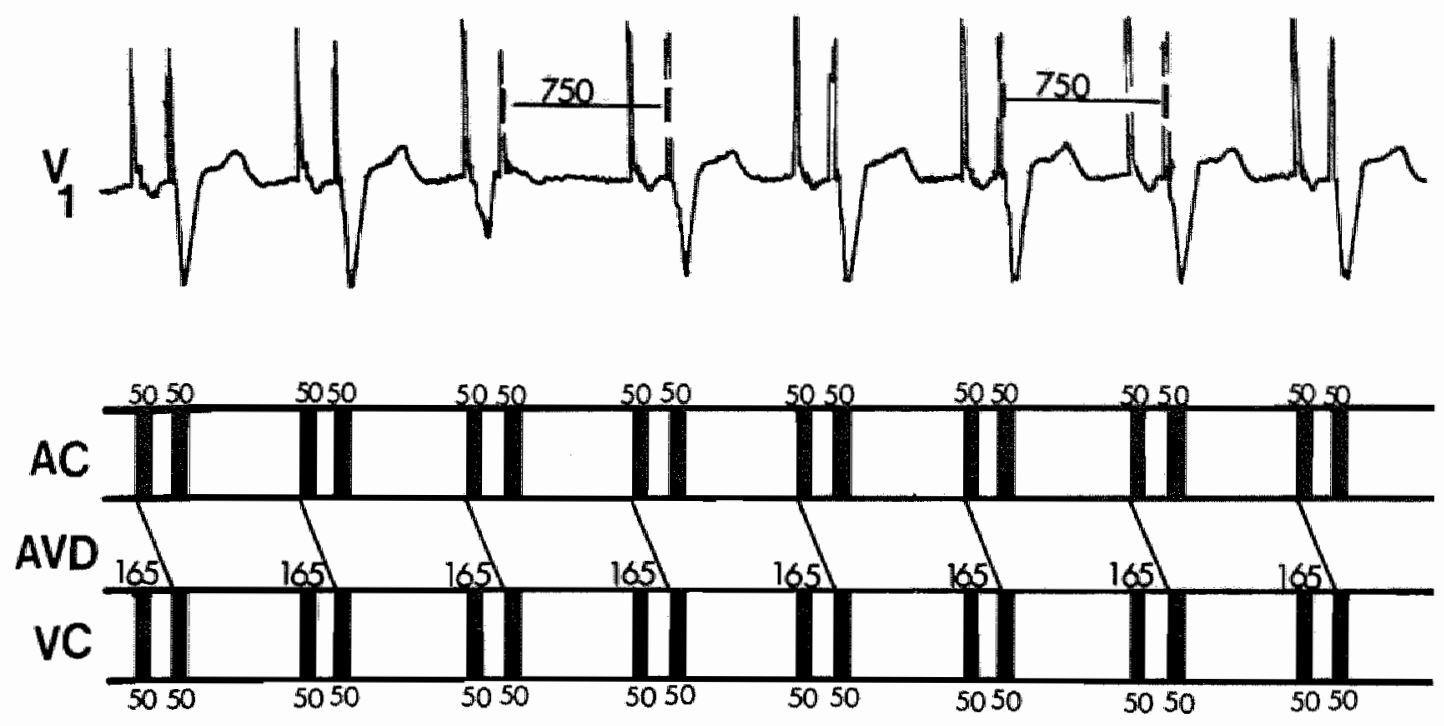

Figure 6. Ventricular extrastimulus during the atrial blanking period. When a programmed, single ventricular extrastimulus is introduced during the atrial blanking period $(50 \mathrm{~ms})$, neither the atrial channel nor the ventricular channel is alert for incoming signals. The pulse generator delivers a ventricular pulse at the end of the programmed AV delay period.

risks of pacemaker-mediated tachycardia. However, although DVI pacing will prevent this tachycardia, dual-chamber pacing without atrial sensing might induce atrial fibrillation, ${ }^{10}$ and atrial synchrony will be limited to the programmed pacing rate. Because of these imperfections we later changed our policy and programmed to the DDD pacing mode and programmable parameters (AV delay period, upper rate limit, tachycardia response] were adjusted to prevent pacemaker-mediated tachycardia. So far, we have not observed pacemaker-mediated tachycardias in our patients during follow-up. However, an adjusted DDD pacing mode is no absolute guarantee against these tachycardias, because the parameters at implantation might become ineffective at a later stage when the functional properties of the conduction system during retrograde conduction change. This would leave the patient without any protection against the risks emerging from these pulse generators.

The introduction of programmed, single ventricular extrastimuli during. DDD pacing helped our understanding of the possible risks of a presently available DDD unit. Our observations indicate that additional refinement of the pulse generator (Cordis 233D) is necessary to eliminate the problem of pacemaker-mediated tachycardia.

Acknowledgments: Invaluable assistance was providod by Ton Scholtes, biomedical engineer, Cordis Europa NV. We are very grateful to Wilma van Hassel for typing the manuacript.

\section{References}

1. Sutton, R., Perrins, J., Citron, P.: Physiological cardiac pacing. PACE, 3:208, 1980 .

2. Clinical Evaluation Protocal, Cordis 233 D, Cordis Corp., Miami, Florida, USA, June 1981.
3. Duncan, I., Pym, J." Goldman, B, ot al.: Initial experience with universal pacemakers. PACE, 5:299, 1982 (Abstract).

4. van Gelider" L.H. "El Gamal, M.I.H.: Magnet appli- 
cation, a cause of persistent arthythruias in phys. iological pacenulers. Report of 2 cases, PACE, $5: 710$, 1982.

5. Rosen, K.M.: Evaluation of cardiac conduction in the cardlac: catheterization laboratory. Am. I. Cardiol., 30:701, 1972.

6. Preston, T.A. Arbor, A.: Anodal stimulation as a cause of pacemaker-induced ventricular fibrillation. Am. Heart $J, 86: 366,1973$.

7. Mehra, R., Furman, S. Crump, J.: Vulnerability of the mildly ischemic ventricle to calhodal, anodial and bipolar stimulation. Circ. Res., 41:159, 1977.

8. Tommaso, C. Belic, N. "Brandfonbrener, M.: Asychronous ventricular pacing: A rare cause of vemtricular tachycardia. PACE, 5561, 1982.

9. Parsonnet, V., Rodgers. T.: The present status of programmable pacemakers. Progr. Cardiovasc. Dis, 23:401, 1981.

10. Furman, S., Cooper, J.A.: Atrial fibrillation during AV sequential pacing. PACE, 5:133, 1982. 


\title{
Prevalence of Retrograde Conduction in Heart Block After DDD Pacemaker Implantation
}

\author{
ROB VAN MECHELEN, MD, JAAP RUITER, MD, YVES VANDERKERCKHOVE, MD, \\ HANS DE BOER, and FRANS HAGEMELER, MD
}

\begin{abstract}
Electrophyslologlc studles were performed before DDD pacemaker Implantation in $\mathbf{5 0}$ pattents with symptomatic heart block. The patlents were separated into 2 groups. Group I conststed of patients whilintact retrograde conduction and group II consksted of patlents with blocked retrograde conduction. After pacemaker Implantation, postventricular atrial refractory periods in patients in group I were programmed at 50 to $100 \mathrm{~ms}$, in excess of the retrograde conduction times measured during electrophyslologlc studiles. In group II patients, postventricular atrlal refractory perlods were routinely programmed at $300 \mathrm{~ms}$. During follow-up, patients vislited the outpatient clinic at 3-month intervals for noninvaslve assessment of the prevalence of retrograde conduction, and to lest the inducibillty of pacemaker-medlated tachycarclas.
\end{abstract}

The mean lollow-up of group I (15 patients) was $27 \pm 10$ months, whereas the mean follow-up of group II (35 patients) was $19 \pm 9$ months. The mean number of nonlinvasive tests performed durhn follow-up was $B \pm 3$ per patient for group $I$ and $5 \pm$ 3 per patient tor group II. In group I, retrograde conduction remained intact in 12 patients $(p<0.01)$. In 29 of 31 patlents in group II, retrograde conduction remained absent $(p<0.01)$. In 4 patients in group II, chronic atrial fibrlliation occurred durting followup. Chronlc atriall flbrlllation did not occur in any pathent in group I. During serlal electrophyslologlc testing, no pacemaker-medlated lachycardilas could be Induced in any patient in group I or II.

These results suggest that electrophysiologlc studles performed belore pacemaker implantatlon rellably predict the prevalence of retrograde cortduction during follow-up of patients with sympiomenthic heart block and that adjusted atrial retractory posrlods of the pulse generator at Implantation prevestut the Induction of pacemaker-medlated tachycardiax during serlal electrophysiologic testing.

(Am J Cardiol 1986;57:797-80 i)

(1)

Fcemaker-mediated tachycardias in patients with DDD units can be prevented by adjusting the postven tricular atrial refractory period. ${ }^{1-5}$ However, an adjusted atrial refractory period may become ineffective in avoiding pacemaker-mediated tachycardias when the functional properties of the alrioventricular $(\mathrm{AV}) \mathrm{con}$ ducting system for retrograde conduction change during follow-up.

We studied retrograde conduction invasively before and noninvasively after DDD pacemaker implan * tation to find out if the electrophysiologic studies performed before pacemaker implantation would reliably predict the prevalence of retrograde conduction

From St. Franciscus Gasthuis. Rotterdam, the Nehberlands. Menuscript received January 9, 1985; revised maruscript received August 16, 1985, accepted September 19, 1985.

Address for reprints: Rob wan Mechelen, MD Department of Cardlology, St. Franciscus Gasthuis, Kleiweg 500. 3045 PM. Rotterdam, The Netherlands.

during long-term follow-up, and if selected postventricular atrial refractory periods at implantation would prevent pacemaker-mediated tachycardias during se. rial electrophysilologic testing.

\section{Methods}

Patients: DDD units were implanted in 50 patients with symplomatic second- or third-degree AV block. All patients were physically active before the onset of conduction disorder.

Electrophysiologic studies: After informed consent was obtained, patients underwent an incremental ventricular pacing study to assess the prevalence and persistence of retrograde conduction. For both stimulation and recording, 3 catheters were placed at the lateral high right atrial wall, tricuspid valve ring and the right ventricular apex. Incremental pacing at steps of $10 \mathrm{beats} / \mathrm{min}$ was initiated at a beginning rate that was slightly faster than the spontaneous sinus rate, up to a pacing rate at which second-degree wentriculo- 


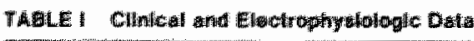

\begin{tabular}{|c|c|c|}
\hline & $\begin{array}{c}\text { Group } \\
\text { RCP Prestent }\end{array}$ & 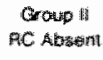 \\
\hline Platilientils & 15 & 35 \\
\hline \multicolumn{3}{|l|}{$A g=\mid y m$} \\
\hline Range & $57-97$ & $37-90$ \\
\hline Meimi & 7.511 & $74 \pm 11$ \\
\hline Mollowimialos & 1.1 & $\$ 1$ \\
\hline \multicolumn{3}{|l|}{ 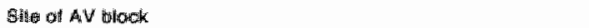 } \\
\hline A W r ousdes & 0 & 9 \\
\hline Hotra-Hibian: & 1 & \\
\hline Inffram & 5 & 19 \\
\hline Untention & 3 & 7 \\
\hline \multicolumn{3}{|l|}{ Patrowiratio conduetion } \\
\hline 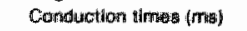 & $170-360$ & \\
\hline Merar & $237 \pm 56$ & \\
\hline Persigtenciof fowats $/ \mathrm{mminj}$ & $100-200$ & \\
\hline Marm & $129 \pm 35$ & \\
\hline Ful duration & $27 \pm 10$ & $19 \pm 9$ \\
\hline \multicolumn{3}{|l|}{ Complications 犆ur } \\
\hline Powkel inloctlon & $\uparrow$ & \\
\hline Chronic atrlal filbriltatlon & & 4 \\
\hline Atrial mulsensing & 1 & \\
\hline Devalonigi & $2(13 \%)$ & $7(20 \%)$ \\
\hline
\end{tabular}

AV bilock $=$ atrlowentrictiar blacke conduction.

atrial block occurred. Each pacing period lasted 1 minute. Retrograde conduction time was defined as the interval from the ventricular spike to the onget of atrial activation at the high right atrial electrogram. Measurements were made at a paper speed of $100 \mathrm{~mm} / \mathrm{s}$.

Pulse generators: In all patients, DDD units were used with programmable postventricular atrial refractory periods. In patients with intact retrograde conduction during electrophysiologic studies (group I], a postventricular atrial refractory period was selected 50 to 100 ms in excess of the measured retrograde conduction time at electrophysiologic studies.

In patients with retrograde block (group II), a postventricular atrial refractory period of $300 \mathrm{~ms}$ was programmed.

Patient follow-up: Patients were prospectively followed in the outpatient clinic at intervals of 3 months. Holler recordings were performed in all patients during the first 6 weeks after hospital discharge and thereafter when history suggested transient brady - or tachy-

1

Doo

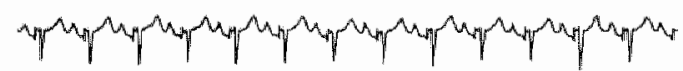

$$
\text { (4) }
$$

FIOUAE 1. Atrlovantriciulat diagociatlon during WVI pacing. Whein the pulse generater is programmend from the DDD to the VVI pacing mode at a rate slightly faster than the spontaneouss sinus rate, atrioventricullar dissociation ts present.

\begin{tabular}{|c|c|c|c|c|}
\hline At & Fut & $\begin{array}{l}\text { Dregs } \\
\text { (nmoreayll }\end{array}$ & AC Tests & $a_{x}$ \\
\hline 1 & 4.2 & $\ldots$ & 14 & + \\
\hline 2 & $39^{*}$ & Digax $x$ in 0.25 & 13 & + \\
\hline \multirow[t]{2}{*}{3} & $38 *$ & Digextin 0.25 & $g$ & + \\
\hline & & $\begin{array}{l}\text { Digpexin } 0.25+ \\
\text { Amiodtarone } 400\end{array}$ & 3 & 而 \\
\hline 4 & 34 & - & 10 & (i) \\
\hline \multirow[t]{2}{*}{5} & 33 & Digoxim 0.25 & 5 & + \\
\hline & & $\begin{array}{l}\text { Digoxin 0.25 }+ \\
\text { Aminodarone } 200\end{array}$ & 5 & 0 \\
\hline 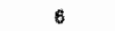 & 32 & $\ldots$ & 10 & + \\
\hline 7 & 31 & $\ldots$ & 8 & $\#$ \\
\hline$B$ & 20 & $\ldots$ & 8 & 音 \\
\hline 9 & 23 & $\ldots$ & 7 & 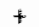 \\
\hline \multirow[t]{2}{*}{10} & 22 & $\therefore$ & 5 & + \\
\hline & & Diltiazem 180 & 3 & \# \\
\hline 11 & 22 & Digoxin 0: 125 & 7 & + \\
\hline 12 & 21 & Dipoxin 0.125 & 6 & + \\
\hline 13 & 19 & Digoxin 0.062 .5 & 5 & + \\
\hline 14 & 14 & Digoxin 0.126 & 4 & + \\
\hline 15 & 8 & $\cdots$ & 3 & + \\
\hline Mean \pm SO & $27 \pm 10$ & & $1 \pm 3$ & \\
\hline
\end{tabular}

TABLE it Rotrograde Conductlon and Antlarrythmic Drugs Durtug Follow-Uip in Croup !

- Pationt died

$F U=1010$ w-up; AC $=$ fotrograde conduction.

arrhythmias. The noninvasive assessment of retrograde conduction was divided into 2 parts:

Prevalence of retrograde conduction: By programming the pulse generator from the DDD to the VVI pacing mode at a rate 10 to 15 beats/min faster than the spontaneous sinus rate, either AV dissociation or retrograde conduction was present. When spontaneous $P$ waves were still present on the electrocardiogram, it was concluded that AV dissociation was present iFig. 1). However when $P$ waves disappeared or when $P$ waves with a different polarity were visible in every ST-segment of the ventricular paced beats, it was inferred that retrograde conduction was present [Fig. 2].

Prevention of pacemaker-mediated tachycardia: In patients with intact retrograde conduction, the pulse generator was programmed in the VDD pacing mode
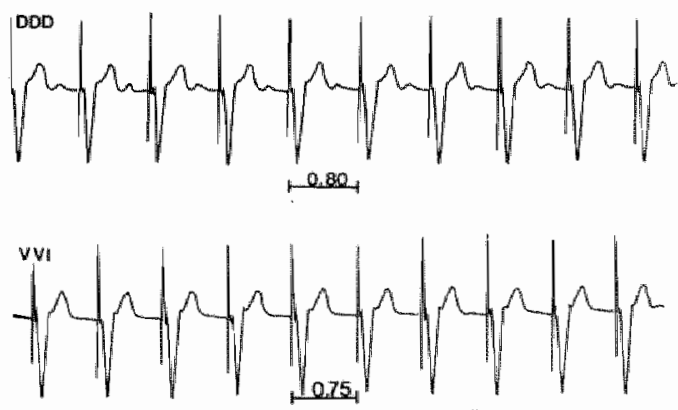

FIGURE 2. Fetrograde conduction durtno VWI pacing. When the putse generator is programmed from the DDD to the VVII pascing mode at a rate silghtly faster than the spontanews sinus rate, wawes are no lenger vistble, indicating the presence of retrograde conduction. 
at a minimal rate of 10 to 15 beats/min faster than the spontaneous sinus rate. When ventricular pacing at the programmed minimal rate was observed, the postventricular atrial refractory period was adequate in preventing pacemaker-mediated tachycardia (Fig. 3). When ventricular pacing occurred at a rate faster than the programmed minimal rate, pacemaker-mediated tachycardia was present and the postventricular atrial refractory period had to be prolonged to prevent sensing of retrograde $\mathrm{P}$ waves (Fig. 4 ).

Statistical analysis: Comparisons between groups were made using Fisher's exact test for unpaired data. All data are presented as mean \pm standard deviation.

\section{Results}

Table I lists the clinical and electrophysiologic data of group I and II patients. Table II and III list the antiarrhythmic drugs prescribed during follow-up.

Group I: After hospital discharge, a pacemaker pocket infection in 1 patient necessitated the removal of the endocardial DDD system, and an epicardial VVI unit was replaced 6 months after the first implantation. In this patient, the prevalence of retrograde conducthon could still be assessed during follow-up. However, the inducibility of pacemaker-mediated tachycardia could no longer be studied. In patients in group I. the mean number of noninvasive tests performed after hospital discharge was $8 \pm 3$ per patient. In 12 patients, retrograde conduction remained intact [p $<0.01)$ throughout the complete follow-up period. In 2 of 3 patients in whom retrograde block occurred, the incidence was related to the initiation of amiodarone therapy to control supraventricular arrhythmias. During serial electrophysiol ogic studies, pacemaker-mediated tachycardias could not be induced in any of these: patients. Howewer, in 1 patient, it was necessary to reprogram the postventricular atrial refractory period,
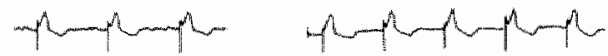

a

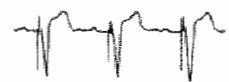

FIGUAE 3. WDD pacting wh an adequately prolonged poistventricular attlal reffactory poriod (PVARP) at a paper of $25 \mathrm{~mm} / \mathrm{at}$ The pulise generator is programmed from DDD to the VDD pacing

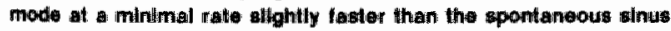
rate. Spontanoous P waves disappear and VDD pacing occurs at the programmed minimal ratle. Avo = atrloventricular delay pertoud.
}

because telemetry recording aftar pacemaker implantation demonstrated pacemaker-medlated tachycardiat during the night [Fig. 5 and 6 ].

Holter tracings did not show pacemaker-mediated tachycairdia in any patient in group I. During follow up, 2 patients [ $13 \%$ ] died: 1 in the hospital because of a cerebrovascular accident and 1 suddenly outside the hospital.

Group II: In 1 patient, atrial malsensing occurred within 3 months after pacemaker implantation, and

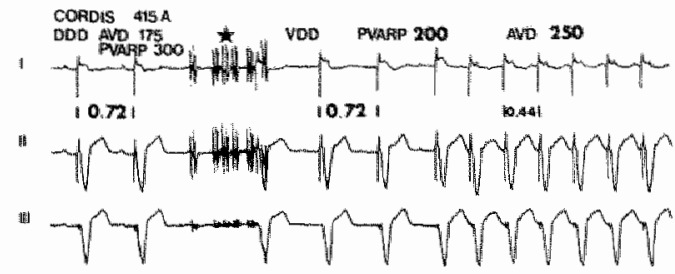

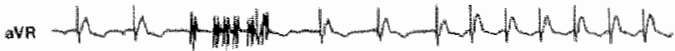

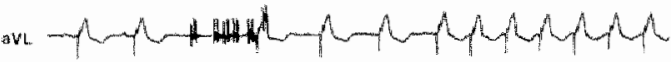

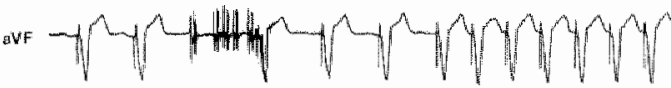

FIGURE 4. WDD pacing with an Insuttlclently prolonged prostwentricular atrial redractory pertod (PWARP) (in the aame pattent as in Figure 3). The pulse generator is agaln programmod trom the DDD to the VDD pacing mocte. Howeven "the postventrlicular atrlal refiracitory perlod is shortened form 300 to $200 \mathrm{~ms}$ and the atrioventricular delay perlod (AVD) is prolonged to 250 ma. A pacemaker-medlated tachycardia is inlitlated at a rate of 135 , beate/ $/ \mathrm{min}$ (cycle length 0.44 sacondi).

A
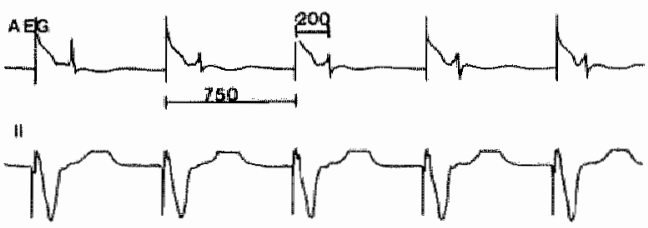

B
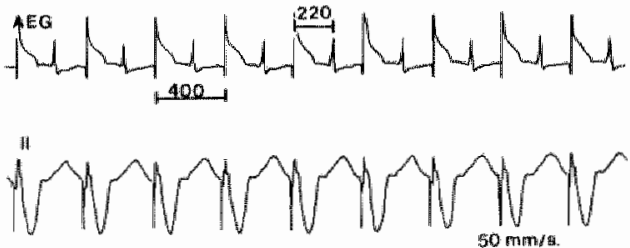

FICUAE 5. A, ventricular pacing during ellectrophyodologlic atudy is Initiated at a rate of $80 \mathrm{beats} / \mathrm{m}$ in. Alutrogradis conduction is present wilth a retrograda conduietlon time of $200 \mathrm{ma}$. 4 , retrograde conductlon remalns austained up to 150 beats/min and the retrogrando conduction time lnereases $10220 \mathrm{~m}$. AEO $=$ atrilual etectrogiam. 


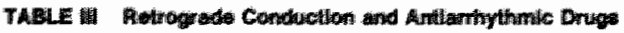

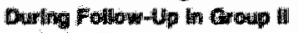

\begin{tabular}{|c|c|c|c|c|}
\hline $\mathrm{Pl}$ & $\begin{array}{l}\text { FU } \\
\text { froth }\end{array}$ & $\begin{array}{c}\text { Drupgs } \\
\text { Gmoldiny }\end{array}$ & RC: Testus & $\mathrm{RC}$ \\
\hline 16 & 42 & Dtgax 0.125 & 13 & 0 \\
\hline 17 & 37 & $\ldots$ & 12 & 0 \\
\hline 1 18 & 35 & Defowin 0.25 & $2(M F)$ & 0 \\
\hline 10 & $13^{*}$ & $\begin{array}{l}\text { Olgovin 0.25 } \\
\text { Amlod }\end{array}$ & 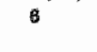 & $\theta$ \\
\hline 20 & 34 & 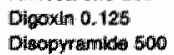 & 首目 & $\theta$ \\
\hline 21 & 32 & $=\ldots$ & $\mathrm{mo}$ & 0 \\
\hline 22 & $7 *$ & $\ldots$ & 2 & 0 \\
\hline 24 & $28^{\circ}$ & 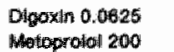 & 110 & 0 \\
\hline 24 & 20 & dolgoxtan 0.26 & $2(\mathrm{AF})$ & 0 \\
\hline 28 & 22 & $\ldots$ & 9 & 0 \\
\hline 26 & 21 & Dotgoxan 0.25 & $2 \mid A F)$ & 0 \\
\hline 27 & $21^{*}$ & $\ldots$ & 4 & 0 \\
\hline 28 & 20 & Atenoto: 100 & 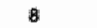 & 0 \\
\hline 29 & 24 & $\ldots$ & 8 & 0 \\
\hline 30 & 13 & Dtgoxin 0.25 & 4 & 0 \\
\hline 31 & $17^{*}$ & Otgoxin 0.126 & 5 & 0 \\
\hline 32 & 23 & Dlgoxin 0.25 & 7 & 0 \\
\hline \multirow[t]{2}{*}{33} & 22 & $\ldots$ & 5 & 0 \\
\hline & & & 2 & + \\
\hline 34 & 19 & $\ldots$ & 6 & 0 \\
\hline 36 & 18 & $\ldots$ & 6 & 0 \\
\hline \multirow[t]{2}{*}{36} & 16 & Digoxth 0.125 & 1 & + \\
\hline & & & 4 & 0 \\
\hline 37 & 16 & $\ldots$ & 5 & 0 \\
\hline 38 & 16 & $\ldots$ & 5 & 0 \\
\hline 30 & 14 & $\ldots$ & 4 & 0 \\
\hline 40 & 14 & Dipoxin 0.25 & 4 & 0 \\
\hline 41 & 13 & Digox in 0.25 & 4 & 0 \\
\hline 42 & 13 & Metoprotol 200 & 4 & 0 \\
\hline 49 & 12 & Digoxlin 0.25 & $\|(A F)$ & 0 \\
\hline 44 & 12 & $\ldots$ & 3 & 0 \\
\hline 46 & 11 & $\ldots$ & 3 & 0 \\
\hline 46 & 11 & Natoproldill 200 & 3 & 0 \\
\hline 47 & $\theta^{\prime \prime}$ & $\begin{array}{l}\text { Digoxila } 0.0025+ \\
\text { Aimlodarono } 200\end{array}$ & 2 & $\begin{array}{l}0 \\
0\end{array}$ \\
\hline 48 & 9 & $\ldots$ & 3 & 0 \\
\hline 48 & 9 & $D: 190 x \ln 0.25$ & 3 & 0 \\
\hline 60 & 9 & Solalol 60 & 3 & 0 \\
\hline Maran $\pm \$ D$ & $19 \pm 9$ & & Ste 3 & \\
\hline
\end{tabular}

- Paitonat dited.

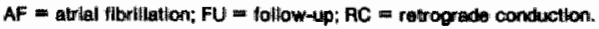

despite repositioning of the atrial lead, malsensing remained present. In this patient, it was also impossible to study the inducibility of pacemaker-mediated tachycardia, although the prevalence of retrograde conduction could be studied by programming the VVI pacing mode. In 4 patients, chronic atrial fibrillation occurred despite the administration of antiarrhythmic drugs or elective cardioversion. These 4 patients were excluded from further study. In the remaining $31 \mathrm{pa-}$ thents, the mean number of noninvasive tests performed after hospital discharge was $5 \pm 3$ per patient. In 29 patients, retrograde conduction remained absent throughout the complete follow-up period [ $p<0.01$ ]. In 2 patients, retrograde conduction was intermittently present, but pacemaker-mediated tachycardias could not be induced.

Pacemaker-mediated tachycardias were not observed during either monitoring by telemetry or holter
邱

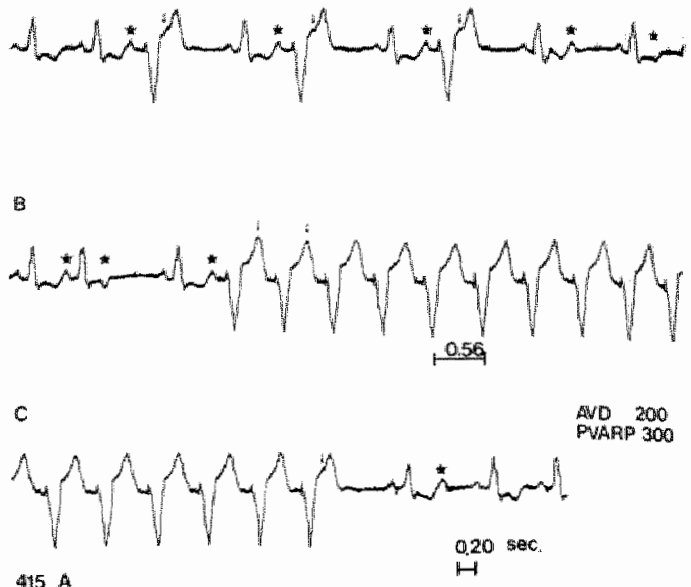

FICUAE 6. Telemekry irecording durling the nlght after pacemaker Impliantation (same patlent ae in Flgure 5 ). $A$, atrial premature beuth

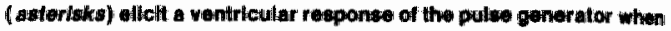
they occur later than 300 mo after sened ventrleutar complox. (postwentricular altial refractory perlod [PVARP] $=300 \mathrm{~ms}$ ). The ventrlfular paced bests are rolirogradely conducted to the atrium and retrogrante $P$ waves (exrows) resel the spontaneous alnut cycle. No pacemaker-mediated tachycandla it Inthlated thecause the

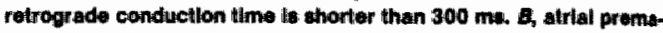
ture beats appear agaln, and a pacemeker-medlaked tachycardis is Inthlated becaure the retrograde $P$ waves now occur outeide the PVAAP of 300 ms. The cycle length of the pacemaker-medileted tachycartla $1560 \mathrm{ma}$, which means thal with a programmed aftiloventricular delay perlod (AVD) of $200 \mathrm{me}$, the retrograde conduce. thon tlme equals 360 ma (560-200). C. techyeardie is terminated by a sudden change of the retrograde conduction thm to lan than 300 ma Panels $A, B$ and $C$ are conthuous tracinge.

recording. Seven patients $(20 \%)$ died during followup. In the hospital, 3 of them died from heart fallure, 2 patients from carcinoma and 1 patient from renal failure. Out of the hospital, 1 patient died from unknown cause.

\section{Discussion}

Serial electrophysiologic testing in humans has been limited by the invasive character of the procedure. However, several pacemakers are currently available that enable us to perform noninvasively seri. al electrophysiologic studies.

In our series, the prevalence of retrograde conduction was assessed by ventricular pacing. Recently, Mahmud et al ${ }^{6}$ suggested that the introduction of ventricular extrastimuli, coupled to AV sequential pacing, may elicit a higher prevalence of retrograde conduction than would be observed with ventricular pacing alone. We therefore may have underestimated the prevalence of retrograde conduction. However, Mahmud et al studied 13 patients with intact AV conduction, and the site of retrograde block in all patients was at the level of the $A V$ node. It is unknown if 
extrapollation of these results to patients with heart block is warranted. Schuilemburg ${ }^{7}$ demonstrated in patients with $A V$ block that retrograde infranodal block is not uncommon, which may eliminate the facillitative elfect of the AV sequential method on retrograde conduction to the atrium.

Taking this limitation into account, our results suggest that retrograde conduction remains stable in most patients with heart block during long-term follow-up after DDD pacemaker implantation. Pacemaker-mediated tachycardias could not be induced in any of our patients during serial electrophysiologic testing, stuggesting adequate protection against these tachycardias. Unfortunately, these observations do not absolutely guarantee protection against pacemakermediated tachycardia, as was shown by 1 of our patients (Fig. 5 and 6). In addition, for safety precautions, we routinely programmed a postventricular atrial refractory period of $300 \mathrm{~ms}$ in patients with retrograde block during preoperative studies, thereby precluding the consequences of retrograde conduction with retrograde conduction times less than $300 \mathrm{~ms}$ [which might have occurred intermittently during follow-up].

Our approach of lengthering postventricular atrial refractory periods proved to be a safe strategy during long-term follow-up. However, we had to accept that maximal tracking rates of the pulse generators were limited. In this regard, several suggestions were made by Den Dull et al" Bipolar atrial sensing will prevent myopotentials from initiating pacemaker-medisted tachycardia; reset of a prolonged postventricular atrial refactory period affer sensed atrial or ventricular premature beat will prevent sensing of retrograde $\mathrm{P}$ waves; and DDD escape, instead of DVI escape, after a premature beat will block subsequent retrograde conduction. In future DDD systems the prolblem of retrograde conduction must be solved without compromising the upper rate limit of the pulse generator.

\section{References}

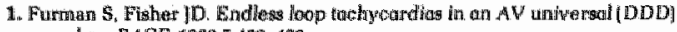

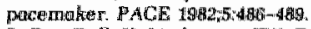

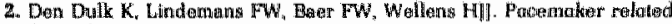

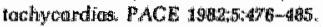

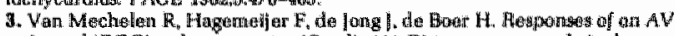

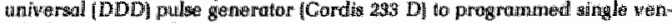

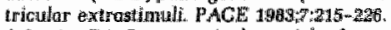

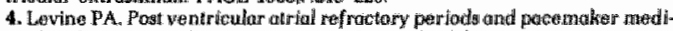
ated tachycardios, Clin Progr Pacing Electrophysiol 19as;1:594-358.

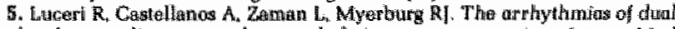

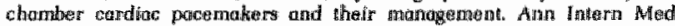
1989:93:354-35

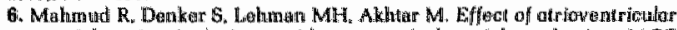

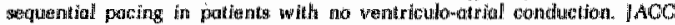
1964:4:273-277

7. Sohullentarng RM. Pouteng of V A condugtion in the human heart in the

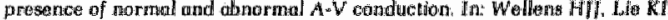
lonse MI, eds. "The Conduction Syatem of the Heart. Leident Stentert Kroen BV. 1986;491-500.

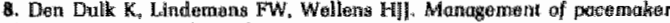
circus unoversent tachycurdias. PACE 1984,7346-355. 


\title{
Pacemaker Electrocardiography of Rate Smoothing During DDD Pacing
}

\author{
ROB VAN MECHELEN, JAAP RUITER, HANS DE BOER, \\ and FRANS HAGEMEIJER \\ From the Department of Cardiology, St. Franciscus Casthuis, Rotterdam, The Netherlandis
}

VAN MECHELEN, $\mathrm{R}_{r,}$ ET AL.: Pacemaker electrocardiography of rate smoothing during DD pacing. A rate smoothing option is avallable in a new bipolar AV universal (DDD) pacemaker. In three patients, two with intact retrograde conduction and one with retrograde block, rate smoothing values of $3 \%$ and $6 \%$ were programmed. Irregular pacemaker-mediated tachycardia accurred in one patient and AV synchrony was temporarily lost in the other two patients. In this report, we describe the pacemaker electrocardiography of rate smoothing during DDD pacing. (PACE, Vol. 8, September-October, 1985)

AV universal (DDD) pacing, pacemaker electrocardiography, rate smoothing

\section{Introduction}

The rate smoothing option in a new bipolar DDD pacemaker (CPI* 925) is intended to eliminate large cycle-to-cycle variations in rate by preventing the paced rate, either atrial or ventricular, from changing by more than a programmed percentage from one cardiac cycle to the next. ${ }^{1}$ In this report we present three patients in whom the rate smoothing option was used.

\section{Methods and Materials}

Patients

AV universal (DDD) pacemakers were implanted in three patients with complete heart block. Patients had been physically active before the onset of conduction disorder.

\section{Electrophysiologic Studies}

Patients underwent an electrophysiologic evaluation to assess the prevalence and persistence of retrograde conduction. The study was conducted according to previously described catheter techniques. ${ }^{2-4}$

Addrosis for reprints: Rob van Mecthelen, M.D., Dept. of Cardiology, St. Franciscus Giasthubs, Klolweg 500; 3045 PM. Rotterdam, "The Natherlunds.

Racaived March. 21, 1985; accepted April 25, 1985.

* Cardiac Pacomakers, Inc. St. Paul, MN. USA.

\section{Pulse Generator}

The CPI 925 bipolar DDD pulse generator is a multiprogrammable, microprocessor-based pacemaker that can function in any standard single or dual chamber pacing mode. Rate smoothing values (RSV) may be set at $3 \%, 6 \%, 12.5 \%$, or $25 \%$. When the rate smoothing option is on, the pulse generator stores in its memory the most recent $R R$ interval and does not allow the next $R R$ interval to be less "than the preceding RR interval minus the programmed percentage nor does it allow it to be greater than the preceding RiR interval plus the programmed percentage.

Based on the previous RR interval and the selected smoothing value, the pulse generator sets up two windows-one for atrial events and another for ventricular events:

atrial window

$$
=\text { (previous RR interval } \pm \text { RSV) - AV delay }
$$
ventricular window

$$
=\text { previous } R R \text { interval } \pm R S V
$$

The timing for both windows is initiated at the end of a ventricular event. When an atrial event occurs before the atrial synchronization window (e.g., APB), the ventricle is paced after an interval that equals the previous $R R$ interval - RSV. When an atrial event occurs within the atrial synchronization window (e.g., sinus beat), the programmed AV delay period is initiated and 
the ventricle is paced at the end of the AV delay period. When no atrial event occurs during the time represented by (previous RR interval + RSV) - AV delay, the atrium is paced at the end of this interval and the ventricle at the end of the programmed AV delay period. When a ventricular event occurs before the ventricular window (e.g., VPB), the timing circuit is reset at an interval equal to the previous RR interval - RSV and a new cycle begins. When a ventricular event occurs within the ventricular synchronization window, ventricular output of the pulse generator is inhibited and the next RR interval will be equal to the previous $R R$ interval \pm RSV.

\section{Case Reports}

\section{Patient No. 1}

A 75-year-old man was admitted to the hospital because of Adam-Stokes attacks. The ECG on admission showed third-degree AV block with a ventricular rate of 30 beats $/ \mathrm{min}$, and a sinus rate of 70 beats/min. The QRS duration was 0.16 $s ;$ the morphology of the QRS complex suggested a ventricular origin of the secondary pacemaker. Monitoring by telemetry showed that heart block was intermittently present.

Electrophysiologic study performed prior to pacemaker implantation demonstrated sinus rhythm with intact $\mathrm{AV}^{\prime}$ conduction. The $\mathrm{AA}$ interyal was $1,050 \mathrm{~ms}$, the $\mathrm{AH}$ interval was 100 $\mathrm{ms}$, and the HV interval was $50 \mathrm{~ms}$. During incremental atrial pacing, infranodal block occurred at an atrial pacing rate of 90 beats/min. During ventricular pacing retrograde conduction was blocked. The site of retrograde block was infra-His.

A CPI 925 pacemaker was implanted. At implantation, a postventricular-atrial refractory period (PVARP) was programmed to $250 \mathrm{~ms}$, the AV delay period to $250 \mathrm{~ms}$, and the RSV to $3 \%$.

The fourth day after pacemaker implantation, the patient was discharged from the hospital. A routine 24-hour Holter recording was performed during the first 6 wegks after hospital discharge. An emergency call from the Holter center warned us that there was something wrong with the pacemaker. Although the patient did not have any complaints written in his diary, irregular tachycardias occurred repeatedly.
Figure 1 shows a representive tracing of the 24-hour Holter recording, during which 20 episodes of irregular tachycardia occurred. Analysis of the ECG (Fig. 1 A) demonstrated that tachycardia was initiated by a sensed atrial event. Although the Holter lead does not clearly show a premature atrial beat, it can be inferred that the pulse generator must have sensed an atrial event that occurred before the atrial synchronization window because during DDD pacing a ventricular response of the pulse generator is always preceded by a sensed or paced atrial event. As a result of the programmed percentage of $3 \%$, the ventricular pacing cycle length gradually decreased (Fig. 1B). The ventricular pacing rate therefore gradually increased. At a rate of \pm 110 beats $/ \mathrm{min}$, (Fig. 1C) atrial pacing suddenly started at a gradually decreasing rate (Fig. 1C, D) until the spontaneous sinus rate exceeded the atrial pacing rate.

The most likely explanation of this pacemaker behavior is that although retrograde conduction was blocked during electrophysiologic study, it was no longer blocked during Holter recording and with a retrograde conduction time to the atrium that exceeded the programmed PVARP (250 ms) a pacemaker-mediated tachycardia could occur. The tachycardia was increasing in rate because of the rate smoothing option. At a rate of 110 beats/min, retrograde conduction was no longer sustained and subsequently atrial pacing occurred because no atrial event was sensed before or during the atrial synchronization window. The pacing rate then gradually decreased again due to the rate smoothing option as long as the paced atrial rate exceeded the spontaneous sinus rate. The problem was solved by program. ming a prolonged PVARP. The rate smoothing option was programmed off.

\section{Patient No. 2}

A 62-year-old female was admitted to the hospital because of symptomatic third-degree AV block. The ECG on admission showed complete heart block. The spontaneous sinus rate was 90 beats/min, and the ventricular rate was 40 beats min. The QRS duration was $0.16 \mathrm{~s}$; the morphology of the QRS complex suggested a ventricular origin of the secondary pacemaker. The patient did not use cardioactive medication prior to the 

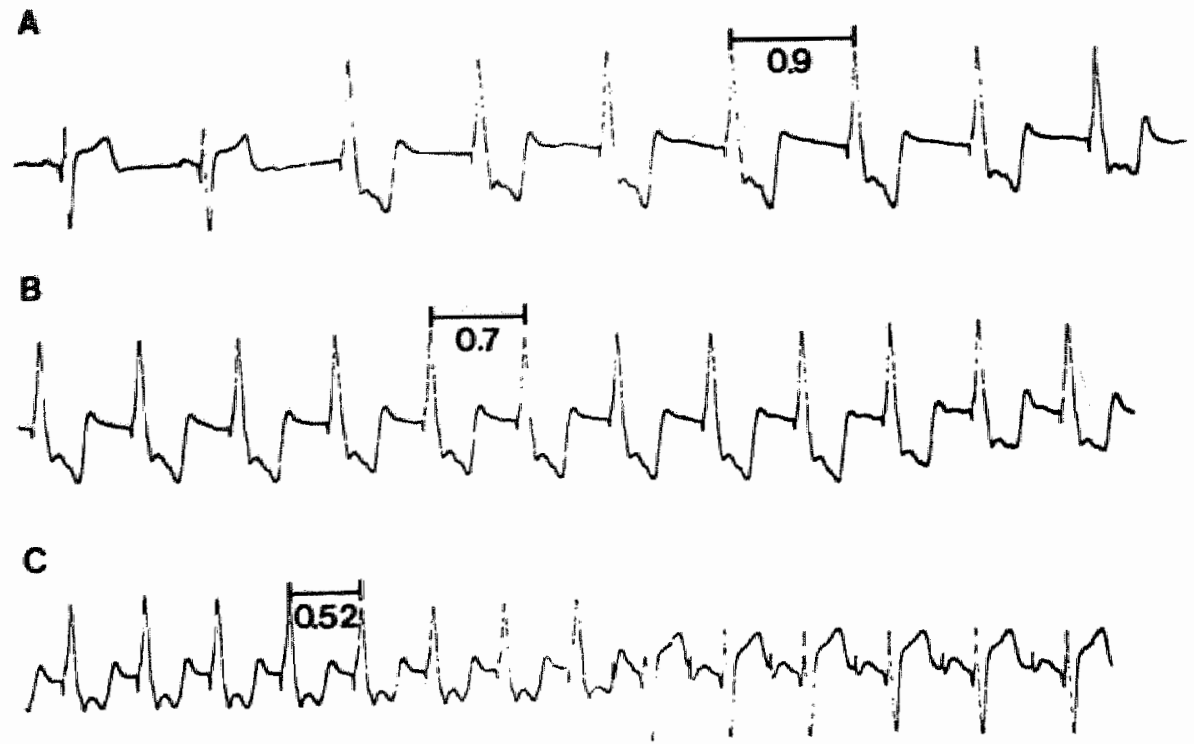

D

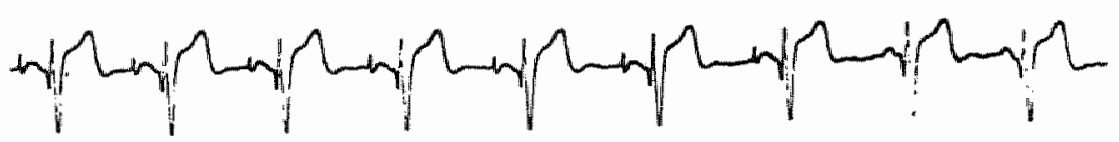

Figure 1. Irregular pacemaker-mediated tachycandia during ambulatory monitoring (continuous tracingl. A. After the frrst two sinus beats, an APB is sensed before the atrial synchronization window. Due to the programmed RSV $(3 \%)$, ventricular pacing with $1: 1$ VA conduction is initiated. B. The ventricular pacing rate gradually increases as long as 1:1 VA conduction remains present. C. At a ventricular cycle length of $520 \mathrm{~ms}$, VA conduction is no longer sustained and because na P-wave occurs before or during the atrial symchronization window, atrial pacing is intiated at a gradually decreasing rate. D. When spontaneous P-waves occur during the atrial synchronization window, atrial pocing is inhibited.

onset of conduction disorder. Electrophysiologic study showed complete anterograde infranodal block. Retrograde conduction was blocked at the level of the AV node. A CPI 925 pacemaker was implanted. A PVARP was programmed at 300 $\mathrm{ms}$, the AV delay period to $200 \mathrm{~ms}$, and the RSV to $3 \%$.

Manitoring by telemetry during 48 hours after implantation revealed loss of AV synchrony, which disappeared after switching the rate smoothing option off. The patient was transferred to the electrophysiology laboratory and a tem- porary bipolar lead was inserted via the femoral vein and advanced into the right ventricular apex. Programmed single ventricular extrastim. ulation was performed during DDD pacing. ${ }^{4}$ Figure 2 shows the ECG when the rate smoothing option was programmed off. Figure 3 shows the ECG when an RSV of $3 \%$ was programmed and a premature ventricular beat was introduced during DDD pacing, leading to loss of AV synchrony as long as the spontaneous sinus rate remained unchanged. Figure 4 shows that AV synchrony was not lost when an RSV of $6 \%$ was 


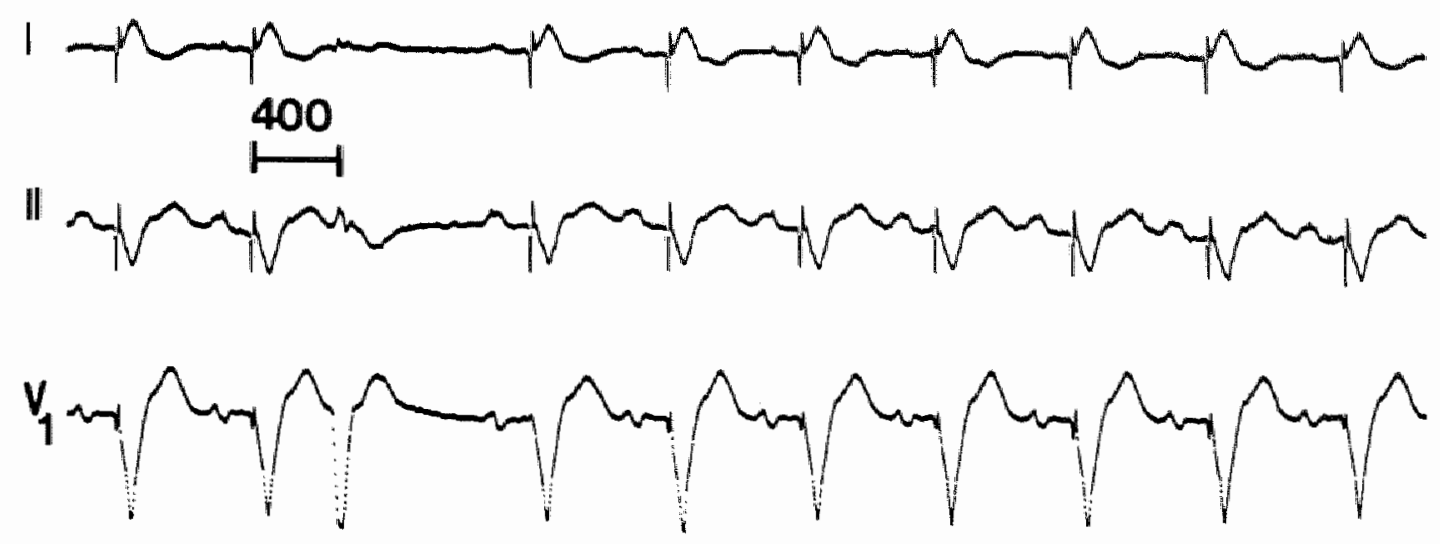

Figure 2. Complete compensatory pause after a sensed VPB. When the rate smoothing option is programmed off. no loss of AV synchrony is noted after a sensed VPB. The pacemaker was programmed in the DDD mode, minimum rate 50 beats/min. AV delay period of $200 \mathrm{~ms}$. PVARP of $300 \mathrm{~ms}$.

programmed. Figure 5 demonstrates that when an RSV of $12.5 \%$ was programmed AV synchrony was immediately restored. In this patient, an RSV of $12.5 \%$ was programmed. Holter recording performed after hospital discharge demonstrated AV synchronous pacing. So far her course $[6$ months after implantationj has been uneventful.

\section{Patient No. 3}

An 81-year-old female was admitted to the cardiology department because of dizziness. The ECG on admission showed sinus rhythm at a rate of 65 beats $/ \mathrm{min}, 3: 1 \mathrm{AV}$ conduction, a QRS duration of $0.12 \mathrm{~s}$, with RBBB and LAHB morphology.

Electrophysiologic study demonstrated advanced second-degree AV black. The site of anterograde block was infre-His; the AH interval was $80 \mathrm{~ms}$ and the HV interval of the anterogradely conducted beats (3:1) was $90 \mathrm{~ms}$. During ventricular pacing, retrograde conduction was intact up to 120 beats/min. Retrograde conduction time, during sustained retrograde conduction, ranged from 280 to $300 \mathrm{~ms}$. A CPl 925 pacemaker was implanted. The RSV was programmed to $6 \%$. the AV delay period was $200 \mathrm{~ms}$, and the PVARP was programmed at $350 \mathrm{~ms}$. After pacemaker implantation, the patient was monitored by telemetry and loss of AV synchrony was noted. Analysis of the ECG (Fig. 6) demonstrated loss of AV synchrony at a spontaneous sinus rate of 70 beats $/ \mathrm{min}$, and a paced ventricular rate of \pm 60 beats/min. When the AV delay period was extended beyond the programmed maximum value, retrograde conduction occurred. The rate smoothing option was programmed off and AV synchronous pacing was restored.

\section{Discussion}

Although dual chamber pacing has corrected some of the original deficiencies of single chamber ventricular pacing, other problems have been created. In this report, some aspects of the electrocardiographic complexity of rate smoothing in patients with heart block are presented.

The problem of irregular pacemaker-mediated tachycardia, which we encountered in the first patient, was a result of the incidence of APBs, an insufficiently long PVARP, and the programmed RSV. Although this problem could easily be solved by prolongation of the PVARP, loss of $\mathrm{AV}$ synchrony could still occur as a consequence of the rate smoothing option. In the other two patients, we found that loss of AV synchrony 


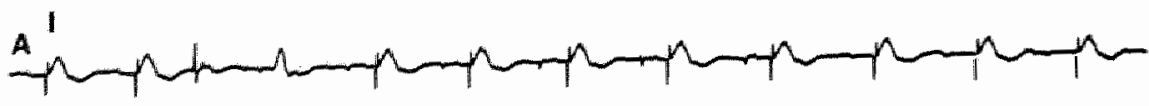

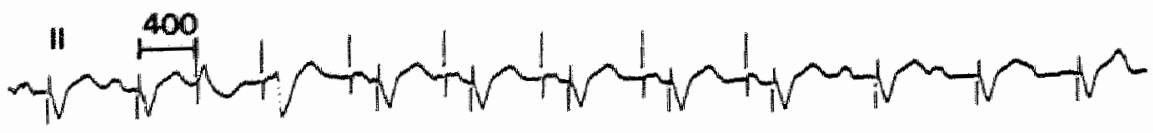

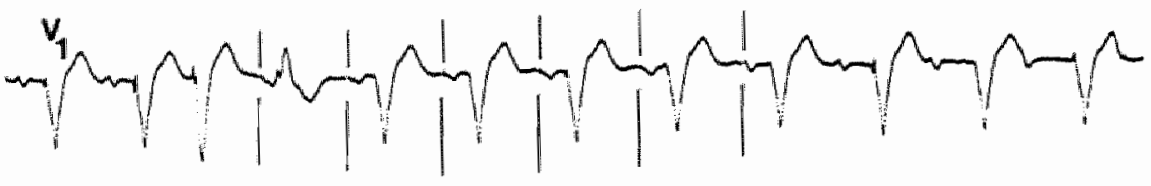

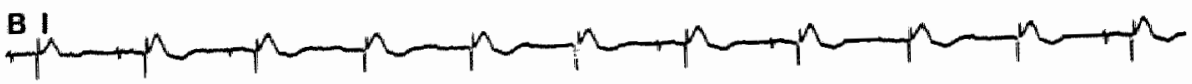

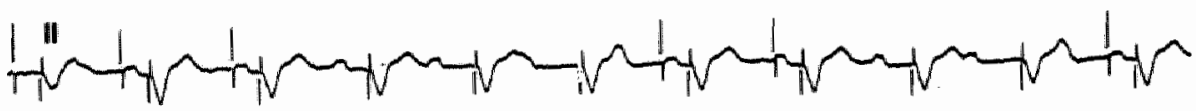

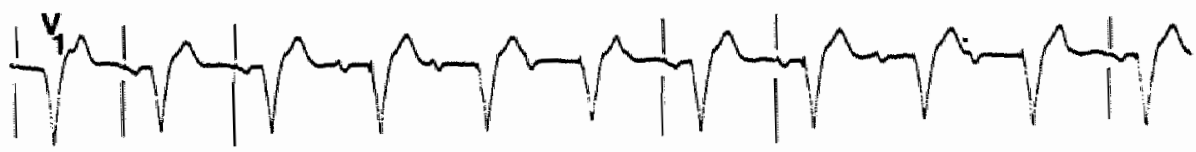

Figure 3. Programmed single ventricular extrastimulation during DDD pacing with an ASV of $3 \%$. A. Due to the rate smoothing option, the compensatory pause after a ventricular extrastimulus is incomplete. AV sequential pacing is initiated at a gradually decreasing rate. During AV sequential pacing, the spontaneous sinus cycle is reset by the atrial paced beats. When $P$-waves occur during or before the atrial synchronization window. AV synchronous pacing is not restored because the RSV does not allow a reduction of the ventricular cycle length $>3 \%$. B. When P-waves march into the PVARP. AV sequential pacing is resumed. As long as the spontaneous sinus rate remains unchanged AV dissoriation remains present. Tracings $A$ and $B$ are continuous. Note that the first beat of tracing $B$ shows poor atrial pocing.

could occur in patients with intact retrograde conduction as well as in patients with retrograde block. We observed that loss of AV synchrony in our patients was initiated by premature beats and that the endurance of AV dissociation was related to the programmed smoothing value, the programmed PVARP, and the spontaneous sinus rate.

Why does AV dissociation occur when low RSV's are programmed? Normally the interval of the sinus beats that surround a VPB equals two times the $\mathrm{PP}$ interval (Fig. 2). However, when the rate smoothing option is used, the compensatory pause after a VPB is always lass than complete (preceding RR interval - RSV) and AV sequential pacing or atrial pacing is initiated (Figs. 3, 4, 5). Since every following AV sequential paced cycle equals the preceding cycle plus the programmed RSV, the pacing rate gradually decreases. Initially, sinus P-waves may collide or 


\section{RSV $6 \%$}

PVARP 300

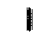

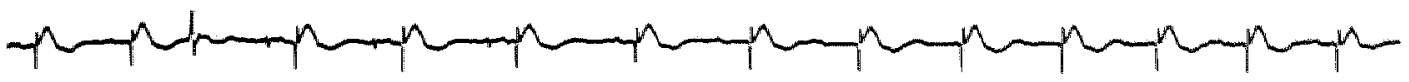

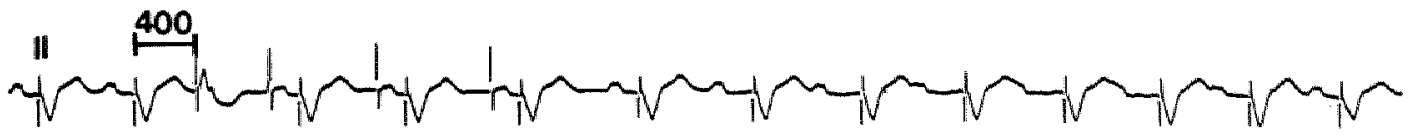

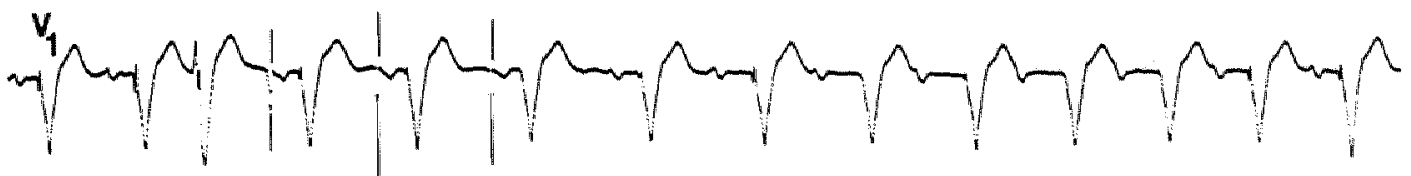

Figure 4. Programmed single ventricular extrastimulation during DDD pacing with an ASV of 6\%. Before P-waves march into the PVARP, AV synchronous pacing is restored.

may be reset by the atrial paced beats during AV sequential pacing. However, because the AV sequential pacing rate decreases and the sinus rate remains unchanged, sinus $P$-wave will become manifest during or before the atrial synchronization window and AV sequential pacing is discontinued. Unfortunately, AV synchronous pac- ing is not immediately restored, because the ventricular paced rate can only increase by decreasing every cycle with the programmed percentage. It is obvious that the duration of $\mathrm{AV}$ sequential pacing after a sensed VPB is dependent on the programmed RSV. When high RSVs $[12.5 \%$, $25 \%$ ) are programmed, fewer AV sequentially

\section{RSV $12.5 \%$}

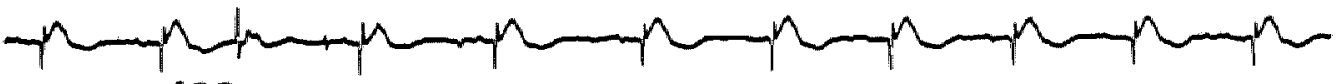

\section{0}
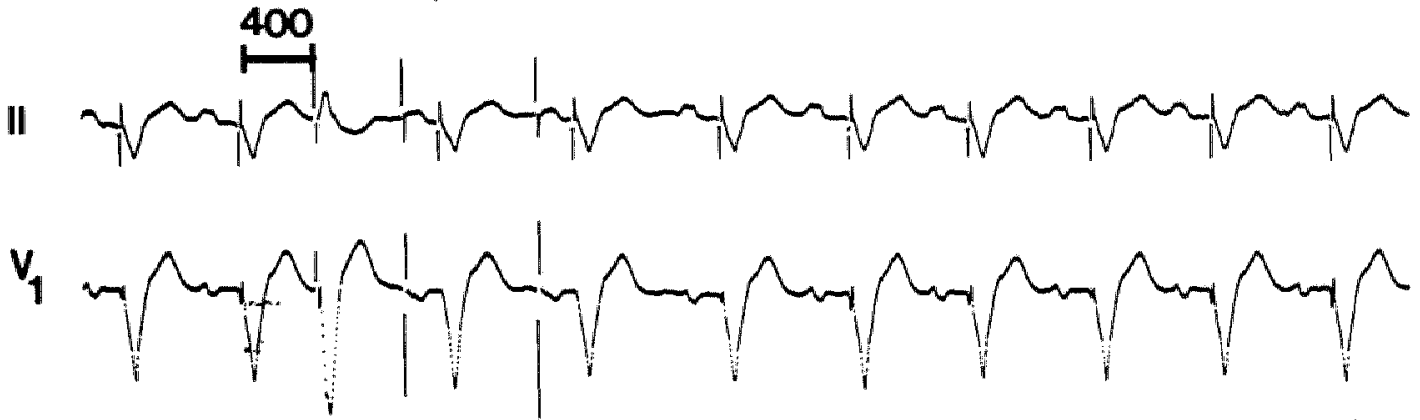

Figure 5. Programmed single ventricular extrastimulation during DDD pacing with ar ASV of 12.5\%. After one cycle of AV sequential pacing. AV synchronous pacing is restored. 

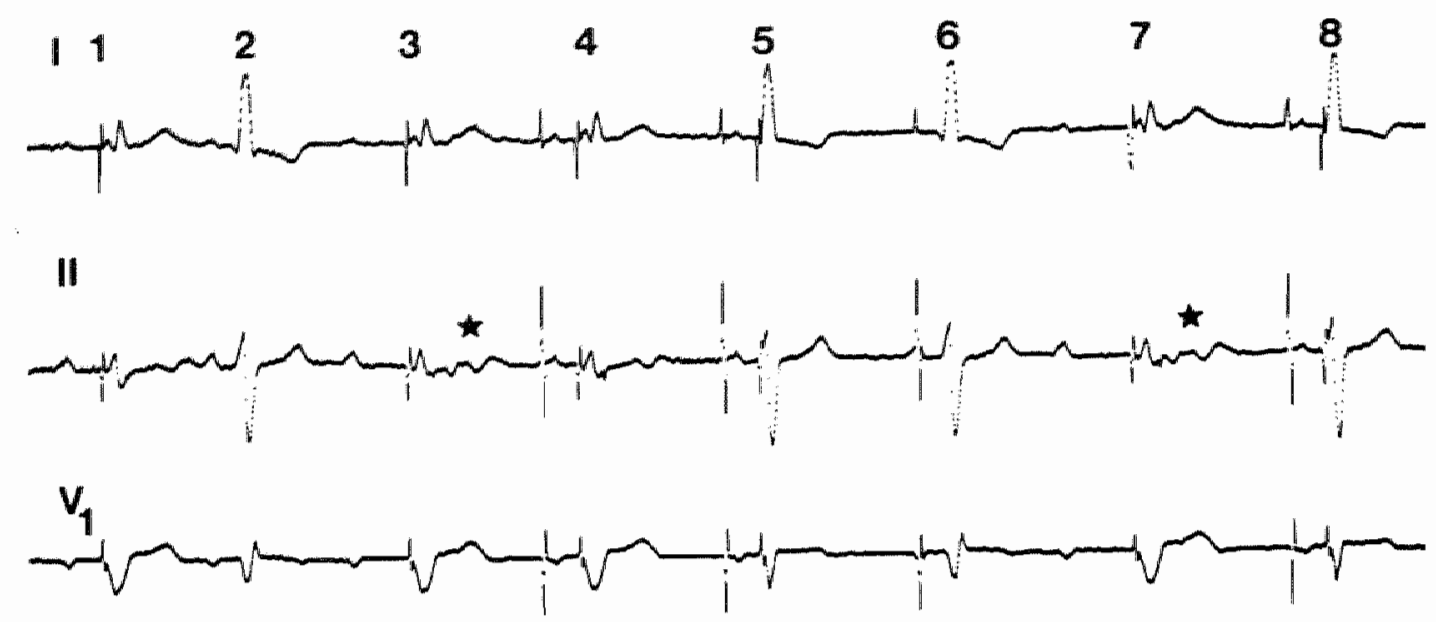

Figure 6. Intact retrograde conduction and rate smoothing. In this patient an RSV of $6 \%$ and a PVARP of $350 \mathrm{~ms}$ were programmed. Although the prolonged PVARP prevents pacemakermediated tachycardia. Joss of AV synchrony is present. QRS complexes 1,4 are ventricular paced beats, QRS complexes 2,6 are anterogradely conducted beats. QRS complexes 3,7 are ventricular paced beats with intact retrograde conduction, and QRS complexes 5,8 show wentricular pseudofusion.

paced cycles are needed before sinus P-waves become manifest during or before the atrial synchronization window than when low RSVs $13 \%$, $6 \%$ | are programmed. Subsequently, fewer cycles are needed to restore AV synchronous pacing when liigh RSV's instead of low RSVs are programmed. Figures 3, 4, and 5 illustrate that when a low RSV is programmed, restoration of $\mathrm{AV}$ synchronous pacing may fail because spontaneous P-waves may occur during the PVARP before AV synchronous pacing is restored. As a result. AV sequential pacing is initiated, leading to persistent AV dissociation as long as the spontaneous simus rate remains unchanged.

We are not yet decided as to whether the rate

\section{References}

1. Physician's Manual, Delta, model 925. St. Paul Minnesota, Cardiac Pacemakers, Inc., 1984.

2. Rosen, KM.: Evaluation of cardiac conduction in the cardiac catheterization laboratory. Am. I. Cardiol., 30:701, 1972.

3. Schuilenburg R.M.: Patterns of V-A conduction in the human heart in the presence of normal and smoothing option is useful for clinical applicatio For patients with intact retrograde conduction : well as patients without retrograde conductio the risk of losing AV synchrony is present di to the rate smoothing option, especially in patien in whom low RSVs are programmed in comb nation with prolonged PVARPs.

In conclusion, the rate smoothing option avai able in new DDD pacemaker might be clinical importance because it eliminates lary cycle-tomcyclle variations in rate. However, irre ular pacemaker-mediated tachycardias and lo of AV synchrony may occur. Fortunately, th pacing system enabled us to solve these problen noninvasively.

abnormal A-V conduction. In H. J. I. Wellens, K. Lie, and M. I. Janse (Eds.): The Conduction Syste of the Heart. Leiden. The Netherlands, Stenfe Kroese, BV, 1976, p. 491.

4. van Mechelen, $R_{\text {. }}$ Hagemeijer, $F$., de Jong, $I_{\text {, }}$ al.: Responses of an AV universal (DDD) pul generator (Cordis 233 D) to programmed sing ventricular extrastimuli. PACE, $7: 215,1984$. 


\section{Atrial Capture and Dual Chamber Pacing}

\section{ROB VAN MECHELEN and YVES VANDEKERCKHOVE}

From the Department of Cardiology, St. Franciscus Gasthuis, Rotterdam. The Netherlands

VAN MECHELEN, R., ET AL.: Atrial capture and dual chamber pacing. During dual chamber pacing it is sometimes impossible to assess atrial capture even on the 12-lead EGG. We developed a strategy to identify atrial capture when it is not possible to do so by ECG, and when the EGG shows no evidence of spontaneous or paced atrial activity. (PACE, Vol. 9. January-February, 1986)

atrial capture, AV sequential pacing, dual chamber pacing

\section{Introduction}

The diagnosis of successful atrial capture during dual chamber pacing may be quite difficult on the conventional ECG, especially in patients with unipolar pacemakers. ${ }^{1,2}$ In patients with intact AV conduction atrial capture can be demonstrated by programming a ventricular output below threshold, or by selecting an AV delay interval that exceeds the natural AV conduction time, or by programming to the atrial demand mode. However, in patients with complete heart block this approach is not appropriate.

In selected patients the bedside physical examination has been proposed as a simple and accurate means of identifying atrial capture. The presence of regular $A$ and $V$ waves in the jugular venous pulse and the presence of a stable intensity of the first heart sound and regular diastolic filling sounds all establish atrioventricular synchrony. In contrast, cannon waves, varying loudness of the first heart sound, and intermittent diastolic filling sounds suggest AV dissociation. Definitive proof of atrial capture can subsequently be oblained by recording the jugular venous pulse, the phonocardiogram, the echocardiogram, or the esophageal electrocardiogram. ${ }^{3-4}$ However, patient variability may be an important factor, and application of these noninvasive techniques may sometimes be very time consuming. Therefore, we questioned the suitability of this approach in the out-patient clinic when, during a pacemaker check-up visit,

\footnotetext{
Address for reprints: R. van Mechelen, MD, Dept of Cardiology, St. Franciscus Gasthüs. Kleiweg 500. 3045 PM, Rotlerdan, The Nethertiands.

Received May 14, 1985; revision received August 26, 1985; accepted August 27, 1985.
}

the ECG does not allow assessment of adequate atrial pacing. For the out-patient setting, it would be desirable to have a simple and rapid technique to assess atrial capture. In this paper we present a strategy to demonstrate atrial pacing in patients with dual chamber pacemakers. At present this approach is routinely used in our oul-patient clinic when it is unclear on the surface ECG whether or not the atrial stimulus is followed by atrial depolarization.

\section{Methods}

The flow chart to assess atrial capture is itlustrated in Figure 1. When a single ECG lead does not show any evidence of spontaneous or paced atrial activity (Fig. 2) a 12-lead ECG us recorded. Special attention must be paid to leads II and VI. because these leads will most likely demonstrate atrial activation (Fig. 3). When no spontaneous or paced atrial activity is observed, the pacemaker is programmed to the VVI mode at the slowest available stimulation rate and spontaneous $\mathrm{P}$ waves may become visible (Fig. 4).

\section{PP Interval Shorter than the VV Interval}

When the VV interval exceeds the measured PP interval (Fig, 4) the pulse generator is programmed to the AV sequential (DVI) pacing mode" at the same rate as the VVIl pacing rate. When there is poor atrial pacing the spontaneous PP interval will not be affected by the atrial stimulus artifacts of the pacemaker. However, when adequate atrial pacing is present, the atrial stimuli will interfere with the spontaneous sinus cycle in the same way as atrial premature beats will interfere during sinus rhythm (Fig. 5), with resetting, interpolation, and collision of the spontaneous sinus beats. 


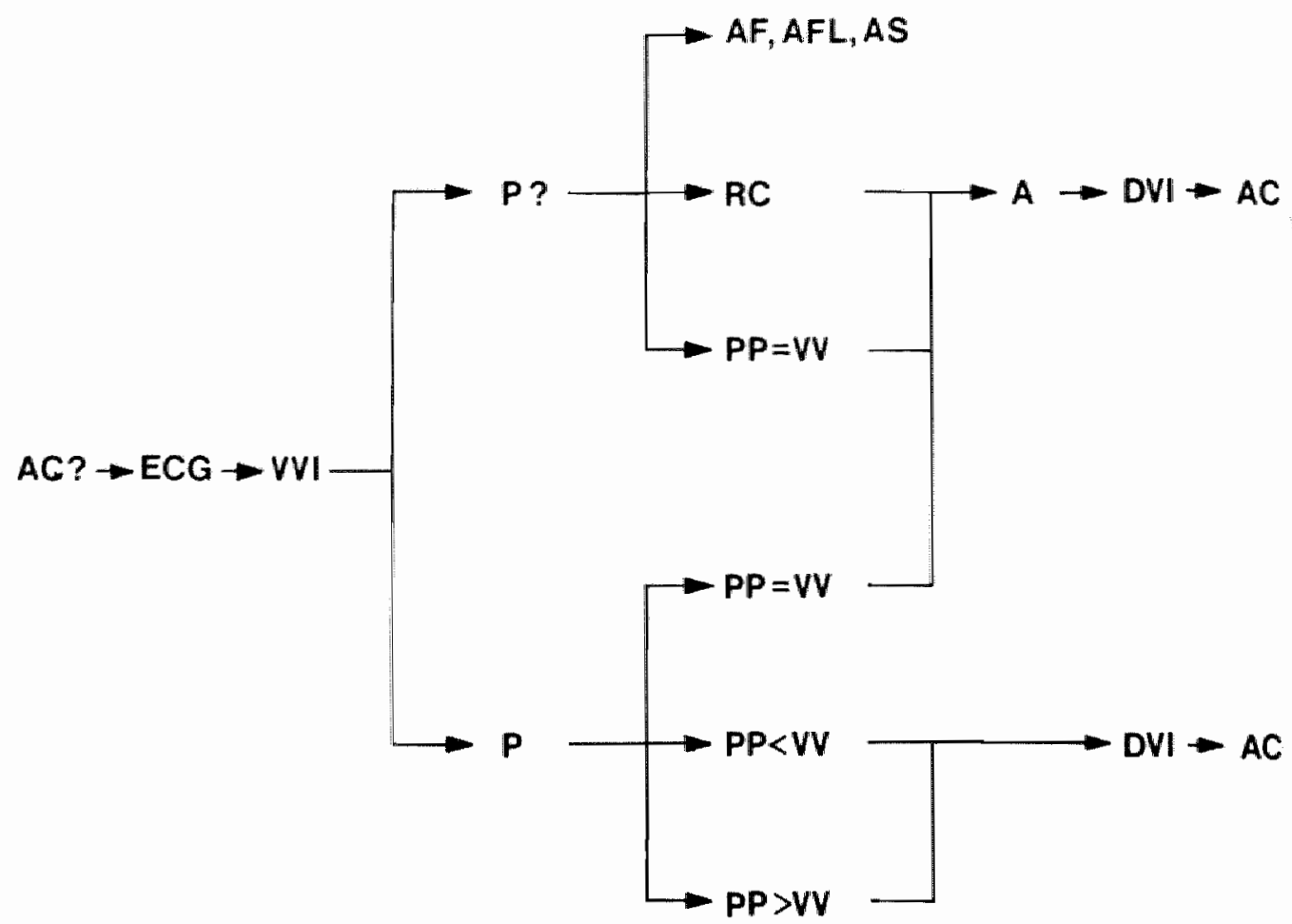

Figure 1. Assessment of atrial capture. $A C=$ atrial capture: $P=$ sirus $P$ wave; $A F=$ atrial fibrillation; $A F L=$ atrial flutter; $A S=$ atrial standstill; $R C=$ retrograde conduction; $P P=P P$ interval; $V V=V V$ interval; $A=$ atropine; $V V I=W I$ pacing mode; $D V I=A V$ sequential pacing mode.

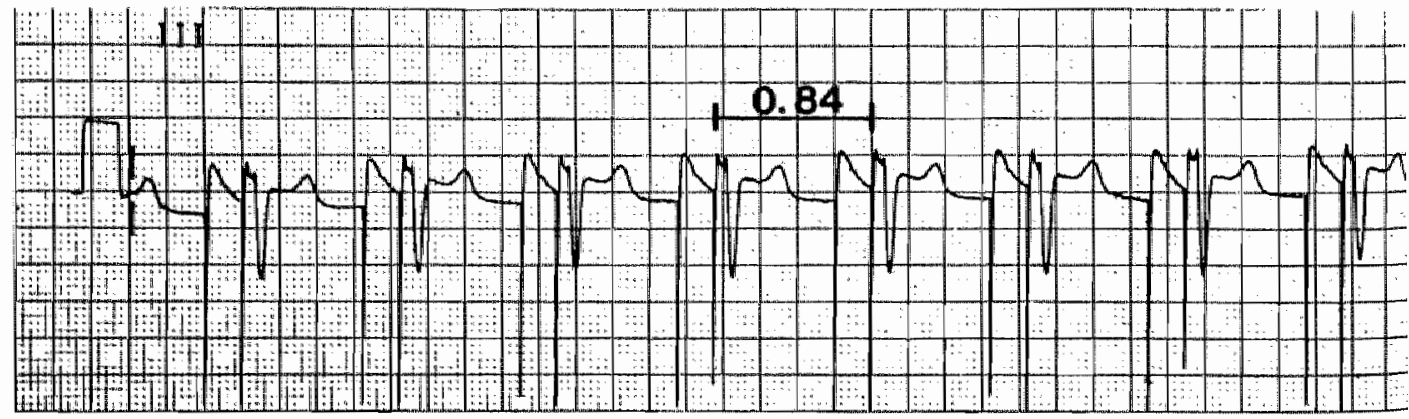

Figure 2. Unipolar AV sequential pacing (ECG lead III). The large unipolar atrial stimulus with its characteristic avershoot makes the diagnosis of successful atrial capture difficult. 


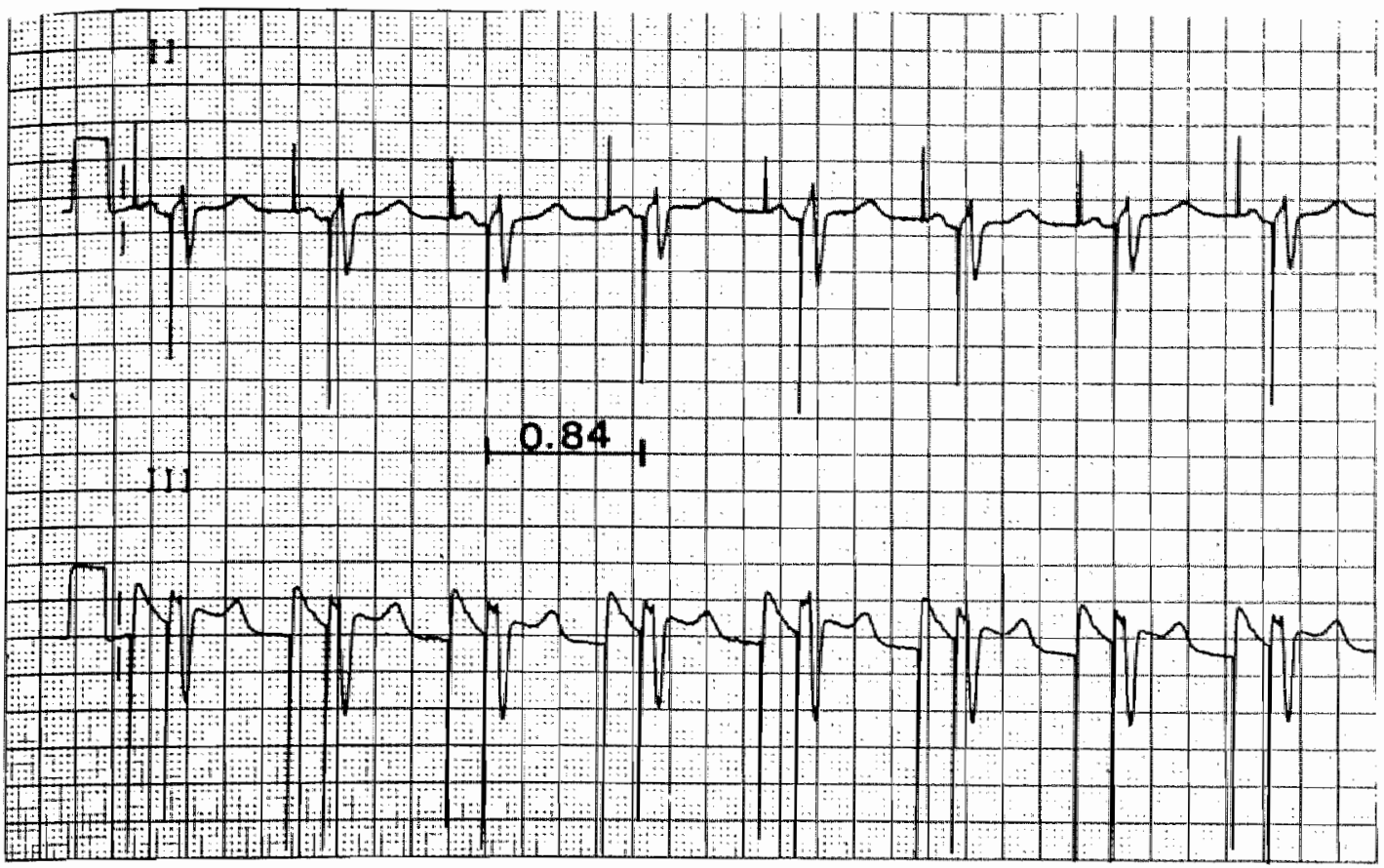

Figure 3. Atrial copture during unipolar AV sequential pacing. Al though lead III of the ECG does not show any evidence of successful atrial pacing, lead 11 of the 12-lead ECG demonstrates atrial copture.

\section{PP Interval Longer than VV Interval}

When the spontaneous sintus rate is slower than the programmed VVI pacing rate, sinus $P$ waves will be absent during adequate $A V$ sequenthal pacing as a result of overdrive suppression of the sinus node. This means that when spontaneous P waves still are present after programming to the DVI pacing mode, the atrium is not captured by the pulse generator.

\section{PP Interval Equals the VV Interval}

When the PP inferval aquals the VV interval, the absence of $\mathrm{P}$ waves during DVI pacing at the same rate does not exclude poor atrial pacing, because dissociated $\mathbf{P}$ waves may be buried in the QRS complexes of the ventricular paced beats. In this setting, atropine $0.5-2.0 \mathrm{mg}$ is administered intravenously to speed up the spontaneous simus rate, and atrial capture can be demonstrated by programming the DVI pacing mode to a rate slower than the sinus rate.

When $P$ waves do not become visible after programming to the minimum VVI pacing rate, atrial fibrillation, atrial flutter, or, more rarely, atrial standstill may be present. However, an isoelectric baseline between the ventricular paced beats, does not, por se, mean that P waves are ab. sent. Dissociated sinus $P$ waves may be buried in the ventricular paced complexes or retrograde $P$ waves may be hidden in the ST segments of the ventricular paced beats. Also, in this setting, atropine $(0.5-2.0 \mathrm{mg})$ is administered to increase the underlying sinus rate in onder to create a PP interval that is shorter than the ventricular paced VV interval. Subsequently, successful atrial pacing can be demonstratted by programming the $\mathrm{AV}$ sequential pacing mode at a slower rate than the spontaneous sinus tate. 

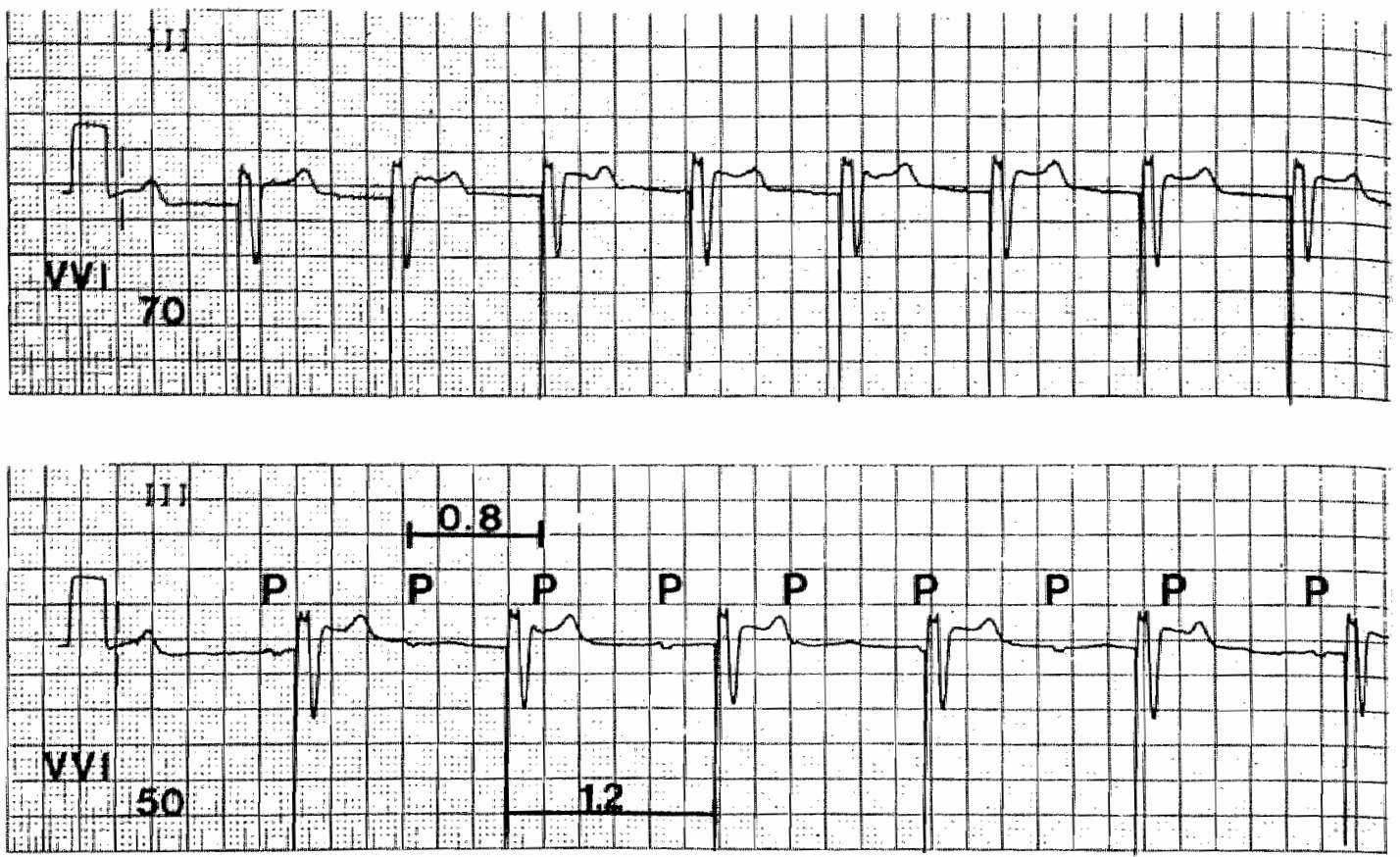

Figure 4. VVI programming. Al a rate of $70 \mathrm{ppm}$ (upper trocing) it is not clear if $P$ waves are present. At a WVI rate of 50 ppm (lower tracingl the PP interval equals $0.8 \mathrm{~s}$; the ventricular paced inlerval is $1.2 \mathrm{~s}$.

\section{Results}

During a 2-year period 87 dual chamber (DDD) pacemakers were implanted in our hospital. All patients were followed in our outpatient clinic at intervals of 3 months. In 13 patients the ECG during pacemak or follow-up did not allow assessment of adeciuate atrial pacing. All 13 patients had ymptomatic second-or third-degree AV block. In aight palients our technique demonstruted atrial capture, which was confirmed by echocardiography. In three patients atrial fibrillation was manifest after programming the pulse generator to the minimum VVI pacing rate. In two patients inad. equate atrial pacing could be demonst rated. Atrial standstill was not observed in any of our patients.

\section{Discussion}

On the conventional ECG the atrial stimulus. in particular the unipolar stimulus, may sometimes make a diagnosis of successful atrial capture quite difficult. We developed a strategy to obtain rapid and definitive proof of appropriate atrial pacing by meams of reprogramming the pulse gen. erator and recording the $\mathrm{ECG}$. Our technique is based on the electrophysiologic principles of overdrive suppression of the sinus node, and on the responses of the sinus node to premature atrial stimulation.

A limitation of our approach is that in patients with atrio-sinus entrance block no resetting of the sinus cycle will be present during adequate $A V$ sequential pacing at a slower rate than the sponlaneous sinus rate. However, the prevalence of atrio-sinus entrance block during premature atrial stimulation has been reported to be less than $7 \%$ in patients with sinus node dysfunction and may be extremely rare in patients with normal sinus node function. ${ }^{\gamma-9}$

In contrast to echocardiography, venous pulse tracings, and esophageal electrocardiography, the electrocardiographic assessment of atrial capture 

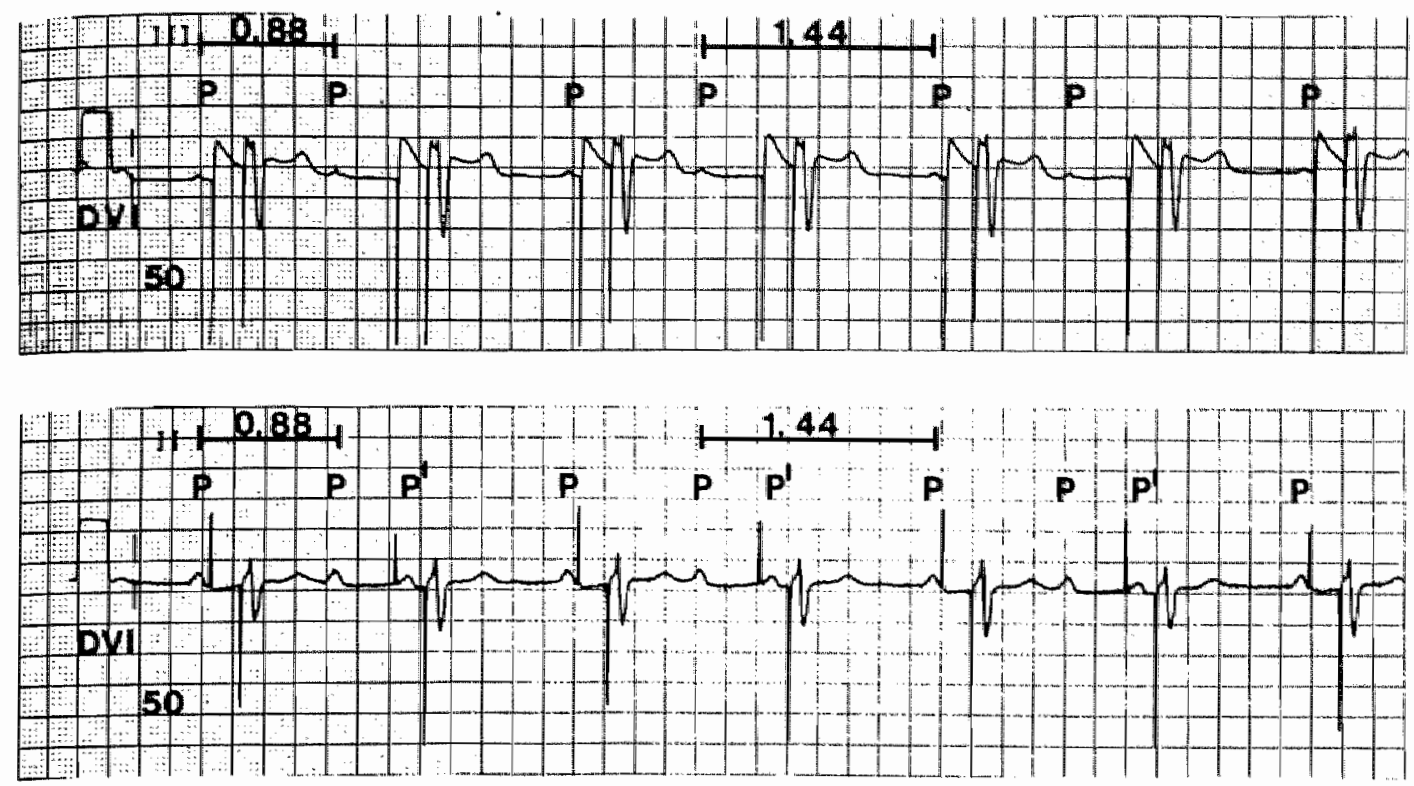

Figure 5. DVI pacing. Although paced $P$ waves cannot be seen during DVI pacing (upper tracing), resetting of the sirus pacemaker demonstrates successful atrial capture. In this particular case atrial capture could clearly be proven by recording lead II of the ECG (lower tracing).

is independent of patient variability, and is available in any out-patient clinic. In addition, this approach is less time consuming than other noninvasive techniques. Therefore, we believe that this

\section{References}

1. Barold. S.S., Falkoff, M.D., Ong, L.S., et al.: Interpretation of electrocardiograms produced by a new unipolar multiprogrammable "committed" AV se. quential (DVI) pulse generator. PACE, 4:692, 1981.

2. Levine, P.A., Brodsky, S. J., Selizar, J.P.: Assessment of atrial capture in committed atrioventricular sequential (DVI) pacing systems. PACE, 6:616, 1983.

3. Ambrose, J.A., Meller. I., Herman, M.V., et al.: The ventricular $A$ wave and a new echocardiographic index of late diastolic filling of the left ventricle. Am. Heart J., 96:615. 1978.

4. Naito, M., Draifus, L.S, Mardelli, T.J, ot al.: Echocardiographic features of atrioventricular and ventriculo-atrial conduction. Am. I. Cardiol, 46:625, 1980.

5. Levine, P.A., Mace, R.C.: Pacing Therapy: A Guide to Ca raiac Pacing for Optimum Hemodynamic Ben- simple technique may be applied during pacemaker check-up visits, when definitive and rapid proof of successful atrial pacing is desired.

efit. New York, Futura Publishing Company. 1983. pp. $177-189$.

6. Parsonmat, V., Furman, S., Simyth, N.P.D.: Implantable cardiac pecemakers: Status report and resource guidelines. Am. J. Cardiol., 34:487, 1974.

7. Strauss, H.C. Saroff, A.L. Bigger, I.T" at al: Premature atrial stimulation as a key to understanding of simo-attrial conduction in man. Circulation, 47:86, 1973 .

b. Stratuss, H.C., Bigger, J.T., Sarof, A.L. et al.: Elactrophysiological evaluation of sinus node function in patients with sinus node dysfunction. Circulation. 53:763, 1976 .

9. Reiffel "J.A., Gang, E., Livwlli, F, et al.: Clinical and electrophysiologic characteristics of sino-atrial entrance block evaluated by direct sinus node electrography: Prevalence, relation to antegrade sinoatrial conduction time and relevance to sinus node disease. Am. Heart I., 102:1011, 1981. 


\title{
Failure to Sense P Waves During DDD Pacing
}

\author{
ROB VAN MECHELEN, CONNIE 'T HART, and HANS DE BOER
}

From the Department of Cardiology. St. Franciscus Gasthuis, Rotterdam, The Netherlands

VAN MECHELEN, R., ET AL.: Failure to sense $P$ waves during DDD pacing. ECG tracings of three patients in whom $A V$ universal (DDD) pacemakers were implanted intermittently demonstrated dropped $P$ waves

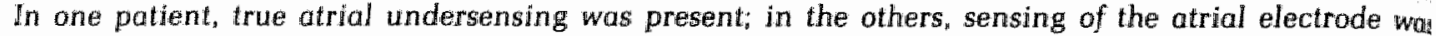
appropriate, but sensing of sinus $P$ waves was intermittently blacked by normal pacemaker operation. In this report we discuss the electrocardiographic diagnosis of atrial undersensing in order to avoid unnecessary reinterventions. (PACE, Vol. 9. July-August, 1986)

atrial malsensing, AV universal (DDD) pacing, atrial undersensing

\section{Introduction}

Undersensing as an expression of single chamber demand pacemaker malfunction (AAI or VVI unit) is manifest when proper pacemaker inhibition fails intermittently or continuously in association with reversion to fixed rate pacing for one or more timing cycles. True single chamber undersensing is present when a ventricular or atrial depolarization occurring during the alert part of the pacemaker escape interval is not detected by the sensing electrode, or when pacemaker malfunction is present. ${ }^{1}$ Likewise, true undersensing of sinus $P$ waves during DDD pacing is present when $P$ waves are not sensed by the atrial electrode although they occur during the alert part of the atrial escape interval or when malfunction of the atrial lead, the atrial connector, or atrial sensing circuitry is present. In this report we discuss ECG tracings of three patients with DDD pacemakers in whom undersensing of sinus $P$ waves was presumed.

\section{Case Reports}

\section{Patient No. 1}

An 87-year-old man was admitted to the CCU because of dyspnea and fainting spells. The patient

Addrows for reprints: Rob van Mechelen. M.D., Dept. of Cordiology, St. Franciscus Gasthuts, Klaiweg 500, 3045 PM, Rotterdam, "The Netherlands.

Receivad Novembar 1, 1985; accepted Decamber 18, 1985. had been in good health untill three days prior to admission.

Physical examination showed the patient to be a well-developed man in no obvious distress. The arterial blood pressure was $160 / 80 \mathrm{mmHg}$ The radial pulse was 30 beats $/ \mathrm{min}$. There was no neck vein distention. The lungs were clear to percussion and auscultation. The heart sounds were dull, with changing loudness of S1. The liver was not palpable. There was no peripheral edema and the peripheral arterial pulses were normal.

The ECG showed complete heart block with a sinus rhythm of 70 beats $/ \mathrm{min}$, a ventricular rate of 30 beats/min, a QRS duration of $0.12 \mathrm{~s}$, a RBBB morphology with left axis deviation; the $\mathrm{QT}$ interval was 0.48 s. Electrophysiologic study dem. onstrated complete infranodal block. During incremental ventricular pacing retrograde conduction was blocked bellow the AV node. A DDD pacemaker (Cordis* 418) was implanted and the patient was monitored by telemetry for 48 hours. The patient was discharged from the hospital the fourth day after admission.

A 24-hour Holter recording, performed three weeks after hospital discharge, intermittently demonstrated poor sensing of sinus $\mathrm{P}$ waves (Fig. 1). Interpretation of the ECG tracing confirmed a diagmosis of true atrial undersensing. When $p$ waves were not sensed, they occurred during the alert part of the programmed atrial escape interval. Chest $x$-ray showed a displaced atrial lead on the right anterior oblique profection. The next day the

* Cordis Corp., Miami, FL, USA. 
J
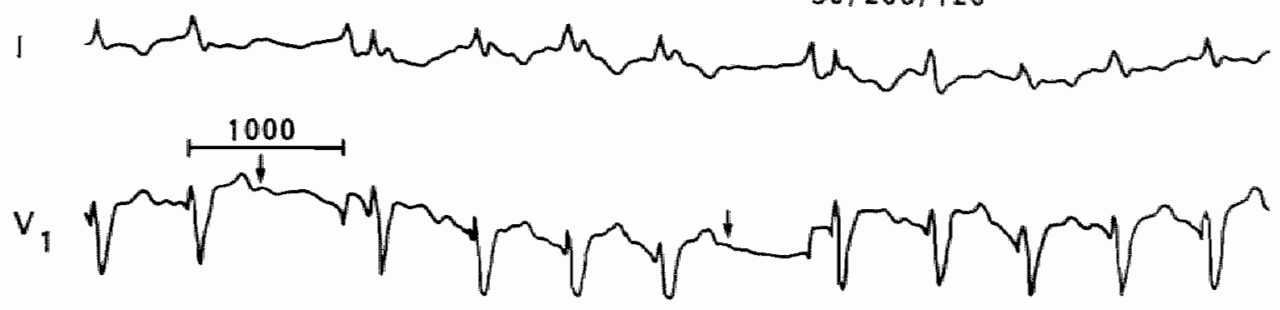

1

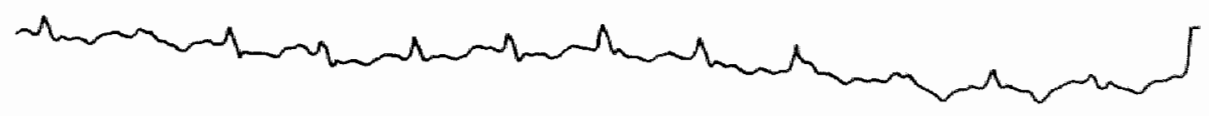

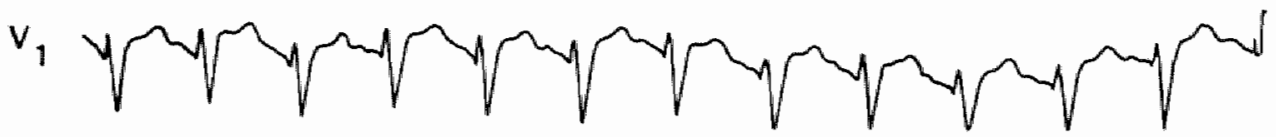

Figure 1. Holter tracing (2-channel) of patient no 1. The pulse generator is programmed to a minimum rate of 50 beats $/ \mathrm{min}$, an AV interval of $200 \mathrm{~ms}_{\text {u }}$ and a maximum rate of $120 \mathrm{beats} / \mathrm{min}$. The atrial escape interval is $1000 \mathrm{~ms}(1200-200)$. The atrial refractory interval is $300 \mathrm{~ms}(500-$ 200). Two sinus $P$ waves (marked with an arrow) do not elicit a ventricular response from the pulse generator, although they occur during the alert part of the atrial escape interval.

atrial lead was repositioned, and atrial sensing was restored.

\section{Patient No. 2}

A 61-year-old woman was admitted to the CCU because she lost consciousness while she was cleaning her kitchen. She had never been hospitalized before.

On physical examination, blood pressure was $180 / 90 \mathrm{mmHg}$. The radial pulse was 45 beats $/ \mathrm{min}$. Central venous pressure was normal. The lungs were clear. The apical impulse was palpated in the 5 th intercostal space in the midclavicular line. The heart sounds S1 and S2 were loud. A systolic murmur was audible at the aortic area. The murmur radiated towards the carotid arteries. The liver was not palpable. The arterial pulsations were normal and there was no peripheral edema.

The ECG showed complete heart block, a simus rate of $70 / \mathrm{min}$, a ventricular rate of $40 / \mathrm{min}$, a QRS duration of $0.08 \mathrm{~s}$, and a QT interval of 0.38 s. Electrophysiologic study showed complete heart. block. The anterograde block was localized in the common His bundle, whereas retrograde conduction was blocked below the level of the AV node. A DDD pacemaker (Cordis $415 \mathrm{~A}$ ) was implanted. The patient was monitored by telemetry for 48 hours and thereafter discharged from the hospital. For the first six weeks after hospitall discharge, a 24-hour Holter recording was performed routinely.

Figure 2 shows four representative ECG tracings of the Holter tape. Although atrial malsensing was presumed, interpretation of the ECG reverled adequate atrial sensing. Figure $2 \mathrm{~A}$ shows a sinus $P$ wave that is not followed by a ventricular stimulus. When this $P$ wave would have been dropped because of atrial undersensing an atrial stimulus would have been emitted after completion of the atrial escape interval. Because no atrial stimulus artifact was produced $950 \mathrm{~ms}$ after the preceding ventricular complex, this $\mathrm{P}$ weve could not be 

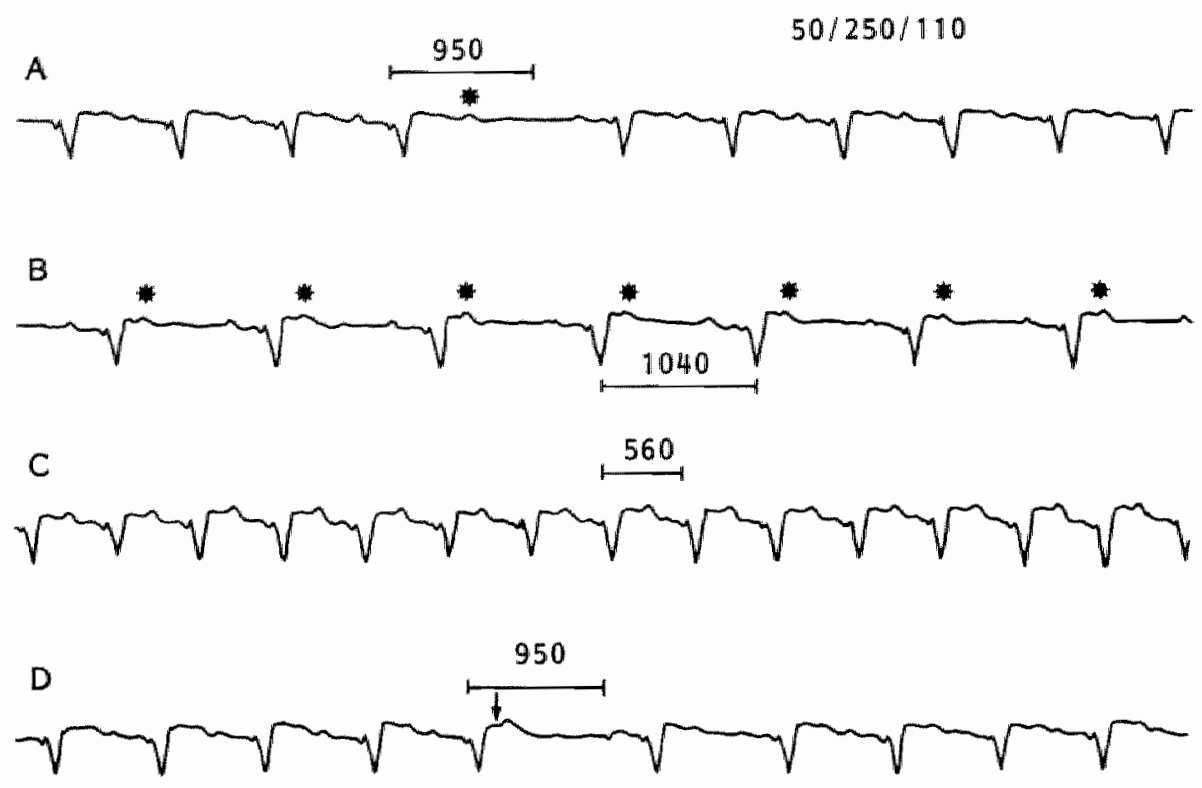

Figure 2. Holter tracings of patient no 2. A A sinus $P$ wave (asterisk) does not elicit a ventricular response from the pulse generator. However, after completion of the atrial escape interval 1950 $\mathrm{ms}$ ) no atrial stimulation occurs. B. Every second $P$ wave is blocked due to the $2: 1 \mathrm{AV}$ block respanse. C. AV synchronous pacing at a rate of 105 beats/min. D. An atrial premature beat occurs during the atrial refractory interval (arrow), and after completion of the atrial escape interval atrial stimulation follows. Minimum rate $=50$ beats $/ \mathrm{min} ; A V$ interval $=250 \mathrm{~ms}$; maximum rate $=110$ beats $/ \mathrm{min}_{\text {; }}$ atrial refractory interval $=300 \mathrm{~ms}(550-250)$; atrial escape interval $=950 \mathrm{~ms}$ $(1200-250)$.

dropped due to atrial undersensing. The most likely explanation for this pacemaker behavior is $\mathrm{T}$ wave sensing by the ventricular electrode, which resets the timing cycle and reiniliates the atrial refractory interval during which the sinus P wave occurred. Alternatively" electromagnetic or myographic interference may also be detected by the ventricular electrode, producing the same phenomenon. However, it is very unlikely that this interference would occur for only one timing cycle.

Figure 2B shows 2:1 AV block when the spontaneous sinus rate exceeded the programmed up- per rate $(110$ beats/min). Figure $2 \mathrm{C}$ shows $\mathrm{AV}$ synchronous pacing at a sinus rate of 105 beats/ min. Figure $2 \mathrm{D}$ shows a normal pacemaker response to a premature atrial beat which occurred during the atrial refractory interval. After completion of the atrial escape interval, an atrial stimulus artifact was produced. In this patient, the ventricular refractory interval was prolonged to prevent $T$ wave sensing; in addition, ventricular sensitivity was progremmed from $1.3 \mathrm{mV}$ to 2.5 $\mathrm{mV}$. The atrial refractory interval and the AV interval were shortened in order to avoid the 2:1 AV block response. A 24-hour Holter recording was 
repeated after reprogramming of the pulse generator and no loss of AV synchrony was noted.

\section{Patient No. 3}

An 85-year-old woman underwent a DVI pacemaker implantation five years prior to admission because of symptomatic second degree $\mathrm{AV}$ block. She was admitted to the CCU because of output failure of the pacemaker.

On physical examination, her blood pressure was $130 / 70 \mathrm{mmHg}$. Radial pulse rate was 50 beats/ min. Neck veins were not distended. The lungs were clear and heart sounds were normal. The liver was not palpable. There was pitting edema on both ankles. Arterial pulsations were normal.

The ECG on admission showed AV sequential pacing at a rate of 50 beats $/ \mathrm{min}$, whereas the minimum rate of the pacemaker was programmed to 70 beats/min. The ECG during pacemaker replacement showed sinus rhythm, 80 beat/min 2:1 AV block, RBBB morphology of the QRS complex, a QRS duration of $0.12 \mathrm{~s}$, an intermediate axis, and a QT interval of $0.44 \mathrm{~s}$.

During ventricullar stimulation at a rate slightly faster than the spontaneous sinus rate. AV dissociation was present. A DDD pulse generator (Cordis 415 A) was connected with the already implanted atrial and ventricular leads. The amplitude of the atrial signal was $4 \mathrm{mV}$. After pacemaker implantation, the patient was monitored by telemetry and a monitor tracing showed atrial malsensing (Fig. 3].

A 12-lead ECG was recorded; Figu re 4 shows two representative tracings of lead 1 . When the spontaneous sinus rate exceeded the programmed upper rate of the pulse generettor, $2: 1 \mathrm{AV}$ block occurred; in addition, the subsequent simus $\mathrm{p}$ wave did not generate a ventricular response of the pacemaker. After a blocked P wave, due to the 2:1 AV block response, neither a sinus $P$ wave fupper tracingl nor a ventricular premature beat (lower tracing) elicited an appropriate response of the pulse generator. "The most likely explanation for this pacemaker behavior is that when a $\mathrm{P}$ wave occurs during the terminal portion of the atrial refractory interval, this $P$ wave might be interpreted by the pulse generator as noise. "The response of this pulse generator to noise is that no sensing occurs either in the atrium or in the ventricle during the complete atrial escape interval. In this patient, atrial sensing was appropriate. In order to avoid the 2:1 AV block response, the atrial refractory interval and $A V$ interval were shortened. Also the sensitivity setting of the atrial channel was changed from $0.5 \mathrm{mV}$ to $2.5 \mathrm{mV}$. which lowered the risk that $P$ waves would be recognized as noise by the pulse generator when they occurred during the termmal part of the atrial refractory interval. ${ }^{2-4}$ A 24-hour Holter recording performed after hospital discharge showed normal AV synchronous pacing.

\section{Discussion}

The variety and complexity of dual chamber pacemakers have introduced complex and intricate diagnostic problems that may be related to benign functional variations or to serious malfunction of the pacing system. In this report we

$50 / 200 / 120$

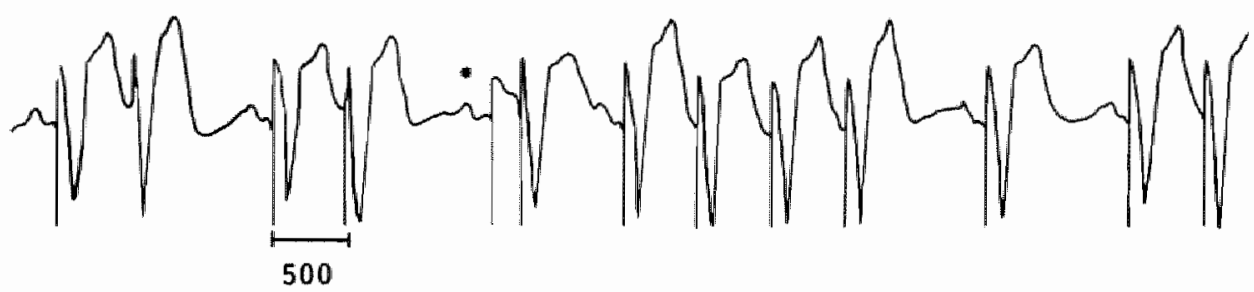

Figure 3. Telemetry tracing of patient no 3. After exceeding the programmed upper rate of the pulse generator, 2:1 AV block occurs. The sinus $P$ wave (asterisk) that follows a blocked $P$ wave is not sensed. Minimum rate $=50$ beats $/$ min: $A V$ interval $=200 \mathrm{~ms}:$ maximum rate $=120 \mathrm{berts} /$ min; atrial escape interval $=1000 \mathrm{~ms}(1200-200)$; atrial refractory interval $=300 \mathrm{~ms}(500-200)$. 


\section{0}

1
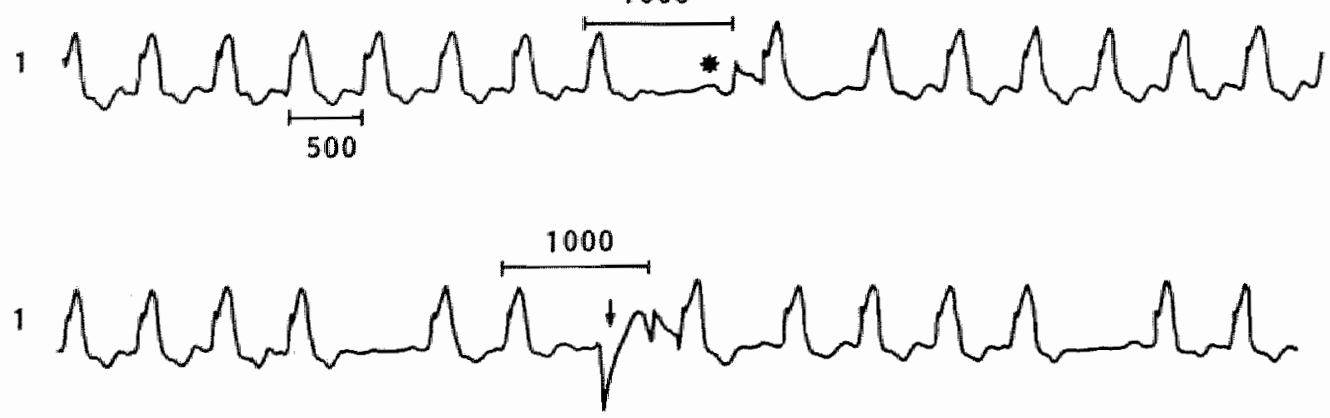

Figure 4. ECG lead I of patient no 3. (Top) After exceeding the programmed upper rate of the pulse generator 2:1 AV block occurs; again, the sinus P wove (asterisk) following a blacked sinus $P$ wave is not sensed as was shown in Figure 3. (Bottom) $A$ ventricular premature beat (arrow) is not sensed when it occurs during the presumed alert interval of the ventricular escape interval. Ventricular refractory interval $=300 \mathrm{~ms}$.

present three patients with dropped P waves during DDD pacing. The pacemaker of the first patient showed failure to sense sinus $P$ waves during the alert part of the atrial escape interval (Fig. 1) which is an example of atrial undersensing. The second patient showed appropriate atrial sensing, but when $P$ waves occurred shortly after a $T$ wave sensed by the ventricular channel, atrial channel refractoriness was reinitiated. The third patient also showed appropriate atrial sensing but dem-

\section{References}

1. Varriale, P, Kwa, R.P.: Pacemaker eloctrocardiography: In P. Varriale, 悲A. Naclerio (Eds.): Cordiac Pacha. Plitadalphla Lea \& Fobiger, 1979 , pp. 295297.

2. Falkoff, M. Ong, S. Heinle, R.A. et al. "The noise sempling period: A new cause of apparent sensing mathunction of demand pacomakers. PACE, 1:250, onstrated the so-called noise mode response ${ }^{3}$ when the atrial rate reached the programmed upper rate of the pulse generator.

In conclusion differentiation between true and pseudo-failure to sense $\mathrm{P}$ waves during DDD pacing has important therapeutic consequences in terms of surgical reintervention. In the presented cases a correct diagnosis was made noninvasively. Full understanding of normal pacemaker operation was essential to interpret the ECGs.

1978 .

3. Sudduth, B.K., Morris, D.L., Gertz, E. W.: Noise mode response t peak exercise in a DDD pacemaker. PACE, B:746, 1985.

4. Cordis Model 415 A, (Theta) Gemini Cordis Corporation, Miami. Florida, January 1984. (Physician's Manual]. 


\section{SUMMARY}

The clinical work-up of sinus node dysfunction and atrio-ventricular (AV) block is described in Chapter I.

In Chapter II to VIII some electrophysiologic and electrocardiographic aspects of conduction disorders related to pacemaker therapy are discussed. The prevalence of retrograde $A V$ conduction in patients with sinus node dysfunction was studied and the results of this study are presented in Chapter II. Especially patients with intact anterograde $\mathrm{AV}$ conduction demonstrated intact retrograde $A V$ conduction. Ventricular demand pacing, in patients with symptomatic sinus node dysfunction, is therefore not the ideal pacemaker therapy. Atrial pacing is an alternative pacing mode for patients with intact anterograde $\mathrm{AV}$ conduction, which is haemodynamically superior to ventricular demand pacing. In Chapter III the reliability of permanent atrial pacing is presented during long term followup. It appeared that permanent atrial pacing was safe, even in patients who used antiarrhythmic drugs that adversely affected AV nodal function.

The introduction of dual chamber (DDD) pacemakers offered patients with symptomatic AV block an alternative for ventricular demand pacing. As was already discussed in Chapter I, DDD pacentakers have solved some of the original deficiences of single chamber ventricular pacing, however other problems have been created. One of these problems is pacemaker mediated tachycardia, a subject which is adressed in Chapter IV.

Chapter $V$ reports on the stability of retrograde AV conduction of patients with symptomatic heart block, after DDD pacemaker implantation. During long term follow-up, retrograde $\mathrm{AV}$ conduction remained stable in the majority of patients. In addition, antiarrhythmic drug therapy adversely affected anterograde as well as retrograde $A V$ conduction. These findings were of clinical importance with regard to the prevention of pacemaker mediated tachycardia. 
Chapter VI, VII and VIII focus on electrocardiographic aspects of DDD pacing. In Chapter VI, some unfamiliar ECG patterns are discussed as a result of an algorhythm in a dual chamber pulse generator that prevents large fluctuations in pacing rate.

In Chapter VII an electrocardiographic technique is presented to assess atrial capture during AV sequential pacing. The value of the ECG to asses atrial malsensing during $\mathrm{AV}$ synchronous pacing is described in Chapter VIII. 


\section{SAMENVATTING}

In Hoofdstuk I wordt de klinische evaluatie besproken van patiënten, met een gestoorde sinus knoop functie of een gestoorde atrio-ventriculaire (AV) geleiding.

In de Hoofdstukken II $\mathrm{t} / \mathrm{m}$ VIII komen enkele electrofysiologische en electrocardiografische aspecten van geleidingsstoornissen in relatie tot pacemaker therapie aan de orde.

Hoofdstuk II handelt over de prevalentie van teruggeleiding naar de boezem tijdens hartkamer stimulatie bij patienten met een gestoorde sinus knoop functie. Vooral bij patiënten met intacte AV geleiding bestaat tevens intacte teruggeleiding naar de boezem. Dit maakt permanente kamerstimulatie niet tot de ideale stimulatie vorm voor patiënten met een gestoorde sinus knoop functie. Boezemstimulatie is een alternatieve stimulatie vorm voor patiënten met een gestoorde sinus knoop functie, waarbij de AV geleiding intact is. Deze stimulatie vorm is bovendien in haemodynamisch opzicht superieur aan kamerstimulatie.

In Hoofdstuk III wordt de betrouwbaarheid van boezemstimulatie besproken. Tijdens een prospectief follow-up onderzoek bleek boezemstimulatie veilig te zijn. Symptomatisch AV blok trad bij geen der patiënten op, zelfs niet bij patiënten die behandeld werden met anti-aritmica die een remmende invloed uitoefenen op de AV knoop.

De introductie van DDD pacemakers, die boezem-kamer synchronie kunnen nabootsen, boden patiënten met een symptomatisch hartblok een alternatief voor pacemakers, die uitsluitend de hartkamer stimuleren. De voordelen van een dergelijke pacemaker kwamen reeds in Hoofdstuk I ter sprake. Hoofdstuk IV is gewijd aan een van de problemen van DDD pacemakers: artificiële pacemaker tachycardie.

Hoofdstuk $V$ gaat over de stabiliteit van teruggeleidling naar de boezem bij patiënten met $\mathrm{AV}$ blok. Tijdens een vervolgstudie na $\mathrm{DDD}$ pacemaker 
implantatie, werd op noninvasieve wijze wastgesteld, dat teruggeleiding stabiel blijft, bij de meerderheid van patiënten. Bovendien bleek, dat antiaritmica zowel anterograde als retrograde AV geleiding kunnen blokkeren. Deze gegevens zijn van klinisch belang, met betrekking tot het voorkomen van pacemaker cirkeltachycardie.

Hoofdstuk VI, VII en VIII handelen over electrocardiografische aspecten van DDD pacemakers. In Hoofdstuk VI worden enkele merkwaardige ECG registraties besproken, die het gevolg zijn van een pacemaker algoritme, dat tot doel heeft om plotselinge veranderingen in stimulatie frequentie tegen te gaan.

Hoofdstuk VII gaat over een electrocardiografische techniek om vast te stellen of de boezem wordt gedepolariseerd tijdens AV sequentiële hartstimulatie.

In Hoofdstuk VIII wordt de betekenis van het ECG besproken, om aan te tonen of DDD pacemakers atriale signalen adequaat of inadequaat detecteren. 


\section{CURRICULUM VITAE}

1947, September 24, geboren te Utrecht.

1966, Middelbare schoolopleiding (HBS-B), St. Bonifacius Lyceum te Utrecht.

1973, Arts diploma, Rijks Universiteit te Utrecht.

1974-1980, Cardiologie opleiding, St. Antonius Ziekenhuis te Utrecht. Opleider: Dr. A.V.G. Bruschke.

1978-1979, Stage Interne Geneeskunde, Diaconessenhuis te Utrecht. Opleider: Dr. J. Sebus.

1980-heden, Cardioloog, staflid van het St. Franciscus Gasthuis te Rotterdam. 